\title{
Diversity-Oriented Library Synthesis from Steviol and Isosteviol-Derived Scaffolds
}

\author{
Trinh A. D. Holth, Michael A. Walters, Oliver E. Hutt, and Gunda I. Georg* \\ Department of Medicinal Chemistry and Institute for Therapeutics Discovery and Development, College \\ of Pharmacy, University of Minnesota, 717 Delaware Street SE, Minneapolis, MN 55414
}

\section{Supporting Information}

\section{Contents}

Activity Tables

Calculations of Drug-like Properties

Experimental Details and Compound Characterization

S10-S22

References

S22-S23

NMR Spectra

S24-S67 
Table S1. Complete current activity table of isosteviol and steviol analogs from PubChem

\begin{tabular}{|c|c|c|c|c|c|}
\hline \multirow[b]{2}{*}{ Compound } & \multirow[b]{2}{*}{$\begin{array}{l}\text { PubChem } \\
\text { ID }\end{array}$} & \multirow[b]{2}{*}{$\begin{array}{l}\text { Assay } \\
\text { ID }\end{array}$} & \multirow[b]{2}{*}{ BioAssay } & \multicolumn{2}{|c|}{ Activity (if given) } \\
\hline & & & & $\begin{array}{l}\text { Assay } \\
\text { Type }\end{array}$ & $\begin{array}{l}\text { Result } \\
\text { or } \\
\text { Value } \\
(\mu \mathrm{M})\end{array}$ \\
\hline 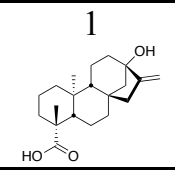 & 9905087 & 602438 & $\begin{array}{l}\text { uHTS identification of modulators of interaction between } \\
\text { CendR and NRP-1 using fluorescence polarization assay }\end{array}$ & $\begin{array}{l}\text { Primary } \\
\text { screen }\end{array}$ & active \\
\hline & 42601320 & 652104 & qHTS of TDP-43 inhibitors & Confirmatory & $\begin{array}{c}\mathrm{IC}_{50}^{\mathrm{A}} \\
19.953\end{array}$ \\
\hline & 42601318 & 720706 & $\begin{array}{l}\text { HTS for bacterial rRNA inhibitors measured in } \\
\text { microorganism-based system }\end{array}$ & $\begin{array}{l}\text { Primary } \\
\text { screen }\end{array}$ & active \\
\hline \multirow{7}{*}{$10\{2\}=0$} & \multirow{7}{*}{42601330} & 540271 & $\begin{array}{l}\text { In vivo-based yeast HTS to detect compounds rescuing yeast } \\
\text { growth/survival of Plasmodium falciparum HSP40-mediated } \\
\text { toxicity measured in whole organism system }\end{array}$ & Confirmatory & $\begin{array}{l}\text { AbsAC } \\
\text { C } 1.427\end{array}$ \\
\hline & & 686978 & $\begin{array}{l}\text { qHTS for inhibitors of human TDP1: qHTS in cells in absence } \\
\text { of CPT }\end{array}$ & Confirmatory & \begin{tabular}{|c|}
$\mathrm{EC}_{50}$ \\
18.356 \\
\end{tabular} \\
\hline & & 652041 & $\begin{array}{l}\text { Cell-based secondary assay to test the inhibitory activity of } \\
\text { small molecule on Plasmodium falciparum (HB3 strain) } \\
\text { survival in red blood cells measured in cell-based system }\end{array}$ & Confirmatory & $\begin{array}{c}\text { AbsAC } \\
21.72\end{array}$ \\
\hline & & 652047 & $\begin{array}{l}\text { Cell-based secondary assay to test the inhibitory activity of } \\
\text { small molecule on Plasmodium falciparum (3D7 strain) } \\
\text { survival in red blood cells measured in cell-based system }\end{array}$ & Confirmatory & $\begin{array}{c}\text { AbsAC } \\
30.22\end{array}$ \\
\hline & & 2825 & $\begin{array}{l}\text { uHTS Luminescent assay for indentification of inhibitors of } \\
\text { NALP3 in yeast }\end{array}$ & $\begin{array}{c}\text { Primary } \\
\text { screen }\end{array}$ & active \\
\hline & & 435006 & $\begin{array}{l}\text { Single concentration confirmation of uHTS for the } \\
\text { identification of inhibitors of NALP3 in yeast using a } \\
\text { luminescent assay }\end{array}$ & $\begin{array}{l}\text { Primary } \\
\text { screen }\end{array}$ & active \\
\hline & & 504582 & $\begin{array}{l}\text { In vivo-based yeast HTS to detect compounds rescuing yeast } \\
\text { growth/survival of Plasmodium falciparum HSP40-mediated } \\
\text { toxicity measured in whole organism system }\end{array}$ & $\begin{array}{l}\text { Primary } \\
\text { screen }\end{array}$ & active \\
\hline \multirow{4}{*}{ оме } & \multirow{4}{*}{42601335} & 624417 & qHTS of GLP-1 receptor inverse agonists & Confirmatory & $\begin{array}{c}\mathrm{EC}_{50} \\
10 \\
\end{array}$ \\
\hline & & 624466 & $\begin{array}{l}\text { Fluorescence-based cell-based primary HTS assay to identify } \\
\text { antagonists of human TAAR1 }\end{array}$ & $\begin{array}{c}\text { Primary } \\
\text { screen }\end{array}$ & active \\
\hline & & 2825 & $\begin{array}{l}\text { uHTS Luminescent assay for indentification of inhibitors of } \\
\text { NALP3 in yeast }\end{array}$ & $\begin{array}{c}\text { Primary } \\
\text { screen }\end{array}$ & active \\
\hline & & 504582 & $\begin{array}{l}\text { In vivo-based yeast HTS to detect compounds rescuing yeast } \\
\text { growth/survival of Plasmodium falciparum HSP40-mediated } \\
\text { toxicity measured in whole organism system }\end{array}$ & $\begin{array}{l}\text { Primary } \\
\text { screen }\end{array}$ & active \\
\hline \multirow{5}{*}{$10\{10\}$} & \multirow{5}{*}{42601331} & 488784 & $\begin{array}{l}\text { Single concentration confirmation of inhibitors of NALP3 in } \\
\text { yeast using Caspase-1-ASC counter screen }\end{array}$ & $\begin{array}{c}\text { Primary } \\
\text { screen }\end{array}$ & active \\
\hline & & 2685 & qHTS assay for lipid storage modulators in drosophila S3 cells & Confirmatory & $\begin{array}{l}\mathrm{EC}_{50} \\
0.651 \\
\end{array}$ \\
\hline & & 2825 & $\begin{array}{l}\text { uHTS Luminescent assay for indentification of inhibitors of } \\
\text { NALP3 in yeast }\end{array}$ & $\begin{array}{c}\text { Primary } \\
\text { screen }\end{array}$ & active \\
\hline & & 463195 & $\begin{array}{l}\text { uHTS identification of small molecule inhibitors of tim10 } \\
\text { yeast via a luminescent assay }\end{array}$ & $\begin{array}{c}\text { Primary } \\
\text { screen }\end{array}$ & active \\
\hline & & 435006 & $\begin{array}{l}\text { Single concentration confirmation of uHTS for the } \\
\text { identification of inhibitors of NALP3 in yeast using a } \\
\text { luminescent assay }\end{array}$ & $\begin{array}{l}\text { Primary } \\
\text { screen }\end{array}$ & active \\
\hline
\end{tabular}




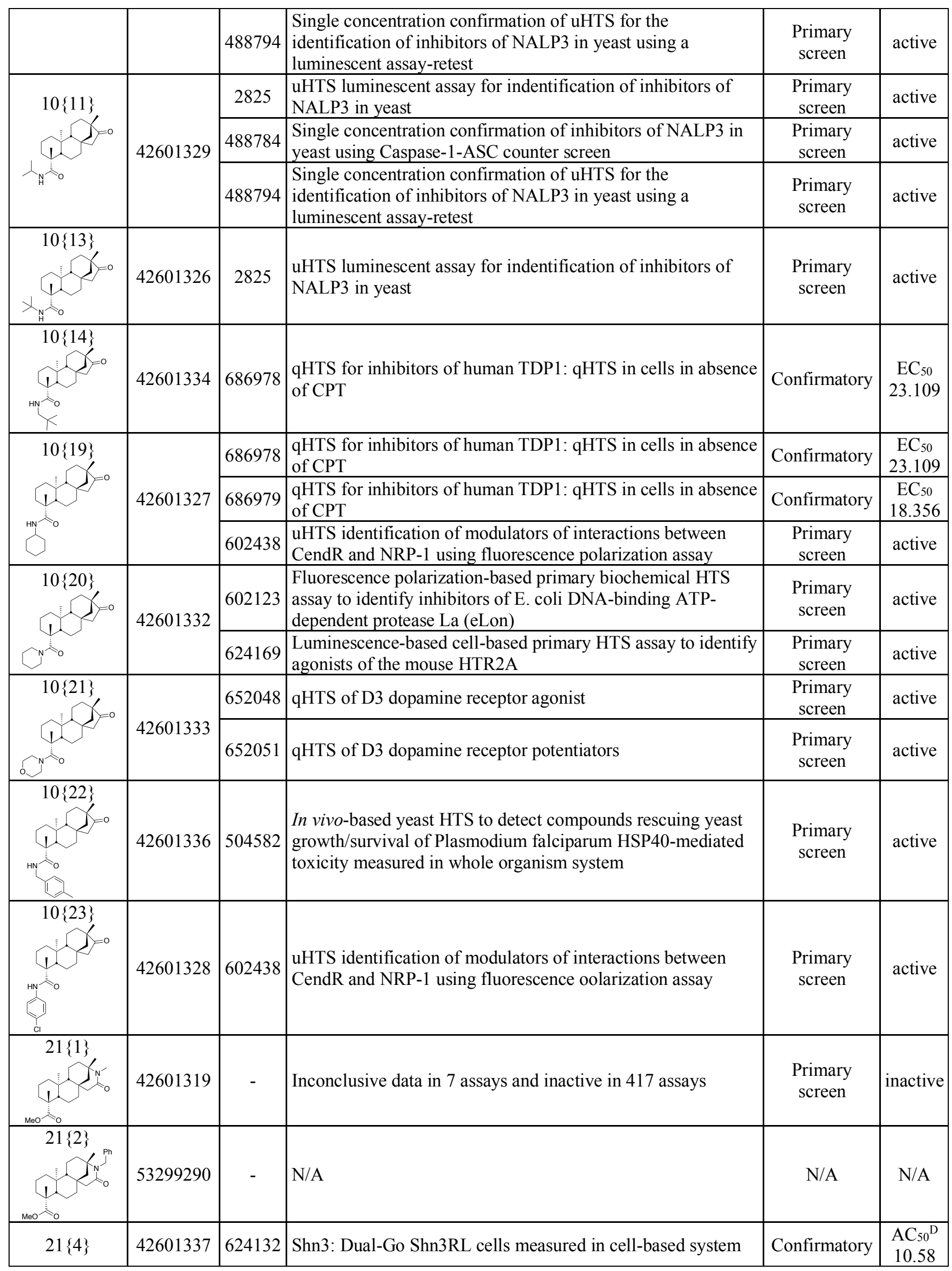




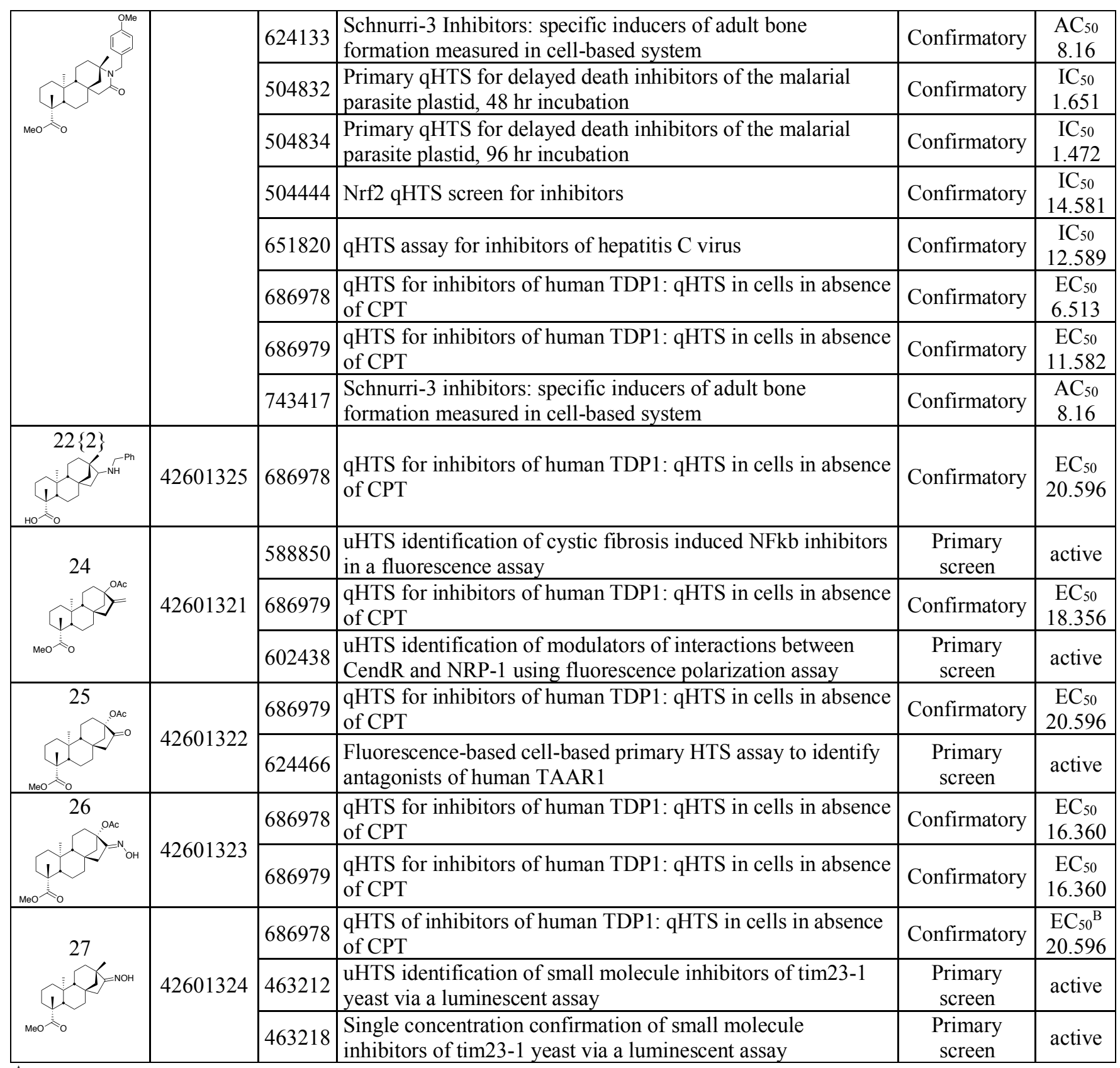

${ }^{\mathrm{A}} \mathrm{IC}_{50}=$ concentration of an inhibitor required for $50 \%$ inhibition of maximum control response

${ }^{\mathrm{B}} \mathrm{EC}_{50}=$ concentration of an agonist required to produce $50 \%$ maximum (effective) response

${ }^{\mathrm{C}} \mathrm{Abs} \mathrm{AC}=\mathrm{Absolute}$ active concentration with compounds below $10 \mu \mathrm{M}$ to be considered active hits

${ }^{\mathrm{D}} \mathrm{AC}_{50}=$ concentration required to elicit a $50 \%$ response in an in vitro assay 


\section{Calculations of Drug-like Properties}

We sought to determine the potential drug-like qualities of these compounds by calculating parameters beyond the Lipinski's "rule of five."1 Walters and coworkers previously analyzed over 415,000 molecules reported in the Journal of Medicinal Chemistry from 1959 to $2009 .^{2}$ In their investigation, they identified the eight important properties for all drugs or drug-like molecules to be molecular weight (MW), cLogP, total polar surface area (TPSA), rotatable bonds, hydrogen bond donors (HBD), hydrogen bond acceptors (HBA), complexity, and fraction of $\mathrm{sp}^{3}$ carbons (Fsp3). From this information, Hergenrother and coworkers established the importance for compounds to have higher Fsp3 values, from 0 to 1 , and lower cLogP values, lower than 5 units, in order to be developed into drugs. ${ }^{3}$ The Fsp3 value pertains to the number of $s p^{3}$-hybridized carbon atoms in a compound divided by the sum of carbon atoms, and this value has been associated with lower melting points as well as enhanced aqueous solubility. ${ }^{4}$ They calculated four main parameters: Fsp3, cLogP, number of stereocenters, and Tanimoto similarity coefficients of their compounds compared to a 150,000-member ChemBridge collection. In our case, we compared our library to the ChemBridge CombiSet and the Maybridge Diversity Set of compounds, which contain 30,000 and about 54,000 compounds, respectively. We expected this would offer insight in to the diversity of our libraries relative to two commercially-available libraries.

We employed Pipeline Pilot to calculate ALogP values, ${ }^{5}$ the number of stereocenters, and the Fsp3 ratio. ${ }^{6}$ While our compounds have an average cLogP of 4.63 (Figure S1), the Hergenrother group reported an average cLogP of $2.90 .^{3}$ The ChemBridge and MayBridge library sets that we chose for comparison had an average cLogP value of 3.11 and 3.04, respectively. With such a lipophilic core scaffold, we endeavored to create less lipophilic compounds by adding various substituents and hydrophilic groups that would lower cLogP values. Our Fsp3 calculations (Figure S2) yielded an average of 0.79, while the ChemBridge and MayBridge libraries have average Fsp3 values of 0.45 and 0.22 , respectively.

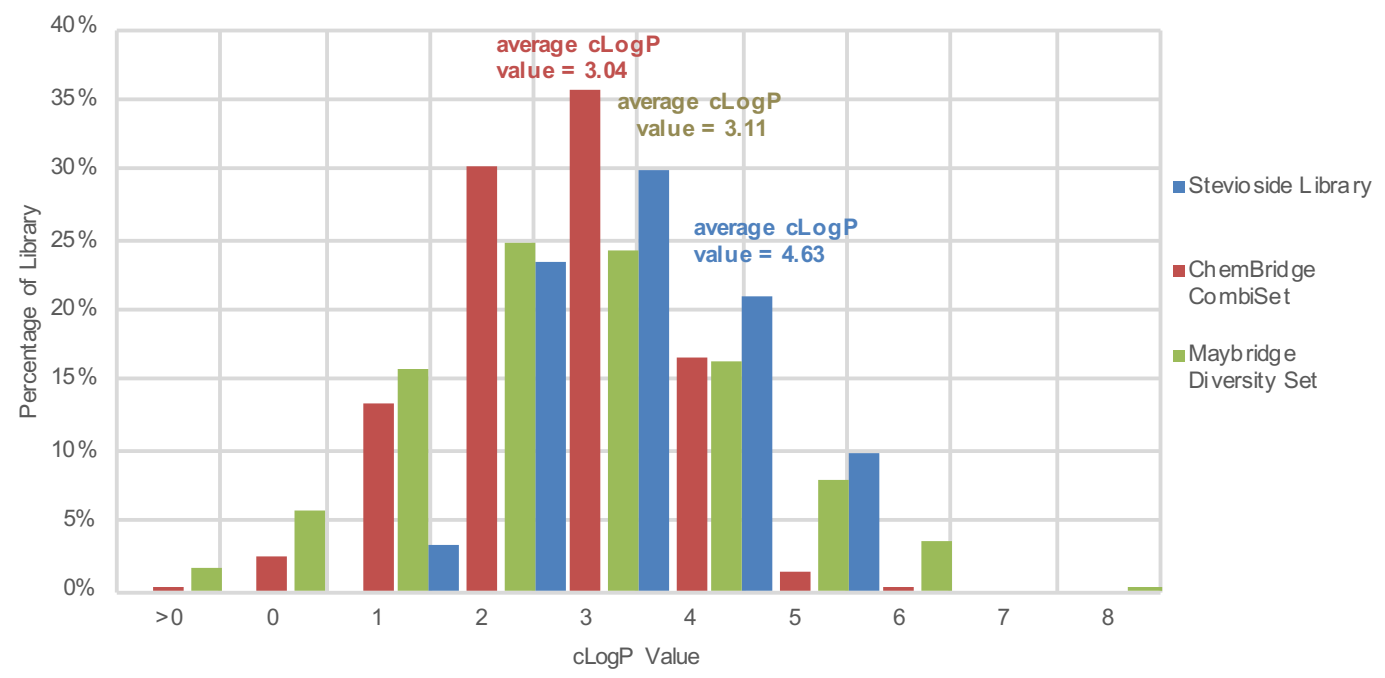

Figure S1. cLogP values of stevioside library vs commercial library sets. 


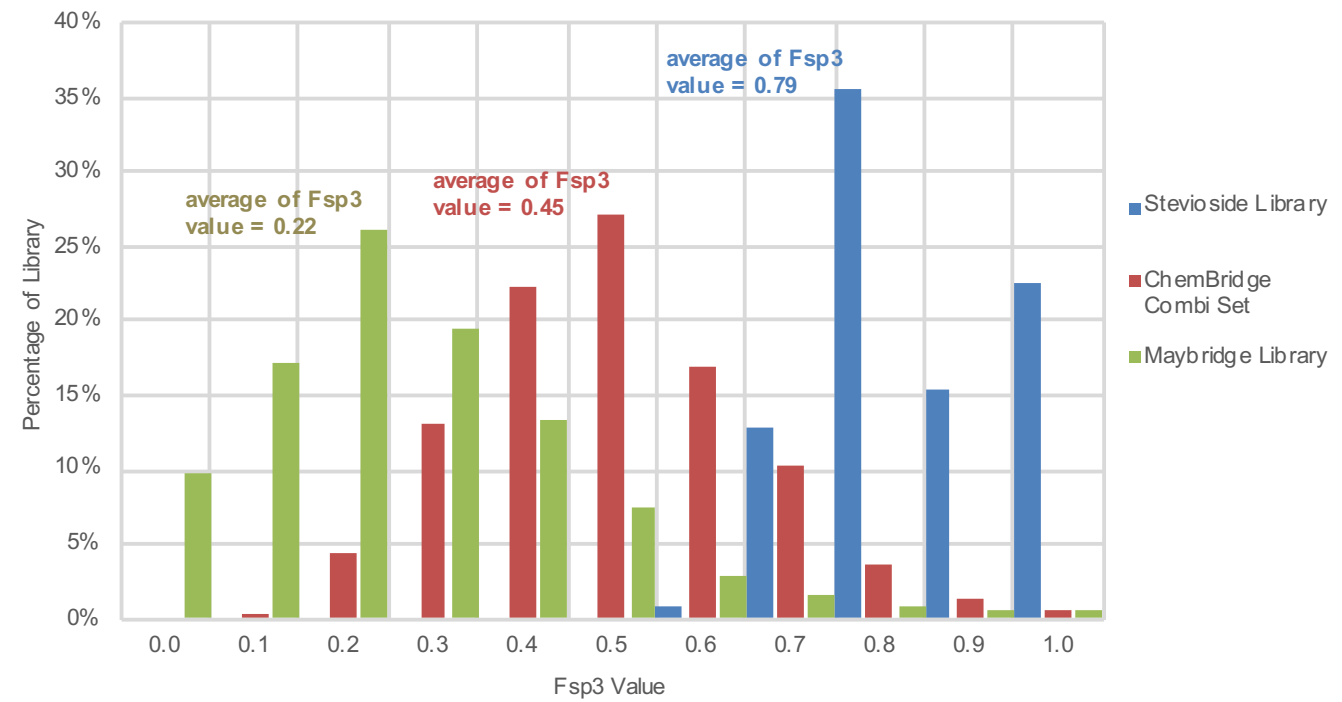

Figure S2. Fsp3 values of stevioside library vs commercial library sets.

The number of stereocenters in a compound can correlate to its structural complexity; on average, the structures in our compound library contained six stereocenters (Figure S3), while the ChemBridge and Maybridge libraries both have zero averages. Interestingly, Hergenrother's library of compounds had an average of 5.17 stereocenters. ${ }^{3}$ The majority of the compounds in the commercial libraries contain aromatic rings and aryl group substitutions and this largely accounts for their lack of stereocenters. Our compounds as well as those in the compound library of Hergenrother's group appear to be more structurally complex with a greater number of stereocenters because they are natural product analogs. ChemBridge and Maybridge compound libraries contain compounds without or few stereocenters, because these compounds are typically less complex and therefore, relatively easier to synthesize. $^{7}$

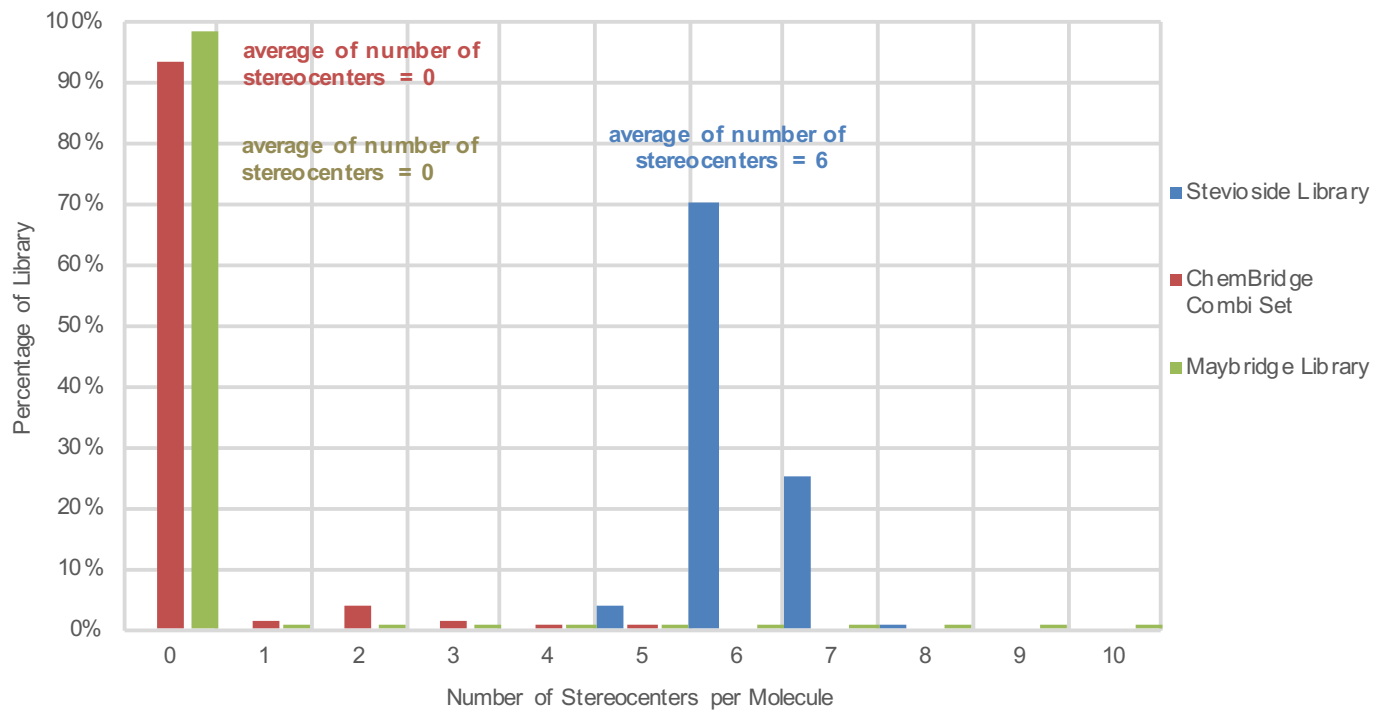

Figure S3. Number of stereocenters in stevioside library vs commercial library sets. 
Furthermore, similarity coefficients were generated (Tanimoto, ECFP_4) to determine the structural similarity between the compounds in our libraries. These values are graphed in a matrix format in Chart S1 to allow visualization of the pairwise similarity of the compounds. That is an intersection of a column and a row contains the calculated similarity between the compounds in the row and column. Low scores (blue) indicate a relatively high level of difference between the structures, while high scores (red) indicate very similar $(0.700<$ ratio $<1.00)$ or the identical structure $($ coefficient $=$ 1.00) when a compound is compared to itself. Low (blue) pairwise similarity is desired in a diverse library. The calculated average similarity between compounds in the library was 0.44 . Over half, or $63 \%$, of the complete steviol and isosteviol analog library compounds had similarities below 0.44 , represented in Chart S1 as indicated by the blue cells in Chart S1. A detailed analysis is shown in Table $\mathrm{S} 2$.

\begin{tabular}{|c|c|c|c|c|c|c|c|c|c|c|c|c|c|c|c|c|c|c|c|c|c|c|c|c|c|}
\hline & 24 & 25 & $\{1$ & $\{1\}$ & $\{1\}$ & $\{5\}$ & $\{3$ & $\{5\}$ & $\{2\}$ & $17\{2\}$ & $15\{2\}$ & $\{3$ & $\{5\}$ & $\{3\}$ & $21\{5\}$ & $22\{3\}$ & $22\{5\}$ & $p\{1\}$ & 20 & 21 & 8 & 5 & 7 & 2 & \\
\hline 24 & .000 & 792 & 456 & 406 & 389 & 403 & 0 & & & & 62 & & 63 & 72 & 07 & & & & & & & & & 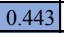 & \\
\hline & 792 & & & 455 & & & & & & & & & & & & & & & & & & & & & \\
\hline & & & & & & & & & & & & & & & & & & & & & & & & & \\
\hline & & 55 & 695 & 006 & 2 & & & & & 437 & 54 & & & & & & & & & & & & & & \\
\hline & 389 & 394 & 661 & 712 & 0 & 436 & 3 & 17 & & 19| & 341 & & & & & & & & & & & & & 438 & 24 \\
\hline & 403 & 38 & t & & 6 & & (1 & 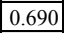 & & & 405 & & & & & & & & & & & & & & \\
\hline & & & & & & & 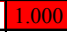 & & & & & & & & & & & & & & & & & & \\
\hline & 33 & 354 & 23 & 53 & 77 & 0 & 746 & 000 & 381 & 487 & 405 & & & & & & & & & & & & & 389 & \\
\hline 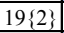 & 677 & 561 & 427 & 382 & 367 & 0 & 5 & 31 & $\overline{000}$ & \begin{tabular}{|l|}
0.434 \\
\end{tabular} & 357 & & 32 & & 73 & & & & & & & & 3 & 391 & 63 \\
\hline & 329 & & & & & & & & & & 521 & & & & & & & & & & & & & & \\
\hline & 62 & & & & & & & & & 1 & 000 & & & & & & & & & & & & & & \\
\hline & 444 & 151 & 321 & 329 & 7 & 318 & t & 8 & 14 & 453 & 0.281 & & 656 & & & & & & & & & & 395 & 352 & 42 \\
\hline 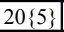 & 463 & 470 & 329 & 338 & 25 & 294 & 55 & 4 & 432 & 411 & 0.241 & & 00 & 21 & 37 & & & 21 & & & & & 가 & 64 & \\
\hline & 172 & 00 & & & & & & & & & 289 & & & & & & & & & & & & & & \\
\hline & 507 & 38 & 68 & 7 & & & & & 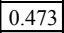 & 325 & 261 & & 37 & 82 & t & 29 & & 93 & & & 34 & & 1 & 43 & \\
\hline & 438 & 144 & 333 & 342 & & & & & 0. & 507 & 0.322 & & & & 29 & & & & & & & & & 47 & \\
\hline$\{5\}$ & 456 & 463 & 342 & 351 & 88 & 6 & 7 & 6 & 0 & 125 & 253 & & 33 & 16 & 529 & 22 & 0 & 3 & 37 & 70 & 32 & & 4 & 358 & \\
\hline & 384 & 389 & 651 & 700 & 57 & & & & 0 & te & 0.337 & & & & & & & & 51 & & & & & 43 & \\
\hline 26 & 737 & 750 & 378 & 370 & & & & & 9 & 16 & 0.253 & & 43 & 53 & 86 & & & & & 32 & & & 03 & 444 & \\
\hline 27 & 567 & 576 & 406 & 462 & 30 & & 411 & 12 & 0.500 & 0.338 & 0.268 & & 77 & 86 & 23 & & & & 0.732 & 00 & $0.544 \mid$ & & 433 & .564 & 467 \\
\hline 8 & 525 & 534 & 348 & 358 & 3 & 308 & 20 & 8 & 0.463 & 0.583 & 0.250 & 0. & 0.643 & \begin{tabular}{|l|}
0.449 \\
\end{tabular} & 0.484 & 71 & 32 & 38 & 0.500 & 0.544 & 1.000 & 54 & 415 & 414 & 400 \\
\hline 5 & 576 & 614 & & & & & & .507 & & 50.4 & 0.272 & & & & & & & & & & 34 & & 0.439 & 491 & \\
\hline 1 & 420 & 426 & 295 & 303 & & 279 & 91 & 0.279 & 0.413 & \begin{tabular}{|l|}
0.288 \\
\end{tabular} & 0.662 & & \begin{tabular}{|l|}
0.389 \\
\end{tabular} & 0.403 & 0.411 & & 84 & 0.288 & 0.403 & 33 & \begin{tabular}{|l|}
0.415 \\
\end{tabular} & & 1.000 & 0.324 & 31 \\
\hline 2 & 443 & 526 & 444 & 648 & 438 & 0.389 & \begin{tabular}{|l|}
0.565 \\
\end{tabular} & \begin{tabular}{|l|}
0.389 \\
\end{tabular} & \begin{tabular}{|l|}
0.391 \\
\end{tabular} & \begin{tabular}{|l|}
0.368 \\
\end{tabular} & 0.289 & & 0.364 & 0.400 & 0.431 & 47 & 58 & 31 & 444 & 64 & 14 & & 0.324 & 1.000 & 0.64 \\
\hline 1 & 525 & 435 & 691 & 444 & 424 & .594 & 375 & .360 & 0.463 & 357 & 0.282 & 42 & .353 & 0.370 & 97 & 38 & 0.348 & 0.418 & 0.431 & \begin{tabular}{|l|}
0.467 \\
\end{tabular} & 00 & 50 & 314 & 0.640 & \\
\hline
\end{tabular}

Chart S1. A representative chart of the pairwise similarity for the steviol and isosteviol library compounds described herein. Red indicates similarity coefficient of 1.0 (identical) and Blue indicates pairwise structural comparison with similarities less than the average pairwise similarity for the entire library.

Table S2. Similarity coefficients for Stevioside compound libraries 


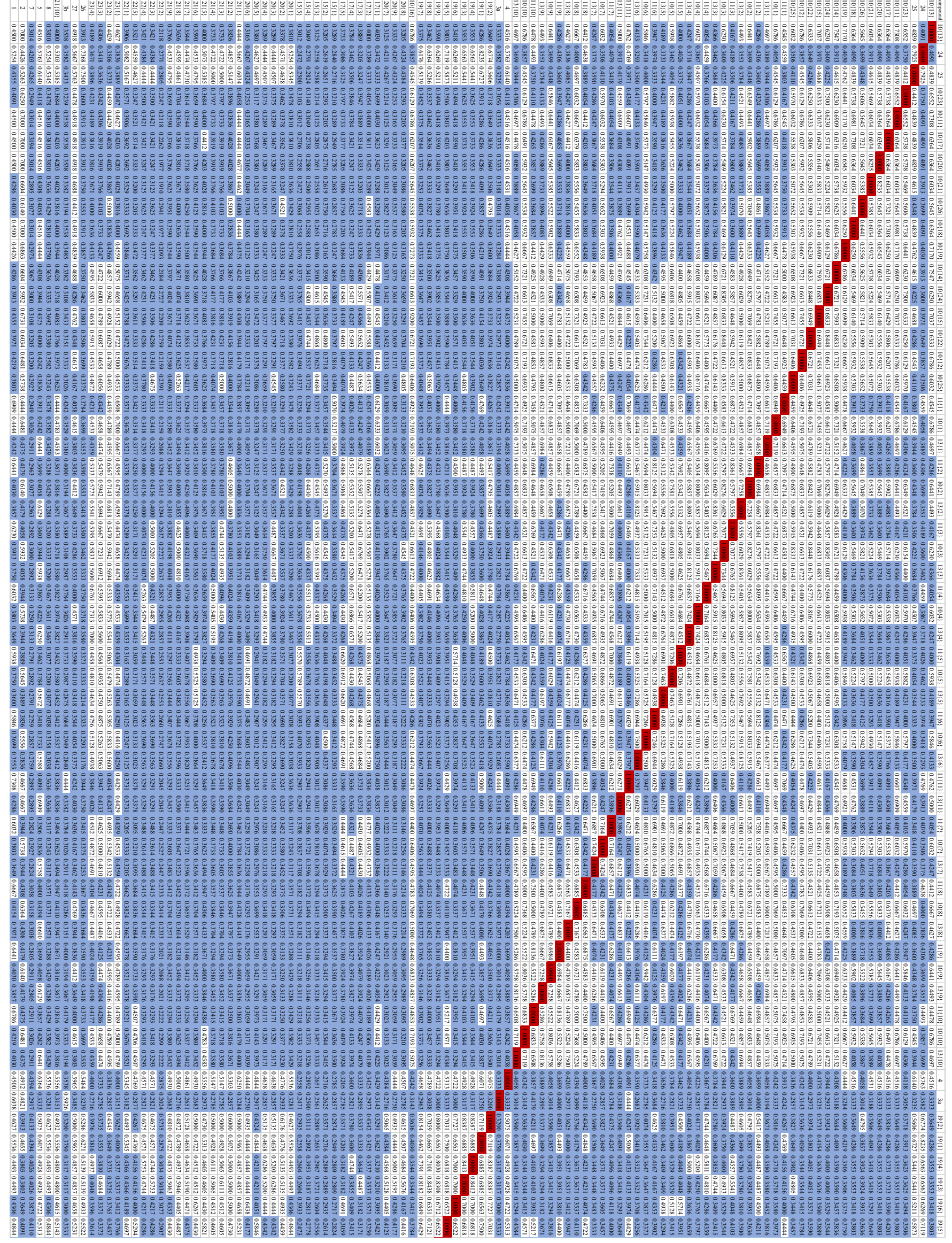




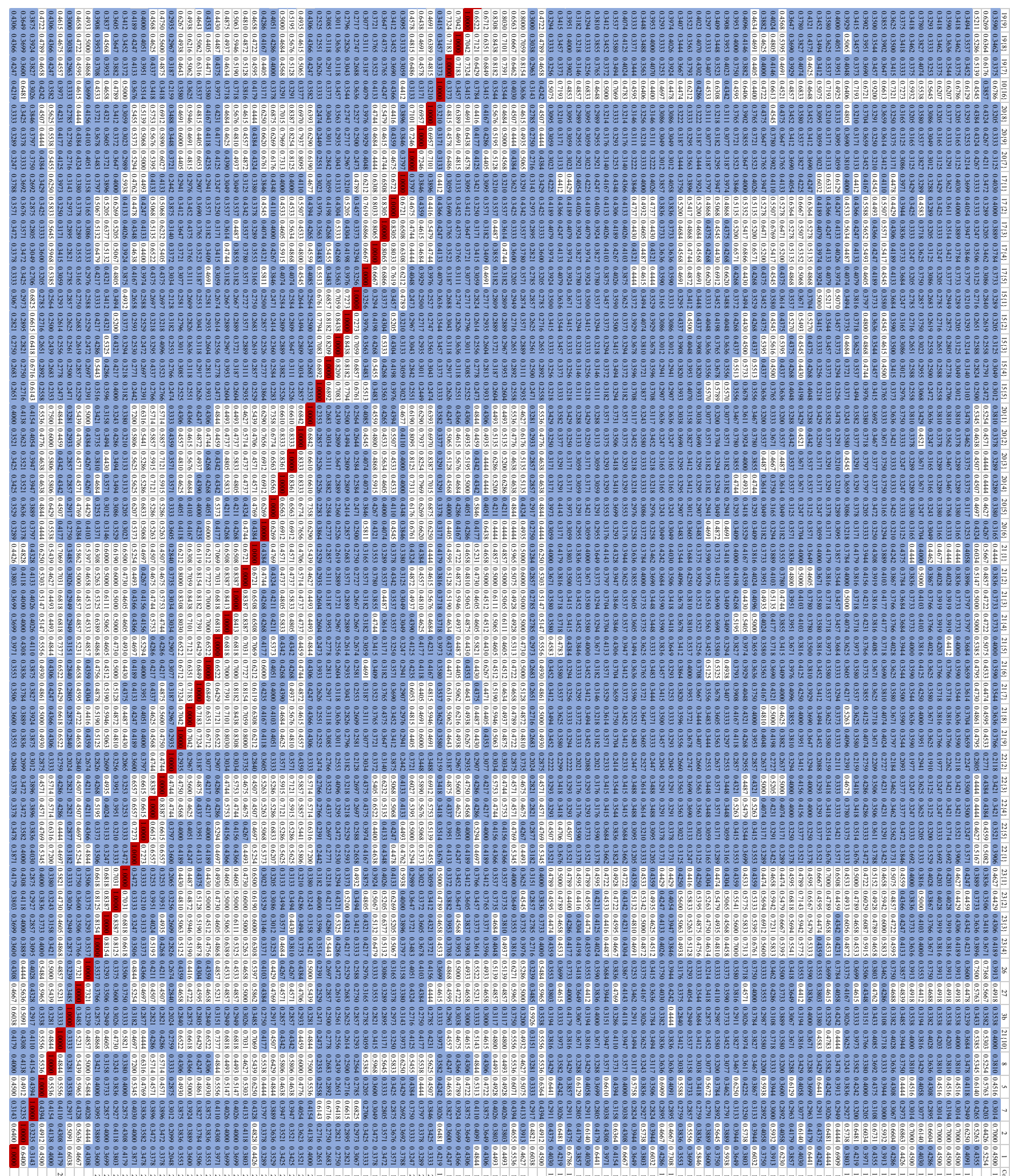

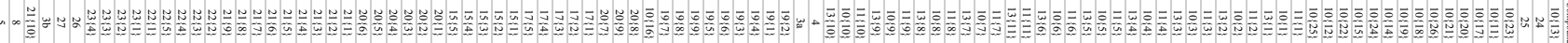




\section{Experimental Details and Compound Characterization.}

General Methods. Unless otherwise noted, all reactions were carried out open to air with reagent grade solvents. Purification of reaction products was carried out by flash column chromatography using silica gel 60 (230-400 mesh). Analytical thin layer chromatography (TLC) was performed on $0.25 \mathrm{~mm}$ silica gel 60-F plates. Visualization was accomplished with UV light or cerium molybdate stain followed by heating. High-resolution mass spectral data were acquired utilizing the electrospray ionization technique. ${ }^{1} \mathrm{H}$ nuclear magnetic resonance (NMR) spectra were recorded at ambient temperature at $400 \mathrm{MHz}$ and are reported in ppm using a solvent as an internal standard $\left(\mathrm{CDCl}_{3}\right.$ at $\left.7.26 \mathrm{ppm}\right)$. Proton-decoupled ${ }^{13} \mathrm{C} \mathrm{NMR}$ spectra were recorded at $100 \mathrm{MHz}$ and are reported in ppm using a solvent as an internal standard $\left(\mathrm{CDCl}_{3}\right.$ at $77.16 \mathrm{ppm})$. The data are reported as follows: chemical shift on the $\delta$ scale in ppm, multiplicity $(\mathrm{b}=$ broad, $\mathrm{s}=$ singlet, $\mathrm{d}=$ doublet, $\mathrm{t}=$ triplet, $\mathrm{q}=$ quartet, $\mathrm{m}=$ multiplet $)$, coupling constants $(\mathrm{Hz})$, and integration. Solvent abbreviations: tetrahydrofuran (THF), dimethylformamide (DMF), Hex (hexanes), methyl tert.-butyl ether (MTBE). Steviol and steviol methyl ester data were in agreement with previous reports. ${ }^{1}$

Syntheses of compounds $\mathbf{2 1}\{\mathbf{1}\}, \mathbf{2 1}\{2\}$, and 24-27 were reported by us before. ${ }^{8}$
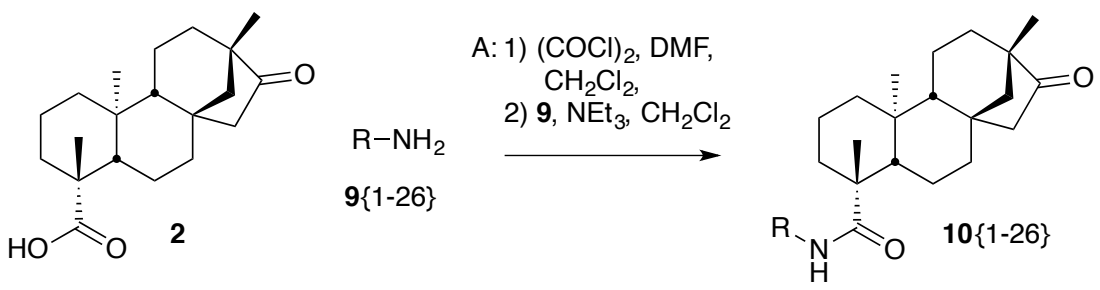

Standard procedure for the solution phase amide bond formation (Scheme 2, A). To an oven-dried reaction flask under nitrogen at $0{ }^{\circ} \mathrm{C}$ (ice bath), was added DMF $\left(37 \mu \mathrm{L}, 0.47 \mathrm{mmol}, 1.5\right.$ equiv) in $\mathrm{CH}_{2} \mathrm{Cl}_{2}(1.0$ $\mathrm{mL})$ followed by oxalyl chloride $(41 \mu \mathrm{L}, 0.47 \mathrm{mmol}, 1.5$ equiv). The ice bath was removed and the mixture was allowed to stir at room temperature for $1 \mathrm{~h}$. Then the reaction flask was cooled to $0{ }^{\circ} \mathrm{C}$ (ice bath) and isosteviol $(2,100 \mathrm{mg}, 0.31 \mathrm{mmol})$ and $\mathrm{Et}_{3} \mathrm{~N}(130 \mu \mathrm{L}, 0.47 \mathrm{mmol}, 3$ equiv $)$ in $\mathrm{CH}_{2} \mathrm{Cl}_{2}(1.0 \mathrm{~mL})$ were added. After stirring for $5 \mathrm{~min}$, allylamine $(\mathbf{9}\{\mathbf{1}\}, 1 \mathrm{~mL}, 13.4 \mathrm{mmol})$ was added and the mixture was stirred for 2 h. (For all reactions $1 \mathrm{~mL}$ of the amine was added). Then the mixture was loaded onto a $20-\mathrm{mL}$ silica gel plug in a $70-\mathrm{mL}$ column and eluted with dry THF. The solvent was removed under vacuum, the residue was dissolved in $\mathrm{CH}_{2} \mathrm{Cl}_{2}(10 \mathrm{~mL})$, and methylisocyanate polystyrene resin was added. The mixture was shaken for $20 \mathrm{~h}$ and was then loaded onto a 20 -mL silica gel plug in a $70-\mathrm{mL}$ column and eluted with ethyl acetate $(40 \mathrm{~mL})$. The solvent was removed and the residues was purified using column chromatography on silica gel with 10\% EtOAc:Hex as the eluent to provide the allyl amide product $\mathbf{1 0} \mathbf{1}\}$ in $47 \%$ yield.
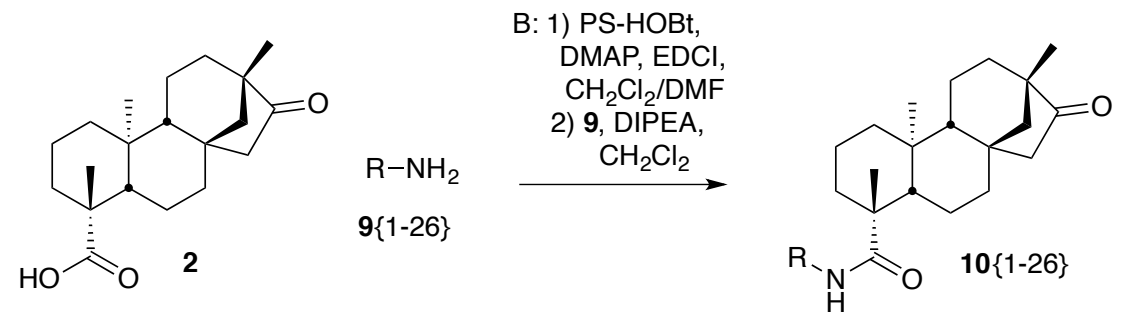

Standard procedure for solid phase amide bond formation (Scheme 2, B). To a flame-dry reaction vial of isosteviol (2, $100.0 \mathrm{mg}, \quad 0.318 \mathrm{mmol}, \quad 1.0$ equiv) in $\mathrm{CH}_{2} \mathrm{Cl}_{2} / \mathrm{DMF}$ (4:1) was added PShydroxybenzotriazole (PS-HOBt, $1.00 \mathrm{mmol} / \mathrm{g}, 0.67$ equiv), 4-dimethylaminopyridine (15.5 mg, 0.127 
mmol, 0.40 equiv), and then 1-ethyl-3-(3-dimethylaminopropyl)carbodiimide (148 mg, $0.954 \mathrm{mmol}, 3.0$ equiv). The reaction mixture was shaken slowly for $24 \mathrm{~h}$ and then filtered. The resin was washed with $\mathrm{MeOH}(5 \mathrm{~mL})$ and $\mathrm{CH}_{2} \mathrm{Cl}_{2}(5 \mathrm{~mL})$ thrice to remove excess acid. Then, the resin was added to a solution of allylamine (9\{1\},15.5 $\mu \mathrm{L}, 0.220 \mathrm{mmol}, 0.70$ equiv) and diisopropylethylamine $(55.4 \mu \mathrm{L}, 0.318 \mathrm{mmol}$, 1.0 equiv) in $\mathrm{CH}_{2} \mathrm{Cl}_{2}$ and shaken slowly for another $24 \mathrm{~h}$. The mixture was filtered again was washed with $\mathrm{MeOH}(5 \mathrm{~mL})$ and $\mathrm{CH}_{2} \mathrm{Cl}_{2}(5 \mathrm{~mL})$ thrice before the solvent was removed under vacuum. Column chromatography on silica gel with 20\% EtOAc:Hex as the eluent gave amide product 10\{1\} in $43 \mathrm{mg}$ (38\% yield).<smiles>C=CCNC(=O)C12CCCC3CC4(C)CC(=O)CC4(CCC3C1)C2</smiles>

(4R,4aS,6aR,9S,11aR,11bS)-N-Allyl-4,9,11b-trimethyl-8-oxotetradecahydro-6a,9methanocyclohepta $[a]$ naphthalene-4-carboxamide $(\mathbf{1 0}\{1\})$. Oil; ${ }^{1} \mathrm{H}$ NMR $\left(400 \mathrm{MHz}, \mathrm{CDCl}_{3}\right): \delta$ $5.83-5.70(\mathrm{~m}, 1 \mathrm{H}), 5.62(\mathrm{~s}, 1 \mathrm{H}), 5.09(\mathrm{dd}, J=23.1,13.7 \mathrm{~Hz}, 2 \mathrm{H}), 3.79(\mathrm{t}, J=5.1 \mathrm{~Hz}, 2 \mathrm{H}), 2.58(\mathrm{dd}, J=$ $18.6,3.6 \mathrm{~Hz}, 1 \mathrm{H}), 2.03-1.85(\mathrm{~m}, 2 \mathrm{H}), 1.73(\mathrm{~d}, J=18.5 \mathrm{~Hz}, 3 \mathrm{H}), 1.66-1.58(\mathrm{~m}, 2 \mathrm{H}), 1.55-1.41(\mathrm{~m}$, $4 \mathrm{H}), 1.43-1.33(\mathrm{~m}, 3 \mathrm{H}), 1.21-1.13(\mathrm{~m}, 2 \mathrm{H}), 1.13(\mathrm{~s}, 3 \mathrm{H}), 1.10-1.02(\mathrm{~m}, 1 \mathrm{H}), 0.91(\mathrm{~s}, 3 \mathrm{H}), 0.87(\mathrm{~d}, J$ $=4.5 \mathrm{~Hz}, 1 \mathrm{H}), 0.71(\mathrm{~s}, 3 \mathrm{H}), 0.66(\mathrm{~d}, J=3.1 \mathrm{~Hz}, 1 \mathrm{H}) ;{ }^{13} \mathrm{C}$ NMR $\left(125 \mathrm{MHz}, \mathrm{CDCl}_{3}\right): \delta 222.6,176.4$, 134.4, 116.6, 57.5, 57.2, 54.7, 54.2, 48.7, 48.4, 43.7, 41.9, 41.7, 40.2, 39.5, 38.1, 37.3, 30.2, 22.2, 20.3, 19.9, 19.2, 13.6; LRMS (ESI) $(m / z):[\mathrm{M}+\mathrm{H}]^{+}$calcd for $\mathrm{C}_{23} \mathrm{H}_{36} \mathrm{NO}_{2} 358.2668$, found $358 ;[\alpha]_{\mathrm{D}}^{23}-80.7(c$ $\left.0.950, \mathrm{CHCl}_{3}\right)$.

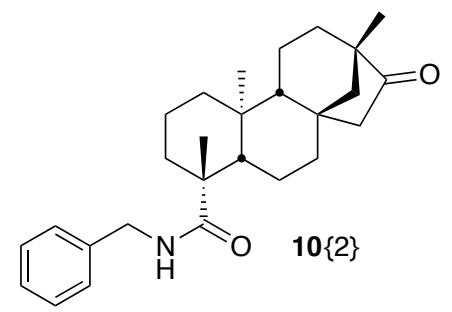

$(4 R, 4 \mathrm{a} S, 6 \mathrm{a} R, 9 S, 11 \mathrm{a} R, 11 \mathrm{~b} S)-N$-Benzyl-4,9,11b-trimethyl-8-oxotetradecahydro-6a,9methanocyclohepta $[a]$ naphthalene-4-carboxamide (10\{2\}). Pale yellow solid; mp $68-69{ }^{\circ} \mathrm{C}$; ${ }^{1} \mathrm{H}$ NMR $\left(400 \mathrm{MHz}, \mathrm{CDCl}_{3}\right): \delta 7.36-7.25(\mathrm{~m}, 5 \mathrm{H}), 5.86(\mathrm{t}, J=4.9 \mathrm{~Hz}, 1 \mathrm{H}), 4.40(\mathrm{~d}, J=5.4 \mathrm{~Hz}, 2 \mathrm{H}), 2.62(\mathrm{dd}, J$ $=18.6,3.6 \mathrm{~Hz}, 1 \mathrm{H}), 2.06-1.90(\mathrm{~m}, 2 \mathrm{H}), 1.83-1.63(\mathrm{~m}, 6 \mathrm{H}), 1.59-1.32(\mathrm{~m}, 7 \mathrm{H}), 1.27-1.22(\mathrm{~m}, 1 \mathrm{H})$, $1.21(\mathrm{~s}, 3 \mathrm{H}), 1.18-1.12(\mathrm{~m}, 2 \mathrm{H}), 0.96(\mathrm{~s}, 3 \mathrm{H}), 0.95-0.79(\mathrm{~m}, 1 \mathrm{H}), 0.74(\mathrm{~s}, 3 \mathrm{H}) .{ }^{13} \mathrm{C} \mathrm{NMR}(125 \mathrm{MHz}$ $\left.\mathrm{CDCl}_{3}\right): \delta 222.4,176.4,138.5,128.9,128.7,128.0,127.5,127.5,57.6,54.7,54.3,48.7,48.4,43.7,41.7$, $40.2,39.5,38.1,38.1,37.3,30.2,22.2,22.2,20.3,19.9,19.2,13.6$; LRMS (ESI) $(\mathrm{m} / \mathrm{z}):[\mathrm{M}+\mathrm{Na}]^{+}$calcd for $\mathrm{C}_{27} \mathrm{H}_{37} \mathrm{NO}_{2} \mathrm{Na} 430.2824$, found $430.4 ;[\alpha]_{\mathrm{D}}^{23}-44.0$ (c 1.00, $\mathrm{CHCl}_{3}$ ).

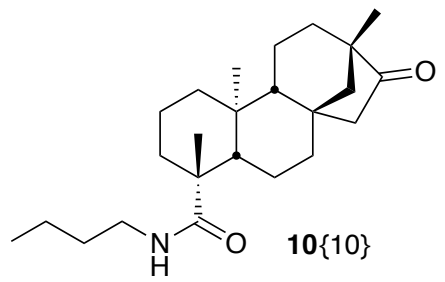


(4R,4aS,6a $R, 9 S, 11 \mathrm{a} R, 11 \mathrm{~b} S)-N$-Butyl-4,9,11b-trimethyl-8-oxotetradecahydro-6a,9-

methanocyclohepta[a]naphthalene-4-carboxamide (10\{1\}). Oil; ${ }^{1} \mathrm{H}$ NMR (400 MHz, $\left.\mathrm{CDCl}_{3}\right): \delta 5.59$ $(\mathrm{s}, 1 \mathrm{H}), 3.21(\mathrm{dt}, J=11.8,6.7 \mathrm{~Hz}, 2 \mathrm{H}), 2.65(\mathrm{dd}, J=18.6,3.6 \mathrm{~Hz}, 1 \mathrm{H}), 2.01(\mathrm{~d}, J=14.3 \mathrm{~Hz}, 1 \mathrm{H}), 1.95(\mathrm{~d}$, $J=13.3 \mathrm{~Hz}, 1 \mathrm{H}), 1.77(\mathrm{dd}, J=19.9,14.1 \mathrm{~Hz}, 4 \mathrm{H}), 1.71-1.65(\mathrm{~m}, 2 \mathrm{H}), 1.63-1.57(\mathrm{~m}, 1 \mathrm{H}), 1.56-1.52$ $(\mathrm{m}, 1 \mathrm{H}), 1.51-1.45(\mathrm{~m}, 4 \mathrm{H}), 1.40(\mathrm{dd}, J=11.8,3.7 \mathrm{~Hz}, 1 \mathrm{H}), 1.37-1.30(\mathrm{~m}, 3 \mathrm{H}), 1.25-1.18(\mathrm{~m}, 2 \mathrm{H})$, $1.17(\mathrm{~s}, 3 \mathrm{H}), 1.16-1.09(\mathrm{~m}, 2 \mathrm{H}), 0.97(\mathrm{~s}, 3 \mathrm{H}), 0.92(\mathrm{t}, J=7.2 \mathrm{~Hz}, 4 \mathrm{H}), 0.77(\mathrm{~s}, 3 \mathrm{H}) ;{ }^{13} \mathrm{C} \mathrm{NMR}(125 \mathrm{MHz}$, $\left.\mathrm{CDCl}_{3}\right): \delta 222.4,176.5,57.6,54.8,54.3,48.7,48.4,43.6,41.8,40.2,39.5,39.2,38.2,38.1,37.3$, $31.5,30.2,22.3,20.3,20.3,19.9,19.2,13.8,13.5$; LRMS (ESI) $(m / z):[\mathrm{M}+\mathrm{H}]^{+}$calcd for $\mathrm{C}_{24} \mathrm{H}_{40} \mathrm{NO}_{2}$ 374.2981 , found $374.3 ;[\alpha]_{\mathrm{D}}^{23}-32.2\left(c 0.500, \mathrm{CHCl}_{3}\right)$.
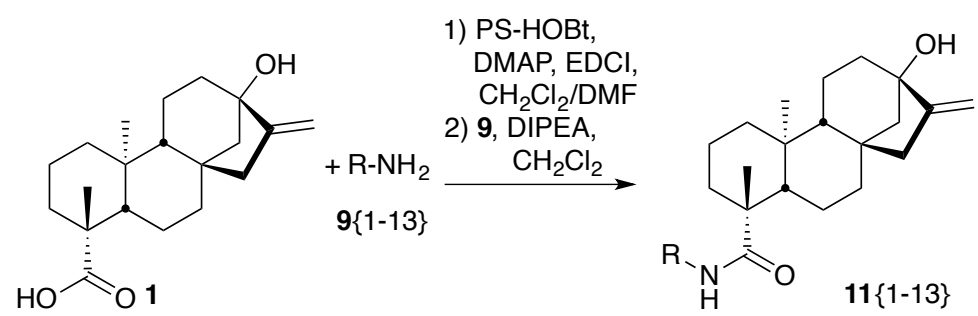

Standard procedure for solid-phase bond formation of steviol amide analogs 11\{1-13\} (Scheme 3). To a solution of steviol (1,100 mg, $0.318 \mathrm{mmol}, 1.00$ equiv) in $\mathrm{CH}_{2} \mathrm{Cl}_{2} / \mathrm{DMF}$ (4:1) in a flame-dry reaction vial, was added PS-hydroxybenzotriazole (PS-HOBt, $1.00 \mathrm{mmol} / \mathrm{g}, 0.213 \mathrm{mmol}, 0.670$ equiv), 4dimethylaminopyridine $(55.4 \mu \mathrm{L}, 0.318 \mathrm{mmol}, 0.40$ equiv), and then 1-ethyl-3-(3-dimethylaminopropyl) carbodiimide (148 mg, $0.954 \mathrm{mmol}, 3.0$ equiv). The reaction mixture was shaken slowly for $24 \mathrm{~h}$ and then filtered. The resins were washed with $\mathrm{MeOH}(5 \mathrm{~mL})$ and $\mathrm{CH}_{2} \mathrm{Cl}_{2}(5 \mathrm{~mL})$ thrice to remove excess acid. Then, the resin was added to a solution of 4-flurobenzylamine (9\{3\}, $27.5 \mathrm{mg}, 0.220 \mathrm{mmol}, 0.70$ equiv) and diisopropylethylamine $\left(55.4 \mu \mathrm{L}, 0.318 \mathrm{mmol}, 1.0\right.$ equiv) in $\mathrm{CH}_{2} \mathrm{Cl}_{2}$ and shaken slowly for another 24 h. The mixture was filtered again was washed with $\mathrm{MeOH}(5 \mathrm{~mL})$ and $\mathrm{CH}_{2} \mathrm{Cl}_{2}(5 \mathrm{~mL})$ thrice before the solvent was removed under vacuum. The crude residue was purified by column chromatography on silica gel with 20\% EtOAc:Hex to furnish the amide 11\{3\}.

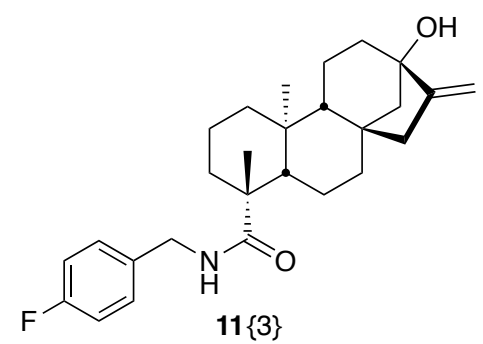

(4R,4aS,6aR,9S,11aR,11bS)-N-(4-Fluorobenzyl)-9-hydroxy-4,11b-dimethyl-8methylenetetradecahydro-6a,9-methanocyclohepta[a]naphthalene-4-carboxamide (11\{3\}). Oil; ${ }^{1} \mathrm{H}$ NMR (400 MHz, $\left.\mathrm{CDCl}_{3}\right): \delta 8.27(\mathrm{~s}, 1 \mathrm{H}), 7.70(\mathrm{dd}, J=8.5,5.7 \mathrm{~Hz}, 2 \mathrm{H}), 7.03(\mathrm{t}, J=8.6 \mathrm{~Hz}, 2 \mathrm{H}), 4.82(\mathrm{~d}$, $J=67.5 \mathrm{~Hz}, 2 \mathrm{H}), 4.69(\mathrm{~s}, 2 \mathrm{H}), 2.13-1.93(\mathrm{~m}, 4 \mathrm{H}), 1.88-1.63(\mathrm{~m}, 6 \mathrm{H}), 1.58-1.22(\mathrm{~m}, 5 \mathrm{H}), 1.20-1.16$ $(\mathrm{m}, 1 \mathrm{H}), 1.11(\mathrm{~s}, 3 \mathrm{H}), 1.08-0.97(\mathrm{~m}, 3 \mathrm{H}), 0.88(\mathrm{~d}, J=7.9 \mathrm{~Hz}, 1 \mathrm{H}), 0.79(\mathrm{~s}, 3 \mathrm{H}), 0.75(\mathrm{dd}, J=12.7,3.7$ $\mathrm{Hz}, 1 \mathrm{H}) .{ }^{13} \mathrm{C}$ NMR $\left(125 \mathrm{MHz}, \mathrm{CDCl}_{3}\right): \delta 176.6,160.6,156.0,130.1,129.6,129.4,115.6,115.4,103.0$, 80.2, 64.2, 57.4, 53.7, 47.4, 46.9, 43.8, 42.9, 41.7, 40.9, 39.4, 38.2, 30.1, 23.0, 22.4, 20.4, 19.3, 15.7; LRMS (ESI) $(m / z):[\mathrm{M}+\mathrm{H}]^{+}$calcd for $\mathrm{C}_{27} \mathrm{H}_{37} \mathrm{FNO}_{2} 426.2730$, found 426 ; $[\alpha]_{\mathrm{D}}^{23}-84.0\left(c 0.451, \mathrm{CHCl}_{3}\right)$. 


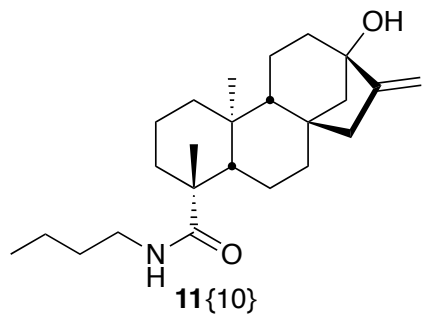

$(4 R, 4 a S, 6 a R, 9 S, 11 \mathrm{a} R, 11 \mathrm{~b} S)$ - $N$-Butyl-9-hydroxy-4,11b-dimethyl-8-methylenetetradecahydro-6a,9methanocyclohepta[a]naphthalene-4-carboxamide (11\{10). Oil; ${ }^{1} \mathrm{H}$ NMR $\left(400 \mathrm{MHz}, \mathrm{CDCl}_{3}\right): \delta 7.99$ (s, $1 \mathrm{H}), 5.58(\mathrm{~s}, 1 \mathrm{H}), 4.88(\mathrm{~d}, J=68.1 \mathrm{~Hz}, 2 \mathrm{H}), 3.20(\mathrm{dt}, J=12.2,6.8 \mathrm{~Hz}, 2 \mathrm{H}), 2.90(\mathrm{~d}, J=30.2 \mathrm{~Hz}, 1 \mathrm{H})$, $2.18(\mathrm{~d}, J=17.0 \mathrm{~Hz}, 1 \mathrm{H}), 2.14-2.09(\mathrm{~m}, 1 \mathrm{H}), 2.07-2.00(\mathrm{~m}, 2 \mathrm{H}), 1.89(\mathrm{dd}, J=21.7,5.2 \mathrm{~Hz}, 3 \mathrm{H}), 1.82$ $-1.71(\mathrm{~m}, 3 \mathrm{H}), 1.63-1.51(\mathrm{~m}, 2 \mathrm{H}), 1.51-1.43(\mathrm{~m}, 4 \mathrm{H}), 1.42-1.30(\mathrm{~m}, 3 \mathrm{H}), 1.26(\mathrm{~d}, J=10.8 \mathrm{~Hz}, 1 \mathrm{H})$, $1.13(\mathrm{~s}, 3 \mathrm{H}), 1.10-0.99(\mathrm{~m}, 2 \mathrm{H}), 0.94-0.90(\mathrm{~m}, 3 \mathrm{H}), 0.89(\mathrm{~s}, 3 \mathrm{H}), 0.86-0.77(\mathrm{~m}, 1 \mathrm{H}) ;{ }^{13} \mathrm{C}$ NMR $(125$ $\left.\mathrm{MHz}, \mathrm{CDCl}_{3}\right): \delta$ 176.6, 156.1, 102.9, 80.2, 57.3, 53.8, 47.4, 46.9, 43.7, 41.7, 41.6, 41.1, 39.4, 39.3, 39.2, $38.3,31.5,30.1,22.4,20.5,20.3,19.4,15.6,13.8$; LRMS $(m / z)$ : $[\mathrm{M}+\mathrm{H}]^{+}$calcd for $\mathrm{C}_{24} \mathrm{H}_{40} \mathrm{NO}_{2} 374.2981$, found $374.3 ;[\alpha]_{\mathrm{D}}^{23}-77.5\left(\right.$ c 1.00, $\left.\mathrm{CHCl}_{3}\right)$.

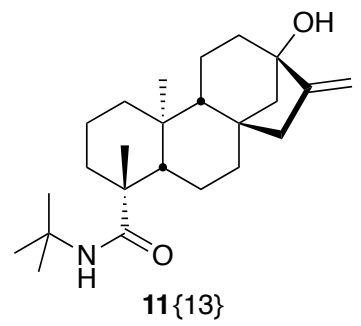

$(4 R, 4 \mathrm{a} S, 6 \mathrm{a} R, 9 S, 11 \mathrm{a} R, 11 \mathrm{~b} S)$ - $N$-(tert-Butyl)-9-hydroxy-4,11b-dimethyl-8-methylenetetradecahydro6a,9-methanocyclohepta[a] naphthalene-4-carboxamide (11\{13\}). Oil; ${ }^{1} \mathrm{H}$ NMR $\left(400 \mathrm{MHz}, \mathrm{CDCl}_{3}\right)$ : $\delta$ $5.34(\mathrm{~s}, 1 \mathrm{H}), 4.88$ (d, $J=66.6 \mathrm{~Hz}, 2 \mathrm{H}), 2.94(\mathrm{~s}, 1 \mathrm{H}), 2.18$ (d, $J=19.5 \mathrm{~Hz}, 1 \mathrm{H}), 2.10$ (d, $J=17.2 \mathrm{~Hz}, 1 \mathrm{H})$, $1.99(\mathrm{~d}, J=13.6 \mathrm{~Hz}, 1 \mathrm{H}), 1.91-1.84(\mathrm{~m}, 4 \mathrm{H}), 1.82-1.73(\mathrm{~m}, 4 \mathrm{H}), 1.60-1.50(\mathrm{~m}, 2 \mathrm{H}), 1.49-1.37(\mathrm{~m}$, $3 \mathrm{H}), 1.33(\mathrm{~s}, 3 \mathrm{H}), 1.31(\mathrm{~s}, 6 \mathrm{H}), 1.27(\mathrm{dd}, J=14.7,3.6 \mathrm{~Hz}, 1 \mathrm{H}), 1.12(\mathrm{~s}, 3 \mathrm{H}), 1.08-0.98(\mathrm{~m}, 2 \mathrm{H}), 0.95(\mathrm{~s}$, $3 \mathrm{H}), 0.82(\mathrm{~d}, J=4.0 \mathrm{~Hz}, 1 \mathrm{H}) ;{ }^{13} \mathrm{C} \mathrm{NMR}\left(125 \mathrm{MHz}, \mathrm{CDCl}_{3}\right): \delta 175.7,156.1,102.9,80.2,57.2,53.8,50.7$, 47.4, 46.9, 44.1, 41.7, 41.6, 41.2, 39.5, 39.3, 38.5, 30.2, 28.8, 28.7, 28.7, 22.5, 20.5, 19.3, 15.9; LRMS (ESI) $(m / z):[\mathrm{M}+\mathrm{H}]^{+}$calcd for $\mathrm{C}_{24} \mathrm{H}_{40} \mathrm{NO}_{2} 374.2981$, found $374.3 ;[\alpha]_{\mathrm{D}}^{23}-102.1\left(c 0.750, \mathrm{CHCl}_{3}\right)$.

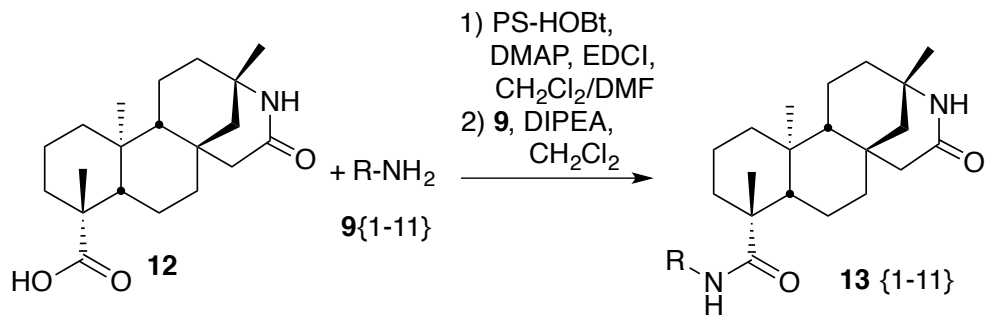

Standard procedure for solid-phase bond formation of isosteviol lactam 13 $\{1-11\}$ from previously reported $\mathbf{1 2}^{2}$ (Scheme 3). To a solution of lactam 12 (100 mg, $0.333 \mathrm{mmol}, 1.00$ equiv) in $\mathrm{CH}_{2} \mathrm{Cl}_{2} / \mathrm{DMF}$ (4:1) in a flame-dry reaction vial, was added PS-hydroxybenzotriazole (PS-HOBt, $1.00 \mathrm{mmol} / \mathrm{g}, 0.223 \mathrm{mmol}, 0.670$ equiv), 4-dimethylaminopyridine (58.0 $\mu \mathrm{L}, 0.333 \mathrm{mmol}, 0.40$ equiv), and then 1-ethyl-3-(3dimethylaminopropyl) carbodiimide (155 $\mathrm{mg}, 1.00 \mathrm{mmol}, 3.0$ equiv). The reaction mixture was shaken 
slowly for $24 \mathrm{~h}$ and then filtered. The resins were washed with $\mathrm{MeOH}(5 \mathrm{~mL})$ and $\mathrm{CH}_{2} \mathrm{Cl}_{2}(5 \mathrm{~mL})$ thrice to remove excess acid. Then, the resin was added to a solution of allylamine $(\mathbf{9}\{\mathbf{1}\}, 29.1 \mathrm{mg}, 0.220 \mathrm{mmol}$, 0.70 equiv) and diisopropylethylamine $\left(58.0 \mu \mathrm{L}, 0.333 \mathrm{mmol}, 1.0\right.$ equiv) in $\mathrm{CH}_{2} \mathrm{Cl}_{2}$ and shaken slowly for another $24 \mathrm{~h}$. The mixture was filtered again was washed with $\mathrm{MeOH}(5 \mathrm{~mL})$ and $\mathrm{CH}_{2} \mathrm{Cl}_{2}(5 \mathrm{~mL})$ thrice before the solvent was removed under vacuum. The crude residue was purified by column chromatography on silica gel with $20 \%$ EtOAc:Hex to furnish the amide $\mathbf{1 3}\{\mathbf{1}\}$.

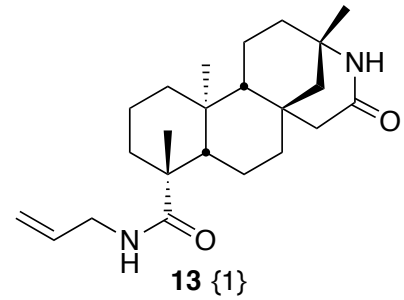

$(3 S, 6 a R, 8 \mathrm{a} S, 9 R, 12 \mathrm{a} S, 12 \mathrm{~b} R)-\mathrm{N}$-Allyl-3,9,12a-trimethyl-5-oxotetradecahydro-2H-3,6amethanonaphtho[2,1-d] azocine-9-carboxamide (13\{1\}). Oil; ${ }^{1} \mathrm{H}$ NMR (400 MHz, $\left.\mathrm{CDCl}_{3}\right): \delta 5.88-5.80$ $(\mathrm{m}, 1 \mathrm{H}), 5.66(\mathrm{~s}, 1 \mathrm{H}), 5.22-5.13(\mathrm{~m}, 2 \mathrm{H}), 3.92-3.79(\mathrm{~m}, 2 \mathrm{H}), 2.92(\mathrm{~d}, J=29.2 \mathrm{~Hz}, 1 \mathrm{H}), 2.52(\mathrm{ddd}, J=$ $52.5,16.6,2.1 \mathrm{~Hz}, 1 \mathrm{H}), 2.20-1.70(\mathrm{~m}, 8 \mathrm{H}), 1.59(\mathrm{~s}, 6 \mathrm{H}), 1.53-1.23(\mathrm{~m}, 4 \mathrm{H}), 1.20(\mathrm{~s}, 3 \mathrm{H}), 1.19-1.08$ $(\mathrm{m}, 3 \mathrm{H}), 0.90(\mathrm{dd}, J=13.6,3.8 \mathrm{~Hz}, 1 \mathrm{H}), 0.80-0.71(\mathrm{~m}, 3 \mathrm{H}) .{ }^{13} \mathrm{C} \mathrm{NMR}\left(125 \mathrm{MHz}, \mathrm{CDCl}_{3}\right): \delta 176.3,134.5$, 131.4, 120.0, 116.8, 57.9, 52.0, 45.9, 43.8, 42.1, 40.3, 39.5, 38.1, 37.6, 35.4, 33.2, 30.2, 23.4, 22.4, 20.5, 20.1, 19.4, 14.0; HRMS (ESI) $(m / z):[\mathrm{M}+\mathrm{Na}]^{+}$calcd for $\mathrm{C}_{23} \mathrm{H}_{36} \mathrm{O}_{2} \mathrm{~N}_{2} \mathrm{Na} 395.2777$, found 395.2680; $[\alpha]_{\mathrm{D}}^{23}$ $-10.3\left(c 1.20, \mathrm{CHCl}_{3}\right)$.

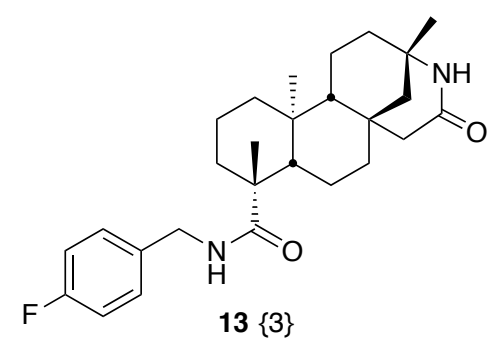

(3S,6aR,8aS,9R,12aS,12bR)- $N$-(4-Fluorobenzyl)-3,9,12a-trimethyl-5-oxotetradecahydro-2H-3,6amethanonaphtho[2,1-d] azocine-9-carboxamide (13\{3\}). Oil; ${ }^{1} \mathrm{H}$ NMR (400 MHz, $\left.\mathrm{CDCl}_{3}\right): \delta 7.33-7.29$ $(\mathrm{m}, 1 \mathrm{H}), 7.25-7.22(\mathrm{~m}, 1 \mathrm{H}), 7.03-6.97(\mathrm{~m}, 2 \mathrm{H}), 6.51(\mathrm{t}, J=6.0 \mathrm{~Hz}, 1 \mathrm{H}), 4.56(\mathrm{dd}, J=15.0,6.5 \mathrm{~Hz}$, $1 \mathrm{H}), 4.49-4.33(\mathrm{~m}, 2 \mathrm{H}), 3.10(\mathrm{~d}, J=17.6 \mathrm{~Hz}, 1 \mathrm{H}), 2.40(\mathrm{~d}, J=12.1 \mathrm{~Hz}, 1 \mathrm{H}), 2.31(\mathrm{~d}, J=17.8 \mathrm{~Hz}, 1 \mathrm{H})$, $2.17(\mathrm{~d}, J=13.4 \mathrm{~Hz}, 1 \mathrm{H}), 1.92-1.83(\mathrm{~m}, 3 \mathrm{H}), 1.78(\mathrm{~d}, J=13.2 \mathrm{~Hz}, 1 \mathrm{H}), 1.73-1.67(\mathrm{~m}, 2 \mathrm{H}), 1.64-$ $1.56(\mathrm{~m}, 2 \mathrm{H}), 1.51-1.42(\mathrm{~m}, 1 \mathrm{H}), 1.39(\mathrm{~s}, 3 \mathrm{H}), 1.36-1.28(\mathrm{~m}, 2 \mathrm{H}), 1.25(\mathrm{~s}, 3 \mathrm{H}), 1.22-1.15(\mathrm{~m}, 1 \mathrm{H})$, $1.13-1.04(\mathrm{~m}, 2 \mathrm{H}), 1.02-0.93(\mathrm{~m}, 2 \mathrm{H}), 0.86(\mathrm{~s}, 3 \mathrm{H}) ;{ }^{13} \mathrm{C} \mathrm{NMR}\left(125 \mathrm{MHz}, \mathrm{CDCl}_{3}\right): \delta 183.0,176.1,171.0$, $161.1,129.5,129.5,115.7,115.5,77.3,77.0,76.7,59.5,57.3,56.6,51.2,43.7,43.6,42.8,42.0,39.8,38.0$, $37.7,37.5,35.0,28.8,26.1,19.5,19.1,18.9,13.8$; LRMS (ESI) $(m / z):[\mathrm{M}+\mathrm{H}]^{+}$calcd for $\mathrm{C}_{27} \mathrm{H}_{38} \mathrm{FN}_{2} \mathrm{O}_{2}$ 441.2339, found 441; $[\alpha]_{\mathrm{D}}^{23} 19.2\left(c 1.00, \mathrm{CHCl}_{3}\right)$.
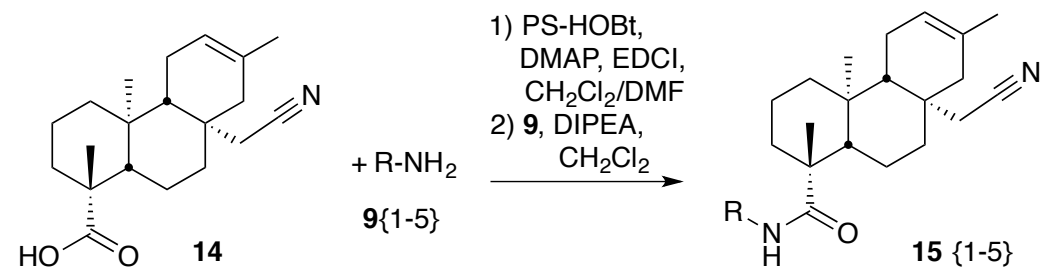
Standard procedure for amide bond formation of $15\{1-5\}$ from 14. To a flame-dried reaction flask of the nitrile acid 14 (1.0 equiv) in $\mathrm{CH}_{2} \mathrm{Cl}_{2} / \mathrm{DMF}$ (4:1) in a flame-dry reaction vial, was added PShydroxybenzotriazole (PS-HOBt, $1.00 \mathrm{mmol} / \mathrm{g}, 0.67$ equiv), 4-dimethylaminopyridine $(55.4 \mu \mathrm{L}, 0.318$ mmol, 0.40 equiv), and then 1-ethyl-3-(3-dimethylaminopropyl) carbodiimide (148 mg, $0.954 \mathrm{mmol}, 3.0$ equiv). The reaction mixture was shaken slowly for $24 \mathrm{~h}$ and then filtered. The resins were washed with $\mathrm{MeOH}(5 \mathrm{~mL})$ and $\mathrm{CH}_{2} \mathrm{Cl}_{2}(5 \mathrm{~mL})$ thrice to remove excess acid. Then, the resin was added to a solution of amine 9 ( $0.220 \mathrm{mmol}, 0.70$ equiv) and diisopropylethylamine $(55.4 \mu \mathrm{L}, 0.318 \mathrm{mmol}, 1.0$ equiv) in $\mathrm{CH}_{2} \mathrm{Cl}_{2}$ and shaken slowly for another $24 \mathrm{~h}$. The mixture was filtered again was washed with $\mathrm{MeOH}(5$ $\mathrm{mL})$ and $\mathrm{CH}_{2} \mathrm{Cl}_{2}(5 \mathrm{~mL})$ thrice before the solvent was removed under vacuum. The crude residue was purified by column chromatography on silica gel with $20 \%$ EtOAc:Hex to furnish the amide $\mathbf{1 5 .}$

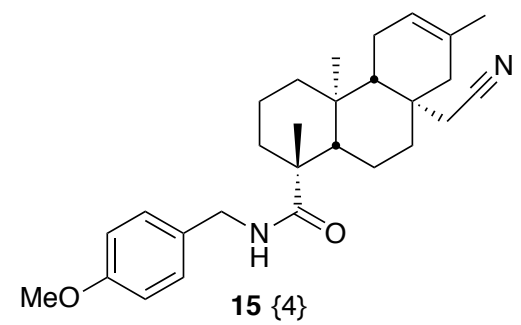

$(1 R, 4 \mathrm{a} S, 4 \mathrm{~b} R, 8 \mathrm{a} R, 10 \mathrm{a} S)-N$-Benzyl-8a-(cyanomethyl)-1,4a,7-trimethyl-1,2,3,4,4a,4b,5,8,8a,9,10,10adodecahydrophenanthrene-1-carboxamide (15\{4\}). Pale yellow crystals; mp $63-64{ }^{\circ} \mathrm{C} ;{ }^{1} \mathrm{H}$ NMR $(400$ $\left.\mathrm{MHz}, \mathrm{CDCl}_{3}\right): \delta 7.21(\mathrm{~d}, J=8.4 \mathrm{~Hz}, 2 \mathrm{H}), 6.86(\mathrm{~d}, J=8.4 \mathrm{~Hz}, 2 \mathrm{H}), 5.69(\mathrm{~s}, 1 \mathrm{H}), 4.36(\mathrm{~d}, J=5.6 \mathrm{~Hz}, 2 \mathrm{H})$, $3.80(\mathrm{~s}, 3 \mathrm{H}), 2.98(\mathrm{dd}, J=19.0,2.5 \mathrm{~Hz}, 1 \mathrm{H}), 2.17(\mathrm{~d}, J=13.1 \mathrm{~Hz}, 1 \mathrm{H}), 2.01(\mathrm{~s}, 3 \mathrm{H}), 2.05-1.96(\mathrm{~m}, 1 \mathrm{H})$, $1.90-1.66(\mathrm{~m}, 4 \mathrm{H}), 1.61(\mathrm{~d}, J=13.6 \mathrm{~Hz}, 2 \mathrm{H}), 1.51-1.38(\mathrm{~m}, 4 \mathrm{H}), 1.28(\mathrm{~s}, 1 \mathrm{H}), 1.23(\mathrm{~s}, 3 \mathrm{H}), 1.09(\mathrm{~s}$, $3 \mathrm{H}), 1.01(\mathrm{td}, J=13.5,3.8 \mathrm{~Hz}, 1 \mathrm{H}), 0.93-0.87(\mathrm{~m}, 1 \mathrm{H}), 0.85(\mathrm{~s}, 3 \mathrm{H}) ;{ }^{13} \mathrm{C}$ NMR $\left(125 \mathrm{MHz}, \mathrm{CDCl}_{3}\right)$ : $\delta 183.0,170.6,170.0,159.2,130.4,129.4,129.4,114.2,114.2,77.5,77.2,76.8,57.3,56.4,55.5,55.1$, 44.0, 43.7, 43.4, 40.8, 40.1, 39.6, 38.4, 37.2, 29.2, 23.4, 22.3, 21.7, 20.6, 19.1, 13.6; LRMS (ESI) $(\mathrm{m} / \mathrm{z})$ : $[\mathrm{M}+\mathrm{Na}]^{+}$calcd for $\mathrm{C}_{28} \mathrm{H}_{38} \mathrm{~N}_{2} \mathrm{O}_{2} 434.2933$, found 457.3; $[\alpha]_{\mathrm{D}}^{23} 3.60\left(c 0.600, \mathrm{CHCl}_{3}\right)$.

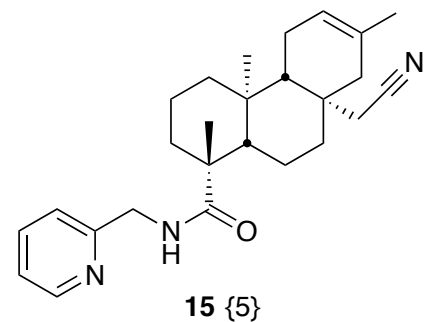

$(1 R, 4 \mathrm{a} S, 4 \mathrm{~b} R, 10 \mathrm{a} S)-8 \mathrm{a}-(\mathrm{Cyanomethyl})-1,4 \mathrm{a}, 7-t$ rimethyl- $N$-(pyridin-2-ylmethyl)$\mathbf{1 , 2 , 3 , 4 , 4 a , 4 b , 5 , 8 , 8 a , 9 , 1 0 , 1 0 a - d o d e c a h y d r o p h e n a n t h r e n e - 1 - c a r b o x a m i d e ~ ( 1 5 ~}\{\mathbf{5}\})$. Oil; ${ }^{1} \mathrm{H}$ NMR (400 $\mathrm{MHz}_{\mathrm{CDCl}}$ ): $\delta 8.57(\mathrm{~d}, J=4.5 \mathrm{~Hz}, 1 \mathrm{H}), 7.67$ (t, $\left.J=7.6 \mathrm{~Hz}, 1 \mathrm{H}\right), 7.27(\mathrm{~d}, J=7.9 \mathrm{~Hz}, 1 \mathrm{H}), 7.25-7.17$ $(\mathrm{m}, 1 \mathrm{H}), 7.11(\mathrm{~s}, 1 \mathrm{H}), 5.35(\mathrm{~s}, 1 \mathrm{H}), 5.31(\mathrm{~s}, 1 \mathrm{H}), 4.53(\mathrm{tdd}, J=16.5,11.7,4.7 \mathrm{~Hz}, 2 \mathrm{H}), 2.78-2.53(\mathrm{~m}$, $1 \mathrm{H}), 2.49-2.29(\mathrm{~m}, 1 \mathrm{H}), 2.26-2.12(\mathrm{~m}, 2 \mathrm{H}), 2.12-1.92(\mathrm{~m}, 5 \mathrm{H}), 1.87-1.77(\mathrm{~m}, 1 \mathrm{H}), 1.75-1.69(\mathrm{~m}$, $1 \mathrm{H}), 1.66(\mathrm{~s}, 3 \mathrm{H}), 1.58-1.49(\mathrm{~m}, 1 \mathrm{H}), 1.35-1.27(\mathrm{~m}, 1 \mathrm{H}), 1.23(\mathrm{~s}, 3 \mathrm{H}), 1.22-1.12(\mathrm{~m}, 3 \mathrm{H}), 0.92(\mathrm{dt}, J$ $=16.0,8.2 \mathrm{~Hz}, 1 \mathrm{H}), 0.65(\mathrm{~s}, 3 \mathrm{H}) ;{ }^{13} \mathrm{C} \mathrm{NMR}\left(125 \mathrm{MHz}, \mathrm{CDCl}_{3}\right): \delta 176.6,156.4,149.0,136.7,131.2,122.4$, 122.3, 119.9, 119.0, 57.7, 51.7, 45.7, 44.4, 43.7, 40.2, 39.4, 37.9, 37.4, 35.3, 29.9, 23.3, 22.2, 20.2, 19.9, 19.1, 13.5; LRMS $(m / z):[\mathrm{M}+\mathrm{Na}]^{+}$calcd for $\mathrm{C}_{26} \mathrm{H}_{35} \mathrm{~N}_{3} \mathrm{ONa} 428.2780$, found 428.3 ; $[\alpha]_{\mathrm{D}}^{23}-34.0(c 1.00$, $\left.\mathrm{CHCl}_{3}\right)$. 

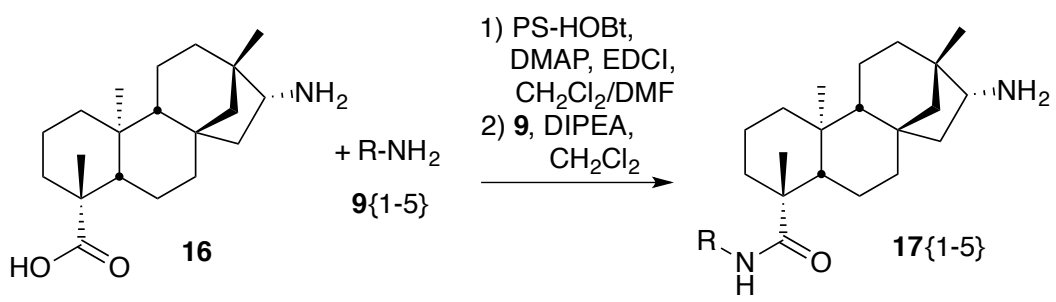

Standard procedure for the amide bond formation for amine $17\{1-5\}$ from previously reported $16 .{ }^{9}$ To a flame-dried reaction flask of the amine $\mathbf{1 6}$ (1.0 equiv) in $\mathrm{CH}_{2} \mathrm{Cl}_{2} / \mathrm{DMF}$ (4:1) in a flame-dry reaction vial, was added PS-hydroxybenzotriazole (PS-HOBt, $1.00 \mathrm{mmol} / \mathrm{g}, 0.67$ equiv), 4-dimethylaminopyridine $(55.4 \mu \mathrm{L}, 0.318 \mathrm{mmol}, 0.40$ equiv), and then 1-ethyl-3-(3-dimethylaminopropyl) carbodiimide (148 $\mathrm{mg}$, $0.954 \mathrm{mmol}, 3.0$ equiv). The reaction mixture was shaken slowly for $24 \mathrm{~h}$ and then filtered. The resins were washed with $\mathrm{MeOH}(5 \mathrm{~mL})$ and $\mathrm{CH}_{2} \mathrm{Cl}_{2}(5 \mathrm{~mL})$ thrice to remove excess acid. Then, the resin was added to a solution of amine $9(0.220 \mathrm{mmol}, 0.70$ equiv) and diisopropylethylamine $(55.4 \mu \mathrm{L}, 0.318 \mathrm{mmol}$, 1.0 equiv) in $\mathrm{CH}_{2} \mathrm{Cl}_{2}$ and shaken slowly for another $24 \mathrm{~h}$. The mixture was filtered again was washed with $\mathrm{MeOH}(5 \mathrm{~mL})$ and $\mathrm{CH}_{2} \mathrm{Cl}_{2}(5 \mathrm{~mL})$ thrice before the solvent was removed under vacuum. The crude residue was purified by column chromatography on silica gel with $5 \% \mathrm{MeOH}: \mathrm{CH}_{2} \mathrm{Cl}_{2}$ to furnish the amide 17.<smiles>CCCCCCC1(C(=O)NCc2ccccc2)CCCC2C3CCC4(C)CC3(CCC21)CC4N</smiles>

$(4 R, 4 \mathrm{a} S, 6 \mathrm{a} R, 8 R, 9 S, 11 \mathrm{a} R, 11 \mathrm{~b} S)-8-\mathrm{Amino}-N$-benzyl-4,9,11b-trimethyltetradecahydro-6a,9methanocyclohepta[a] naphthalene-4-carboxamide (17\{2\}). Oil; ${ }^{1} \mathrm{H}$ NMR $\left(400 \mathrm{MHz}, \mathrm{CDCl}_{3}\right): \delta 7.96-$ $7.83(\mathrm{~m}, 1 \mathrm{H}), 7.36$ (d, $J=6.8 \mathrm{~Hz}, 2 \mathrm{H}), 7.34-7.30(\mathrm{~m}, 3 \mathrm{H}), 4.53(\mathrm{~d}, J=6.2 \mathrm{~Hz}, 2 \mathrm{H}), 2.18(\mathrm{~d}, J=13.9 \mathrm{~Hz}$, $1 \mathrm{H}), 1.94-1.78(\mathrm{~m}, 4 \mathrm{H}), 1.76-1.71(\mathrm{~m}, 3 \mathrm{H}), 1.69-1.58(\mathrm{~m}, 3 \mathrm{H}), 1.49-1.41(\mathrm{~m}, 3 \mathrm{H}), 1.40-1.33(\mathrm{~m}$, $2 \mathrm{H}), 1.30-1.26(\mathrm{~m}, 1 \mathrm{H}), 1.25(\mathrm{~s}, 3 \mathrm{H}), 1.17-1.12(\mathrm{~m}, 1 \mathrm{H}), 1.11-1.01(\mathrm{~m}, 3 \mathrm{H}), 0.98(\mathrm{t}, J=7.4 \mathrm{~Hz}, 1 \mathrm{H})$, $0.93(\mathrm{~s}, 3 \mathrm{H}), 0.92-0.85(\mathrm{~m}, 1 \mathrm{H}), 0.82(\mathrm{~s}, 3 \mathrm{H}) ;{ }^{13} \mathrm{C} \mathrm{NMR}\left(125 \mathrm{MHz}, \mathrm{CDCl}_{\mathrm{s}}\right): \delta 182.3,159.9,136.9$, 128.8, 128.8, 127.9, 127.9, 57.6, 56.9, 56.0, 55.6, 43.8, 43.6, 42.6, 42.0, 41.3, 40.5, 39.9, 38.2, 37.8, 33.9, 29.0, 24.8, 21.6, 20.7, 18.8, 13.5; LRMS $(m / z):[\mathrm{M}+\mathrm{H}]^{+}$calcd for $\mathrm{C}_{27} \mathrm{H}_{40} \mathrm{~N}_{2} \mathrm{O} 408.3141$, found $409 ;[\alpha]_{\mathrm{D}}^{23}-5.25\left(\right.$ c $\left.0.750, \mathrm{CHCl}_{3}\right)$.
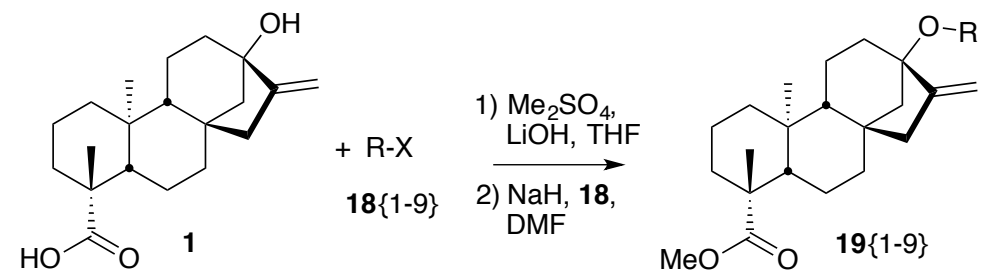

Steviol Methyl Ester. ${ }^{3}$ To a solution of steviol $(1,10 \mathrm{~g}, 32 \mathrm{mmol})$ in THF $(50 \mathrm{~mL})$ in a $500-\mathrm{mL}$ roundbottomed flask at room temperature was added $\mathrm{LiOH} \cdot \mathrm{H}_{2} \mathrm{O}(1.5 \mathrm{~g}, 34 \mathrm{mmol})$. The reaction stirred at room temperature for $1 \mathrm{~h}$ under nitrogen, then $\mathrm{Me}_{2} \mathrm{SO}_{4}(3.3 \mathrm{~mL}, 35 \mathrm{mmol})$ was added slowly, and the reaction vessel was fitted with a reflux condenser. The reaction was refluxed for $18 \mathrm{~h}$ at $80^{\circ} \mathrm{C}$. Once the reaction cooled to room temperature, the off-white precipitate was collected via filtration to furnish steviol methyl 
ester (7.6 g, 73\%) as off-white crystals. mp $117-118^{\circ} \mathrm{C}$ (Lit $\left.113-115{ }^{\circ} \mathrm{C}\right) ;{ }^{1} \mathrm{H}$ NMR $\left(400 \mathrm{MHz}, \mathrm{CDCl}_{3}\right): \delta$ $4.92(\mathrm{~d}, \mathrm{~J}=64.0 \mathrm{~Hz}, 2 \mathrm{H}), 3.66(\mathrm{~s}, 3 \mathrm{H}), 2.28-2.04(\mathrm{~m}, 4 \mathrm{H}), 1.93-1.73(\mathrm{~m}, 7 \mathrm{H}), 1.62-1.40(\mathrm{~m}, 5 \mathrm{H})$, $1.33-1.26(\mathrm{~m}, 1 \mathrm{H}), 1.19(\mathrm{~s}, 3 \mathrm{H}), 1.10-0.93(\mathrm{~m}, 3 \mathrm{H}), 0.85(\mathrm{~s}, 3 \mathrm{H}), 0.82-0.75(\mathrm{~m}, 1 \mathrm{H}) . ;{ }^{13} \mathrm{C}$ NMR $(100$ $\left.\mathrm{MHz}_{\mathrm{CDCl}}\right): \delta 178.0,156.0,102.9,80.3,56.9,53.8,51.2,47.4,46.9,43.8,41.6,41.3,40.7,39.4,39.2$, 38.0, 28.7, 21.9, 20.4, 19.1, 15.3. HRMS (ESI) $(\mathrm{m} / \mathrm{z})$ : $[\mathrm{M}+\mathrm{Na}]^{+}$calcd for $\mathrm{C}_{21} \mathrm{H}_{32} \mathrm{O}_{3} \mathrm{Na} 355.2249$, found $355.2080 ;[\alpha]_{\mathrm{D}}^{23}-191.3\left(c 1.00, \mathrm{CHCl}_{3}\right)$.

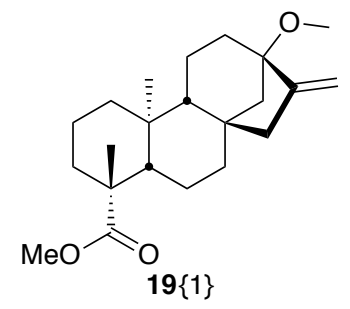

Methyl (4R,4aS,6aR,9S,11aR,11bS)-9-Methoxy-4,11b-dimethyl-8-methylenetetradecahydro-6a,9methanocyclohepta[a]naphthalene-4-carboxylate $(19\{1\})$. To a solution of steviol methyl ester (100 $\mathrm{mg}, 0.318 \mathrm{mmol}, 1.0$ equiv) in $\mathrm{DMF}(5 \mathrm{~mL})$ in a flame-dry reaction vial was added slowly via cannula a solution of sodium hydride (38.3 $\mathrm{mg}$ in $60 \%$ dispersion in oil, $0.954 \mathrm{mmol}, 3.0$ equiv) in dry DMF (5 mL). Then, methyl iodide ( $90.3 \mathrm{mg}, 0.636 \mathrm{mmol}, 2.0$ equiv) was added to the reaction flask and the mixture was allowed to stir for $2 \mathrm{~h}$ at ambient temperature. The reaction was quenched with MTBE and the organic phase was washed successively with water. The aqueous phase was extracted with MTBE and the combined organic layers were dried over $\mathrm{MgSO}_{4}$, filtered, and concentrated in vacuo. Purification by flash column chromatography on silica gel with 20\% EtOAc:Hex yielded the product 19. Oil; ${ }^{1} \mathrm{H}$ NMR (400 $\left.\mathrm{MHz}, \mathrm{CDCl}_{3}\right): \delta 4.87(\mathrm{~d}, J=6.1 \mathrm{~Hz}, 2 \mathrm{H}), 3.64(\mathrm{~s}, 3 \mathrm{H}), 3.22(\mathrm{~s}, 3 \mathrm{H}), 2.18(\mathrm{~d}, J=13.2 \mathrm{~Hz}, 1 \mathrm{H}), 2.14-$ $2.00(\mathrm{~m}, 2 \mathrm{H}), 1.89-1.80(\mathrm{~m}, 4 \mathrm{H}), 1.79-1.71(\mathrm{~m}, 3 \mathrm{H}), 1.69-1.58(\mathrm{~m}, 1 \mathrm{H}), 1.57-1.49(\mathrm{~m}, 2 \mathrm{H}), 1.48-$ $1.40(\mathrm{~m}, 3 \mathrm{H}), 1.17(\mathrm{~s}, 3 \mathrm{H}), 1.07-0.94(\mathrm{~m}, 3 \mathrm{H}), 0.82(\mathrm{~s}, 3 \mathrm{H}), 0.85-0.76(\mathrm{~m}, 1 \mathrm{H}) ;{ }^{13} \mathrm{C} \mathrm{NMR}(125 \mathrm{MHz}$, $\left.\mathrm{CDCl}_{3}\right): \delta 178.0,151.0,103.7,85.2,57.0,54.0,51.2,50.1,48.1,43.8,41.7,41.5,40.7,40.0,39.3$, 38.8, 38.0, 28.7, 21.9, 20.2, 19.1, 15.3, LRMS (ES) $(\mathrm{m} / z):\left[\mathrm{M}+\mathrm{CH}_{2} \mathrm{O}_{2}\right]^{+}$calcd for $\mathrm{C}_{22} \mathrm{H}_{34} \mathrm{O}_{3} 390.2508$, found $390.3 ;[\alpha]_{\mathrm{D}}^{23}-93.5\left(c 0.800, \mathrm{CHCl}_{3}\right)$.

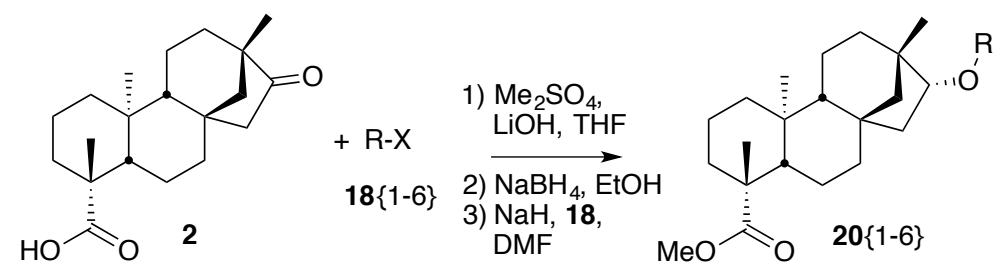

Isosteviol methyl ester. ${ }^{8}$ To a flame-dried $500 \mathrm{~mL}$ round-bottomed flask was added isosteviol (2, $20 \mathrm{~g}$, $63 \mathrm{mmol})$ and dry THF $(120 \mathrm{~mL})$. Upon dissolution, $\mathrm{LiOH} \cdot \mathrm{H}_{2} \mathrm{O}(2.9 \mathrm{~g}, 68 \mathrm{mmol})$ was added and the reaction stirred for $1 \mathrm{~h}$ at room temperature under an atmosphere of nitrogen. $\mathrm{Me}_{2} \mathrm{SO}_{4}(6.5 \mathrm{~mL}, 69 \mathrm{mmol})$ was slowly added, then a reflux condenser was fitted to the flask and the temperature was raised to $80{ }^{\circ} \mathrm{C}$ for $18 \mathrm{~h}$. The colorless precipitate was then recovered through filtration. The cake was washed repeatedly with $\mathrm{Et}_{2} \mathrm{O}$ and then concentrated in vacuo to furnish isosteviol methyl ester $(18.3 \mathrm{~g}, 88 \%)$. The reaction was quenched with $10 \% \mathrm{NaOH}$ and then washed with brine and dried over $\mathrm{MgSO}_{4} . \mathrm{R}_{f}=0.3(\mathrm{Hex}:$ EtOAc 9:1); white crystals; mp 200-202 ${ }^{\circ} \mathrm{C}$ (Lit 202-203 $\left.{ }^{\circ} \mathrm{C}\right){ }^{1} ;{ }^{1} \mathrm{H}$ NMR $\left(400 \mathrm{MHz}, \mathrm{CDCl}_{3}\right): \delta 3.63$ (s, $\left.3 \mathrm{H}\right), 2.62$ $(\mathrm{dd}, J=18.6,3.8 \mathrm{~Hz}, 1 \mathrm{H}), 2.18(\mathrm{~d}, J=13.3 \mathrm{~Hz}, 1 \mathrm{H}), 1.89(\mathrm{dd}, J=13.6,2.9 \mathrm{~Hz}, 1 \mathrm{H}), 1.74-1.85(\mathrm{~m}, 2 \mathrm{H})$, 1.57-1.74 (m, 5H), 1.52 (ddd, $J=17.8,12.5,3.3 \mathrm{~Hz}, 2 \mathrm{H}), 1.33-1.45(\mathrm{~m}, 3 \mathrm{H}), 1.19-1.30(\mathrm{~m}, 2 \mathrm{H}), 1.19(\mathrm{~s}$, $3 \mathrm{H}), 1.10-1.16(\mathrm{~m}, 1 \mathrm{H}), 0.99-1.06(\mathrm{~m}, 1 \mathrm{H}), 0.97(\mathrm{~s}, 3 \mathrm{H}), 0.92(\mathrm{dd}, J=13.2,4.2 \mathrm{~Hz}, 1 \mathrm{H}), 0.68(\mathrm{~s}, 3 \mathrm{H}) ;{ }^{13} \mathrm{C}$ 
NMR (100 MHz, $\left.\mathrm{CDCl}_{3}\right): \delta 222.4,177.8,57.0,54.7,54.3,51.2,48.7,48.5,48.4,43.8,41.5,39.8,39.4$, 37.9, 37.3, 28.8, 21.7, 20.3, 19.9, 18.9, 13.2; IR (film) 2952, 1744, 1720, 1452, 1240, 1175, $1153 \mathrm{~cm}^{-1}$; HRMS (ESI) $(m / z):[\mathrm{M}+\mathrm{Na}]^{+}$calcd for $\mathrm{C}_{21} \mathrm{H}_{32} \mathrm{O}_{3} \mathrm{Na} 355.2244$; found 355.2234; $[\alpha]_{\mathrm{D}}^{23}-82.2\left(\mathrm{c} 1.00, \mathrm{CHCl}_{3}\right)$; reported $[\alpha]_{\mathrm{D}}^{25}-69.0\left(c 1.02, \mathrm{CHCl}_{3}\right){ }^{8}$

Reduction of isosteviol methyl ester. ${ }^{10}$ To a solution of the isosteviol methyl ester $(1.00 \mathrm{~g}, 3.00 \mathrm{mmol})$ in $\mathrm{MeOH}(25 \mathrm{~mL})$ at $0{ }^{\circ} \mathrm{C}$ (ice bath), was slowly added $\mathrm{NaBH}_{4}(134 \mathrm{mg}, 3.55 \mathrm{mmol})$. The reaction mixture was stirred for $1 \mathrm{~h}$ at $0{ }^{\circ} \mathrm{C}$ (ice bath), and then the solvent was evaporated under reduced pressure, followed by dilution with water and extraction with MTBE. Evaporation of the solvent and purification of the product on a silica gel column using 10\% EtOAc:Hex gave the hydroxyl methyl ester (450 mg, 45\%) as a white crystals. Mp $169-171^{\circ} \mathrm{C}\left(\mathrm{Lit} 163-166^{\circ} \mathrm{C}\right){ }^{11} ;{ }^{1} \mathrm{H}$ NMR $\left(400 \mathrm{MHz}, \mathrm{CDCl}_{3}\right): \delta 3.85(\mathrm{dd}, \mathrm{J}=10.6,4.6$ $\mathrm{Hz}, 1 \mathrm{H}), 3.42(\mathrm{~s}, 3 \mathrm{H}), 1.96(\mathrm{~d}, \mathrm{~J}=13.4 \mathrm{~Hz}, 1 \mathrm{H}), 1.73(\mathrm{~s}, 1 \mathrm{H}), 1.68-1.47(\mathrm{~m}, 6 \mathrm{H}), 1.45-1.27(\mathrm{~m}, 4 \mathrm{H})$, $1.24-0.97(\mathrm{~m}, 4 \mathrm{H}), 0.96(\mathrm{~s}, 3 \mathrm{H}), 0.86-0.75(\mathrm{~m}, 4 \mathrm{H}), 0.70(\mathrm{~s}, 3 \mathrm{H}), 0.69-0.61(\mathrm{~m}, 1 \mathrm{H}), 0.52(\mathrm{~s}, 3 \mathrm{H}),{ }^{13} \mathrm{C}$ NMR (100 MHz, $\left.\mathrm{CDCl}_{3}\right): \delta 178.1,80.4,57.1,55.8,55.2,51.1,43.7,42.8,42.0,42.0,41.7,39.9$, 38.0, 38.0, 33.7, 28.9, 24.9, 21.7, 20.4, 18.9, 13.1. HRMS (ESI) $(m / z):[\mathrm{M}+\mathrm{Na}]^{+}$calcd for $\mathrm{C}_{21} \mathrm{H}_{34} \mathrm{O}_{3} \mathrm{Na}$ 357.2406 , found $357.2398 ;[\alpha]_{\mathrm{D}}^{23}-57.1\left(c 0.833, \mathrm{CHCl}_{3}\right)$.

Standard procedure for the synthesis of 20\{1-6\}. To a solution of the above hydroxyl methyl ester (100 $\mathrm{mg}, 0.345 \mathrm{mmol}, 1.0$ equiv) in DMF ( $5 \mathrm{~mL})$ in a flame-dry reaction vial was added slowly via cannula a solution of sodium hydride (38.3 mg in $60 \%$ dispersion in oil, $0.954 \mathrm{mmol}, 3.0$ equiv) in dry DMF (5 mL). Then, methyl iodide ( $90.3 \mathrm{mg}, 0.636 \mathrm{mmol}, 2.0$ equiv) was added to the reaction flask and the mixture was allowed to stir for $2 \mathrm{~h}$ at ambient temperature. The reaction was quenched with MTBE and the organic phase was washed successively with water. The aqueous phase was extracted with MTBE and the combined organic layers were dried over $\mathrm{MgSO}_{4}$, filtered, and concentrated in vacuo. Purification by flash column chromatography on silica gel with 20\% EtOAc:Hex yielded the product 20.

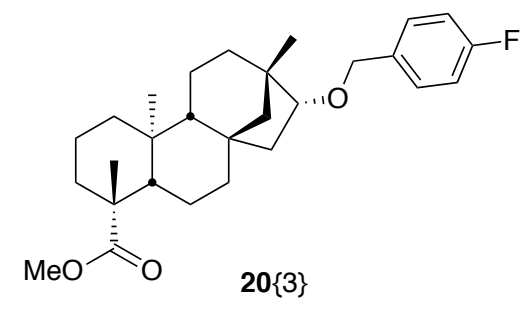

Methyl (4R,4aS,6aR,8S,9S,11aR,11bS)-8-((4-Fluorobenzyl)oxy)-4,9,11b-trimethyltetradecahydro6a,9-methanocyclohepta[a]naphthalene-4-carboxylate $(\mathbf{2 0}\{3\})$. White crystals; mp $151-152{ }^{\circ} \mathrm{C} ;{ }^{1} \mathrm{H}$ NMR (400 MHz, $\left.\mathrm{CDCl}_{3}\right): \delta 7.29(\mathrm{dd}, J=8.4,5.7 \mathrm{~Hz}, 2 \mathrm{H}), 7.01(\mathrm{t}, J=8.7 \mathrm{~Hz}, 2 \mathrm{H}), 4.45(\mathrm{dd}, 2 \mathrm{H}), 3.63$ $(\mathrm{s}, 3 \mathrm{H}), 3.54(\mathrm{dd}, J=10.3,4.1 \mathrm{~Hz}, 1 \mathrm{H}), 2.17(\mathrm{~d}, J=13.3 \mathrm{~Hz}, 1 \mathrm{H}), 1.96-1.79(\mathrm{~m}, 4 \mathrm{H}), 1.76-1.62(\mathrm{~m}$, $3 \mathrm{H}), 1.59-1.53(\mathrm{~m}, 2 \mathrm{H}), 1.50-1.36(\mathrm{~m}, 3 \mathrm{H}), 1.33-1.24(\mathrm{~m}, 2 \mathrm{H}), 1.17(\mathrm{~s}, 3 \mathrm{H}), 1.06-0.96(\mathrm{~m}, 4 \mathrm{H})$, $0.93(\mathrm{~s}, 3 \mathrm{H}), 0.91-0.83(\mathrm{~m}, 1 \mathrm{H}), 0.72(\mathrm{~s}, 3 \mathrm{H}) ;{ }^{13} \mathrm{C} \mathrm{NMR}\left(125 \mathrm{MHz}, \mathrm{CDCl}_{3}\right): \delta 178.3,135.3,129.0,128.9$, $115.9,115.2,115.0,87.0,71.3,57.3,56.0,55.5,51.3,43.9,42.4,42.2,42.0,40.3,40.0,38.2,38.1,34.5$, 29.0, 25.6, 21.9, 20.6, 19.1, 13.3; HRMS (ESI) $(\mathrm{m} / z)$ : $[\mathrm{M}+\mathrm{Na}]^{+}$calcd for $\mathrm{C}_{28} \mathrm{H}_{39} \mathrm{O}_{3} \mathrm{FNa} 465.2883$, found 465.2795; $[\alpha]_{\mathrm{D}}^{23}-103.7$ (c 0.655, $\left.\mathrm{CHCl}_{3}\right)$. 


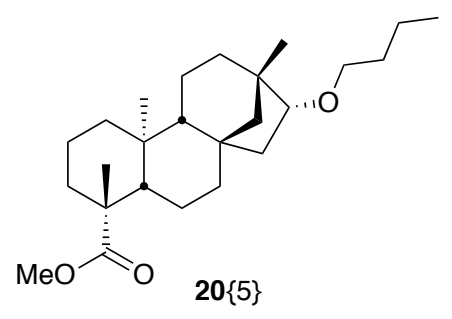

Methyl

(4R,4aS,6aR,8R,9S,11aR,11bS)-8-Butoxy-4,9,11b-trimethyltetradecahydro-6a,9methanocyclohepta[a]naphthalene-4-carboxylate $(\mathbf{2 0}\{\mathbf{5}\})$. Oil; ${ }^{1} \mathrm{H}$ NMR $\left(400 \mathrm{MHz}, \mathrm{CDCl}_{3}\right): \delta 3.65(\mathrm{~s}$, $3 \mathrm{H}), 3.53-3.43(\mathrm{~m}, 1 \mathrm{H}), 3.43-3.31(\mathrm{~m}, 2 \mathrm{H}), 2.17(\mathrm{~d}, J=13.0 \mathrm{~Hz}, 1 \mathrm{H}), 1.89-1.84(\mathrm{~m}, 2 \mathrm{H}), 1.83-1.77$ (m, 3H), $1.72-1.66(\mathrm{~m}, 2 \mathrm{H}), 1.64-1.56(\mathrm{~m}, 3 \mathrm{H}), 1.51(\mathrm{dd}, J=12.2,6.1 \mathrm{~Hz}, 3 \mathrm{H}), 1.44-1.37(\mathrm{~m}, 4 \mathrm{H})$, $1.32-1.24(\mathrm{~m}, 2 \mathrm{H}), 1.21(\mathrm{~d}, J=4.7 \mathrm{~Hz}, 1 \mathrm{H}), 1.18(\mathrm{~s}, 3 \mathrm{H}), 1.12-1.03(\mathrm{~m}, 2 \mathrm{H}), 1.02-0.97(\mathrm{~m}, 2 \mathrm{H}), 0.94$ (s, 3H), $0.92-0.83(\mathrm{~m}, 2 \mathrm{H}), 0.73(\mathrm{~s}, 3 \mathrm{H}) ;{ }^{13} \mathrm{C} \mathrm{NMR}\left(125 \mathrm{MHz}, \mathrm{CDCl}_{3}\right): \delta 178.2,87.3,69.9,57.3,56.0$, 55.5, 51.1, 43.8, 42.2, 42.0, 40.5, 39.9, 38.1, 38.0, 34.4, 32.3, 28.9, 25.6, 21.8, 21.7, 20.4, 19.5, 19.0, 14.0, 13.1; HRMS (ESI) $(m / z)$ : $[\mathrm{M}+\mathrm{Na}]^{+}$calcd for $\mathrm{C}_{25} \mathrm{H}_{42} \mathrm{O}_{3} \mathrm{Na} 413.3134$, found 413.2998; $[\alpha]_{\mathrm{D}}^{23}-42.8(c 0.850$, $\left.\mathrm{CHCl}_{3}\right)$.
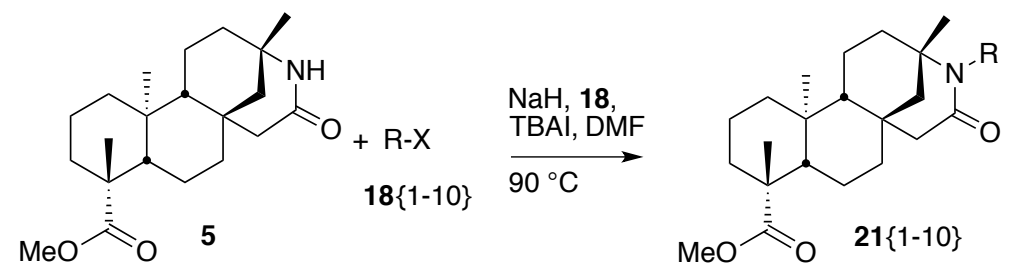

Standard procedure for $N$-alkylation of known lactam 5 to form 21(1-10.$^{8}$ To a solution of the lactam methyl ester 5 ( $100 \mathrm{mg}, 0.347 \mathrm{mmol}, 1.0$ equiv) in DMF $(5 \mathrm{~mL})$ in a flame-dried reaction flask, was added sodium hydride (3.0 equiv, pre-washed with hexanes), alkyl halide 18 (5.0 equiv) and a catalytic amount of tetrabutylammonium iodide (TBAI, $10 \mathrm{~mol} \%$ ). The reaction flask was heated to $90{ }^{\circ} \mathrm{C}$, stirred overnight and then the reaction was carefully quenched with water $(2 \mathrm{~mL})$. The organic layer was then washed with brine and the aqueous layers were re-extracted with $\mathrm{Et}_{2} \mathrm{O}(2 \times 10 \mathrm{~mL})$. The combined organic layers were then dried over $\mathrm{MgSO}_{4}$, filtered, and the $\mathrm{Et}_{2} \mathrm{O}$ was removed under reduced pressure, while a centrifugal evaporator was used to remove the DMF to furnish alkylated lactam methyl ester 21. Column chromatography on silica gel with $5 \% \mathrm{MeOH}: \mathrm{CH}_{2} \mathrm{Cl}_{2}$ gave the substituted-lactam products.

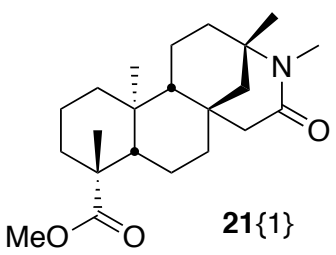

$(3 S, 8 \mathrm{a} S, 9 R, 12 \mathrm{a} S, 12 \mathrm{~b} R)$-Methyl

3,4,9,12a-Tetramethyl-5-oxotetradecahydro-1 $\mathrm{H}-3,6 \mathrm{a}-$ methanonaphtho[2,1-d] azocine-9-carboxylate $(21\{\mathbf{1}\})$. Yellow solid; mp $168-172{ }^{\circ} \mathrm{C}$; ${ }^{1} \mathrm{H}$ NMR $(400$ $\mathrm{MHz}, \mathrm{CDCl}_{3}$ ): $\delta 3.62(\mathrm{~s}, 3 \mathrm{H}), 2.98(\mathrm{dd}, J=18.3,2.9 \mathrm{~Hz}, 1 \mathrm{H}), 2.84$ (s, $\left.3 \mathrm{H}\right), 2.16(\mathrm{~d}, J=13.3 \mathrm{~Hz}, 1 \mathrm{H})$, $2.04(\mathrm{~d}, J=18.3 \mathrm{~Hz}, 1 \mathrm{H}), 1.95-1.22(\mathrm{~m}, 2 \mathrm{H}), 1.83-1.66(\mathrm{~m}, 3 \mathrm{H}), 1.65-1.54(\mathrm{~m}, 2 \mathrm{H}), 1.51(\mathrm{dt}, J=$ $12.9,3.2,3.2 \mathrm{~Hz}, 1 \mathrm{H}), 1.48-1.37(\mathrm{~m}, 1 \mathrm{H}), 1.30(\mathrm{dd}, J=12.8,2.9 \mathrm{~Hz}, 1 \mathrm{H}), 1.25(\mathrm{~s}, 3 \mathrm{H}), 1.21$ (d, $J=13.0$, $3.8 \mathrm{~Hz}, 1 \mathrm{H}), 1.16(\mathrm{~s}, 3 \mathrm{H}), 1.16-0.93(\mathrm{~m}, 4 \mathrm{H}), 0.92-0.78(\mathrm{~m}, 2 \mathrm{H}), 0.75(\mathrm{~s}, 3 \mathrm{H}) ;{ }^{13} \mathrm{C}$ NMR $(100 \mathrm{MHz}$, $\left.\mathrm{CDCl}_{3}\right): \delta 177.7,171.9,57.4,56.8,55.3,51.1,51.0,44.3,43.7,41.0,39.9,38.0,37.8,35.7,33.9,28.5$, 
27.4, 26.8, 19.7, 18.8, 18.7, 13.5; HRMS (ESI) $(\mathrm{m} / z)$ : $[\mathrm{M}+\mathrm{H}]^{+}$calcd for $\mathrm{C}_{22} \mathrm{H}_{36} \mathrm{NO}_{3} 362.2695$; found $362.2677 ;[\alpha]_{\mathrm{D}}^{23} 18.9\left(c 0.800, \mathrm{CHCl}_{3}\right)$.

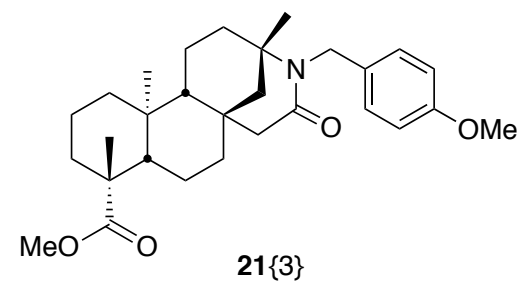

Methyl (3S,6aR,8aS,9R,12aS,12bR)-4-(4-Methoxybenzyl)-3,9,12a-trimethyl-5-oxotetradecahydro2H-3,6a-methanonaphtho[2,1-d] azocine-9-carboxylate (21\{3\}). Pale yellow solid; mp 151-152 ${ }^{\circ} \mathrm{C} ;{ }^{1} \mathrm{H}$ NMR (400 MHz, $\left.\mathrm{CDCl}_{3}\right): 7.16(\mathrm{~d}, J=8.7 \mathrm{~Hz}, 2 \mathrm{H}), 6.81(\mathrm{~d}, J=8.7 \mathrm{~Hz}, 2 \mathrm{H}), 4.86(\mathrm{~d}, J=15.4 \mathrm{~Hz}, 1 \mathrm{H})$, $4.20(\mathrm{~d}, J=15.5 \mathrm{~Hz}, 1 \mathrm{H}), 3.78(\mathrm{~s}, 3 \mathrm{H}), 3.64(\mathrm{~s}, 3 \mathrm{H}), 3.07(\mathrm{dd}, J=18.4,2.7 \mathrm{~Hz}, 1 \mathrm{H}), 2.16(\mathrm{~d}, J=18.2 \mathrm{~Hz}$, $2 \mathrm{H}), 1.93-1.82(\mathrm{~m}, 1 \mathrm{H}), 1.81-1.72(\mathrm{~m}, 4 \mathrm{H}), 1.67(\mathrm{dd}, J=13.0,2.8 \mathrm{~Hz}, 1 \mathrm{H}), 1.54(\mathrm{dd}, J=12.9,3.1 \mathrm{~Hz}$, $2 \mathrm{H}), 1.48-1.39(\mathrm{~m}, 1 \mathrm{H}), 1.31-1.19(\mathrm{~m}, 3 \mathrm{H}), 1.17(\mathrm{~s}, 3 \mathrm{H}), 1.14(\mathrm{~s}, 3 \mathrm{H}), 1.12-0.95(\mathrm{~m}, 3 \mathrm{H}), 0.90-0.79$ (m, 2H), 0.78 (s, 3H); ${ }^{13} \mathrm{C}$ NMR (125 MHz, $\left.\mathrm{CDCl}_{3}\right): 177.8,172.3,158.3,132.1,128.3(2 \mathrm{C}), 113.7$ (2C), 57.5, 56.9, 56.4, 55.2, 51.7, 51.2, 44.3, 44.0, 43.8, 41.2, 40.0, 38.0, 37.8, 37.1 , 34.1, 28.6, 28.1 , 19.8, 18.9, 18.6, 13.7; LRMS (ESI) $(m / z):[\mathrm{M}+\mathrm{H}]^{+}$calcd for $\mathrm{C}_{29} \mathrm{H}_{42} \mathrm{NO}_{4} 468.3036$, found $468.3 ;[\alpha]_{\mathrm{D}}^{23}-15.6(c 1.00$, $\left.\mathrm{CHCl}_{3}\right)$.

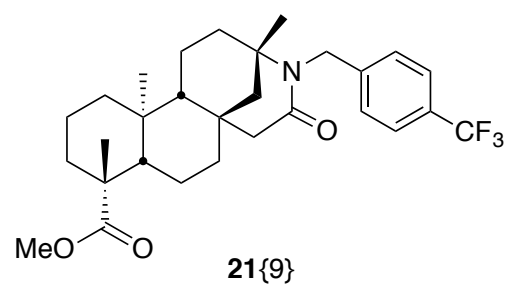

\section{Methyl} (3S,6a $R, 8 \mathrm{a} S, 9 R, 12 \mathrm{a} S, 12 \mathrm{~b} R)-3,9,12 \mathrm{a}-T$ rimethyl-5-0xo-4-(4(trifluoromethyl)benzyl)tetradecahydro-2H-3,6a-methanonaphtho[2,1- $d]$ azocine-9-carboxylate (21\{9\}). Lightly yellow solid; mp 151-152 ${ }^{\circ} \mathrm{C} ;{ }^{1} \mathrm{H} \mathrm{NMR}\left(400 \mathrm{MHz}, \mathrm{CDCl}_{3}\right): \delta 7.53(\mathrm{~d}, J=8.1 \mathrm{~Hz}, 2 \mathrm{H})$, $7.32(\mathrm{~d}, J=8.1 \mathrm{~Hz}, 2 \mathrm{H}), 5.08(\mathrm{~d}, J=16.2 \mathrm{~Hz}, 1 \mathrm{H}), 4.15(\mathrm{~d}, J=16.1 \mathrm{~Hz}, 1 \mathrm{H}), 3.64(\mathrm{~s}, 3 \mathrm{H}), 3.09(\mathrm{dd}, J=$ $18.2,2.5 \mathrm{~Hz}, 1 \mathrm{H}), 2.23-2.15(\mathrm{~m}, 2 \mathrm{H}), 1.91-1.75(\mathrm{~m}, 5 \mathrm{H}), 1.71(\mathrm{dd}, J=13.1,2.5 \mathrm{~Hz}, 1 \mathrm{H}), 1.64-1.55$ $(\mathrm{m}, 2 \mathrm{H}), 1.45(\mathrm{~d}, J=13.7 \mathrm{~Hz}, 1 \mathrm{H}), 1.36-1.29(\mathrm{~m}, 1 \mathrm{H}), 1.27-1.20(\mathrm{~m}, 2 \mathrm{H}), 1.18(\mathrm{~s}, 3 \mathrm{H}), 1.17-1.11(\mathrm{~m}$, $1 \mathrm{H}), 1.10(\mathrm{~s}, 3 \mathrm{H}), 1.08-0.96(\mathrm{~m}, 2 \mathrm{H}), 0.94-0.84(\mathrm{~m}, 2 \mathrm{H}), 0.79(\mathrm{~s}, 3 \mathrm{H}) ;{ }^{13} \mathrm{C} \mathrm{NMR}\left(125 \mathrm{MHz}, \mathrm{CDCl}_{3}\right): \delta$ 177.7, 172.7, 144.0, 127.1, 127.1, 127.1, 125.4, 125.3, 125.3, 57.4, 56.8, 56.6, 51.5, 51.2, 44.5, 44.2, 43.8, 41.1, 40.0, 38.0, 37.8, 36.9, 34.1, 28.6, 28.0, 19.7, 18.9, 18.6, 13.7; LRMS (ESI) $(\mathrm{m} / \mathrm{z}):[\mathrm{M}]^{+}$calcd for $\mathrm{C}_{29} \mathrm{H}_{38} \mathrm{~F}_{3} \mathrm{NO}_{3} 505.2814$, found $506.4 ;[\alpha]_{\mathrm{D}}^{23}-36.6\left(c 0.905, \mathrm{CHCl}_{3}\right)$.

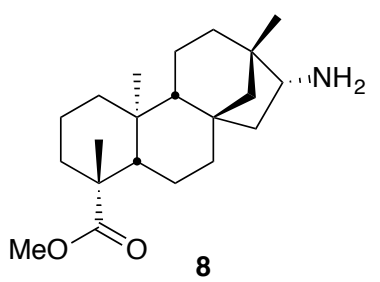

Methyl methanocyclohepta

$(4 R, 4 \mathrm{a} S, 6 \mathrm{a} R, 9 \mathrm{~S}, 11 \mathrm{a} R, 11 \mathrm{bS})-8$-Amino-4,9,11b-trimethyltetradecahydro-6a,9[a]naphthalene-4-carboxylate

(8). ${ }^{12}$ To a solution of methyl 
(4R,4aS,6aR,9S,11aR,11bS)-8-(hydroxyimino)-4,9,11b-trimethyltetradecahydro-6a,9-

methanocyclohepta[ $a$ ]naphthalene-4-carboxylate ${ }^{1}(348 \mathrm{mg}, 1.00 \mathrm{mmol}, 1.0$ equiv) in $\mathrm{MeOH}$, cooled to 0 ${ }^{\circ} \mathrm{C}$ (ice bath), was added sodium borohydride ( $189 \mathrm{mg}, 5.0$ equiv) then molybdenum (VI) oxide (216 mg, 1.5 equiv). The reaction was stirred at room temperature overnight. The next day the reaction was filtered, and then the solvent was evaporated. The resulting residue was treated with aqueous $\mathrm{KOH}(20 \%)$ and extracted with $\mathrm{CH}_{2} \mathrm{Cl}_{2}$. The combined organic layers were washed with brine, dried with $\mathrm{MgSO}_{4}$, and then concentrated in vacuo. Column chromatography on silica gel with $5 \% \mathrm{MeOH} / \mathrm{CH}_{2} \mathrm{Cl}_{2}$ provided amine 8 in $20 \%$ yield as an off-white solid. mp: $255-258{ }^{\circ} \mathrm{C} ;{ }^{1} \mathrm{H} \mathrm{NMR}\left(400 \mathrm{MHz}, \mathrm{CDCl}_{3}\right): \delta 3.60(\mathrm{~s}, 3 \mathrm{H}), 3.12(\mathrm{dd}$, $J=10.6,6.7 \mathrm{~Hz}, 1 \mathrm{H}), 2.13(\mathrm{~d}, J=13.2 \mathrm{~Hz}, 1 \mathrm{H}), 1.86-1.49(\mathrm{~m}, 10 \mathrm{H}), 1.42-1.25(\mathrm{~m}, 4 \mathrm{H}), 1.26-1.21$ $(\mathrm{m}, 1 \mathrm{H}), 1.14(\mathrm{~s}, 3 \mathrm{H}), 1.11-1.01(\mathrm{~m}, 2 \mathrm{H}), 1.00(\mathrm{~s}, 3 \mathrm{H}), 0.99-0.92(\mathrm{~m}, 2 \mathrm{H}), 0.88-0.78(\mathrm{~m}, 2 \mathrm{H}), 0.71$ $(\mathrm{s}, 3 \mathrm{H}) ;{ }^{13} \mathrm{C} \mathrm{NMR}\left(125 \mathrm{MHz}, \mathrm{CDCl}_{3}\right): \delta 178.1,77.0,76.7,59.6,57.0,56.0,55.6,51.1,43.7,42.4,41.2$, $41.1,39.7,39.0,38.0,38.0,33.0,28.8,24.6,21.6,20.2$, 18.8, 12.9; HRMS (ESI) $(\mathrm{m} / \mathrm{z}):[\mathrm{M}+\mathrm{H}]^{+}$calcd for $\mathrm{C}_{21} \mathrm{H}_{36} \mathrm{NO}_{2} 334.2688$, found 334.2747; $[\alpha]_{\mathrm{D}}^{23}-153.1$ ( c 1.00, $\mathrm{CHCl}_{3}$ ).

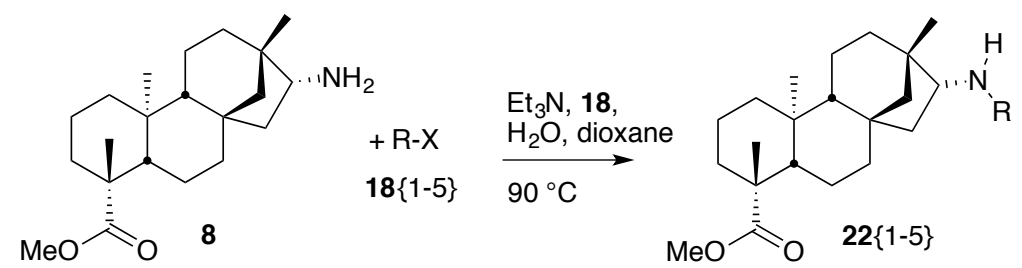

Standard procedure for $N$-alkylation of amine 8 for the synthesis of $22\{1-5\}$. To a flame-dried reaction flask of the amine $8(100 \mathrm{mg}, 0.333 \mathrm{mmol}, 1.0$ equiv) and triethylamine (1.5 equiv) in a 1,4-dioxane-water mixed solvent $(1: 1,6 \mathrm{~mL})$, the alkyl halide $(\mathbf{1 8}, 1.0$ equiv) was added. The reaction flask was heated to 90 ${ }^{\circ} \mathrm{C}$ and allowed to stir for one day. The reaction mixture was quenched with EtOAc and the organic layer was washed with saturated aqueous $\mathrm{NH}_{4} \mathrm{Cl}$. The organic layer was then washed with brine and the aqueous layers were extracted with EtOAc $(2 \times 10 \mathrm{~mL})$. The combined organic layers were then dried over $\mathrm{MgSO}_{4}$, filtered, and concentrated in vacuo to give the crude alkylated amine product 22. Purification was done by column chromatography on silica gel with $5 \% \mathrm{MeOH}: \mathrm{CH}_{2} \mathrm{Cl}_{2}$.

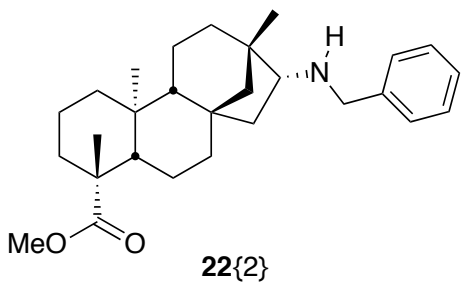

Methyl (4R,4aS,6aR,8R,9S,11aR,11bS)-8-(Benzylamino)-4,9,11b-trimethyltetradecahydro-6a,9methanocyclohepta[a]naphthalene-4-carboxylate (22\{2\}). Oil; ${ }^{1} \mathrm{H}$ NMR $\left(400 \mathrm{MHz}, \mathrm{CDCl}_{3}\right): \delta 7.35$ (d, $J=7.6 \mathrm{~Hz}, 4 \mathrm{H}), 7.29-7.25$ (m, 1H), 3.80 (q, $J=46.0,13.4,12.4 \mathrm{~Hz}, 2 \mathrm{H}), 3.66(\mathrm{~s}, 3 \mathrm{H}), 3.64(\mathrm{~s}, 1 \mathrm{H}), 2.77$ $(\mathrm{dd}, J=10.6,5.4 \mathrm{~Hz}, 1 \mathrm{H}), 2.19(\mathrm{~d}, J=13.3 \mathrm{~Hz}, 1 \mathrm{H}), 1.86-1.80(\mathrm{~m}, 2 \mathrm{H}), 1.74(\mathrm{~d}, J=13.5 \mathrm{~Hz}, 3 \mathrm{H}), 1.64$ $-1.59(\mathrm{~m}, 3 \mathrm{H}), 1.57-1.51(\mathrm{~m}, 2 \mathrm{H}), 1.46-1.40(\mathrm{~m}, 1 \mathrm{H}), 1.38-1.31(\mathrm{~m}, 2 \mathrm{H}), 1.19(\mathrm{~s}, 3 \mathrm{H}), 1.10-1.04$ $(\mathrm{m}, 2 \mathrm{H}), 1.03-0.98(\mathrm{~m}, 3 \mathrm{H}), 0.92(\mathrm{~s}, 3 \mathrm{H}), 0.90-0.86(\mathrm{~m}, 1 \mathrm{H}), 0.74(\mathrm{~s}, 3 \mathrm{H}) ;{ }^{13} \mathrm{C} \mathrm{NMR}\left(125 \mathrm{MHz}, \mathrm{CDCl}_{3}\right)$ : $\delta 178.2,141.4,128.3,128.2,128.0,128.0,126.7,66.2,57.3,57.0,55.9,53.2,51.1,43.8,42.4,41.8,41.6$, 41.2, 40.0, 38.1, 38.1, 34.3, 28.9, 25.6, 21.8, 20.7, 19.0, 13.3; $\operatorname{HRMS~(ESI)~}(\mathrm{m} / \mathrm{z}):[\mathrm{M}]^{+}$calcd for $\mathrm{C}_{28} \mathrm{H}_{41} \mathrm{NO}_{2} 423.3137$, found $424.3 ;[\alpha]_{\mathrm{D}}^{23}-58.5\left(c 1.00, \mathrm{CHCl}_{3}\right)$. 

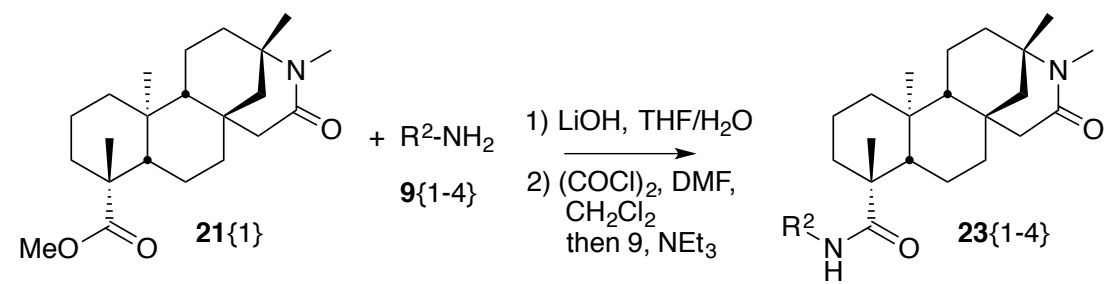

Standard procedure for amide bond formation lactam ester $\mathbf{2 3}\{1-4\}$ from $\mathbf{2 1}\{1\}$. To a solution of $N$-methyl lactam ester $21\{1\}(1.00 \mathrm{~g}, 2.77 \mathrm{mmol})$ in $\mathrm{THF} / \mathrm{H}_{2} \mathrm{O}(1: 1,10 \mathrm{~mL})$ in a round-bottom flask was added $\mathrm{LiOH}(1 \mathrm{M}$ aq. $5 \mathrm{~mL})$ at room temperature. The reaction was heated to reflux and stirred overnight. Then, it was cooled to room temperature and quenched with $\mathrm{HCl}(1 \mathrm{M}$ aq.) to $\mathrm{pH} 4$. The resultant mixture was extracted with EtOAc and the combined organic layers were washed with brined and dried over $\mathrm{MgSO}_{4}$. The acid was carried on without further purification. To an oven-dried reaction flask under nitrogen at 0 ${ }^{\circ} \mathrm{C}$ (ice bath), was added DMF (37 $\mu \mathrm{L}, 0.47 \mathrm{mmol}, 1.5$ equiv) in $\mathrm{CH}_{2} \mathrm{Cl}_{2}(1.0 \mathrm{~mL}$ ) followed by oxalyl chloride ( $41 \mu \mathrm{L}, 0.47 \mathrm{mmol}, 1.5$ equiv). The ice bath was removed and the mixture was allowed to stir at room temperature for $1 \mathrm{~h}$. Then the reaction flask was cooled to $0{ }^{\circ} \mathrm{C}$ (ice bath) and $\mathrm{N}$-methyl lactam acid (108 mg, $0.31 \mathrm{mmol})$ and $\mathrm{Et}_{3} \mathrm{~N}\left(130 \mu \mathrm{L}, 0.47 \mathrm{mmol}, 3\right.$ equiv) in $\mathrm{CH}_{2} \mathrm{Cl}_{2}(1.0 \mathrm{~mL})$ were added. After stirring for $5 \mathrm{~min}$, amine $9(1 \mathrm{~mL})$ was added and the mixture was stirred for $2 \mathrm{~h}$. Then, the solvent was removed and the reaction was purified using column chromatography on silica gel with $10 \%->20 \%$ EtOAc:Hex as the eluent to provide the substituted lactam amide product $\mathbf{2 3}$.

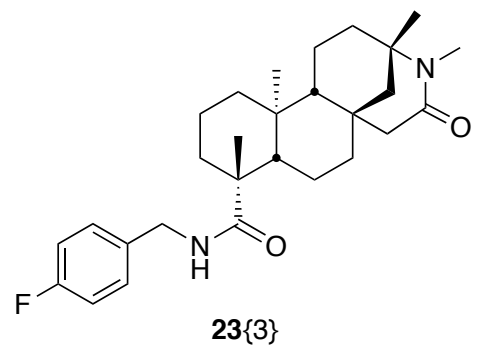

$(3 S, 6 \mathrm{a} R, 8 \mathrm{a} S, 9 R, 12 \mathrm{a} S, 12 \mathrm{~b} R)-\mathrm{N}$-(4-Fluorobenzyl)-3,4,9,12a-tetramethyl-5-oxotetradecahydro- $2 \mathrm{H}$ 3,6a-methanonaphtho[2,1- $\boldsymbol{d}$ ] azocine-9-carboxamide(23\{3\}). Oil; ${ }^{1} \mathrm{H}$ NMR $\left(400 \mathrm{MHz}, \mathrm{CDCl}_{3}\right): \delta 7.23$ $(\mathrm{dd}, J=8.3,5.4 \mathrm{~Hz}, 2 \mathrm{H}), 7.00$ (t, $J=8.5 \mathrm{~Hz}, 2 \mathrm{H}), 5.20$ (d, $J=15.4 \mathrm{~Hz}, 1 \mathrm{H}), 4.67(\mathrm{~s}, 1 \mathrm{H}), 4.44$ (d, $J=15.4$ $\mathrm{Hz}, 1 \mathrm{H}), 3.63(\mathrm{~s}, 3 \mathrm{H}), 2.15$ (dd, $J=23.4,13.3 \mathrm{~Hz}, 2 \mathrm{H}), 1.87-1.72(\mathrm{~m}, 2 \mathrm{H}), 1.70(\mathrm{~s}, 3 \mathrm{H}), 1.67-1.56(\mathrm{~m}$, $3 \mathrm{H}), 1.55-1.44(\mathrm{~m}, 2 \mathrm{H}), 1.42-1.32(\mathrm{~m}, 3 \mathrm{H}), 1.30(\mathrm{~s}, 3 \mathrm{H}), 1.28-1.18(\mathrm{~m}, 2 \mathrm{H}), 1.15(\mathrm{~s}, 3 \mathrm{H}), 1.11-0.89$ $(\mathrm{m}, 4 \mathrm{H}), 0.87(\mathrm{dd}, J=13.0,3.8 \mathrm{~Hz}, 1 \mathrm{H}), 0.78(\mathrm{td}, J=13.4,3.9 \mathrm{~Hz}, 1 \mathrm{H}) ;{ }^{13} \mathrm{C}$ NMR $\left(125 \mathrm{MHz}, \mathrm{CDCl}_{3}\right): \delta$ 188.2, 177.4, 133.8, 129.1, 129.0, 116.1, 115.9, 96.4, 58.7, 56.9, 56.2, 51.3, 51.2, 43.7, 43.1, 39.5, 39.3, 37.7, 37.3, 37.2, 35.4, 28.9, 25.2, 19.2, 19.2, 19.0, 14.2, 12.9; LRMS (ESI) $(\mathrm{m} / \mathrm{z}):[\mathrm{M}+\mathrm{H}]^{+}$calcd for $\mathrm{C}_{28} \mathrm{H}_{40} \mathrm{FN}_{2} \mathrm{O}_{2} 455.2996$, found $455 ;[\alpha]_{\mathrm{D}}^{23}-74.3\left(c 0.450, \mathrm{CHCl}_{3}\right)$.

\section{References}

1. Lipinski, C. A.; Lombardo, F.; Dominy, B. W.; Feeney, P. J. Experimental and computational approaches to estimate solubility and permeability in drug discovery and development settings. $A d v$. Drug Delivery Rev. 2001, 46, 3-26.

2. Walters, W.; Green, J.; Weiss, J.; Murcko, M. What do medicinal chemists actually make? A 50year retrospective. J. Med. Chem. 2011, 54, 6405-6416.

3. Huigens, R.; Morrison, K.; Hicklin, R.; Flood, T.; Richter, M.; Hergenrother, P. A ring-distortion strategy to construct stereochemically complex and structurally diverse compounds from natural products. Nat. Chem. 2013, 5, 195-202. 
4. Lovering, F.; Bikker, J.; Humblet, C. Escape from flatland: increasing saturation as an approach to improving clinical success. J. Med. Chem. 2009, 52, 6752-6756.

5. Ghose, A. K.; Crippen, G. M. Atomic physicochemical parameters for three-dimensionalstructure-directed quantitative structure-activity relationships. 2. Modeling dispersive and hydrophobic interactions. J. Chem. Inf. Model. 1987, 27, 21-35.

6. Lovering, F.; Bikker, J.; Humblet, C. Escape from flatland: Increasing saturation as an approach to improving clinical success. $J$. Med. Chem. 2009, 52, 6752-6756.

7. Nicolaou, K. C. Organic synthesis: the art and science of replicating the molecules of living nature and creating others like them in the laboratory. Proc. R. Soc. London, Ser. A 2014, 470, 1-17. 8. Hutt, O. E.; Doan, T. L.; Georg, G. I. Synthesis of skeletally diverse and stereochemically complex library templates derived from isosteviol and steviol. Org. Lett. 2013, 15, 1602-1605.

9. Wu, Y.; Yang, J. H.; Dai, G. F.; Liu, C. J.; Tian, G. Q.; Ma, W. Y.; Tao, J. C. Stereoselective synthesis of bioactive isosteviol derivatives as alpha-glucosidase inhibitors. Bioorg. Med. Chem. 2009, 17, 1464-1473.

10. Mosettig, E.; Beglinger, U.; Dolder, F.; Lichti, H.; Quitt, P.; Waters, J. A. The absolute configuration of steviol and isosteviol. J. Am. Chem. Soc. 1963, 85, 2305-2309.

11. Terai, T.; Ren, H.; Mori, G.; Yamaguchi, Y.; Hayashi, T. Mutagenicity of steviol and its oxidative derivatives in Salmonella typhimurium TM677. Chem. Pharm. Bull. 2002, 50, 1007-10.

12. Coates, R. M.; Bertram, E. F. Structural modifications of isosteviol. Partial synthesis of atiserene and isoatiserene. J. Org. Chem. 1971, 36, 2625-2631. 
아 $1.20 \mathrm{E}+08$

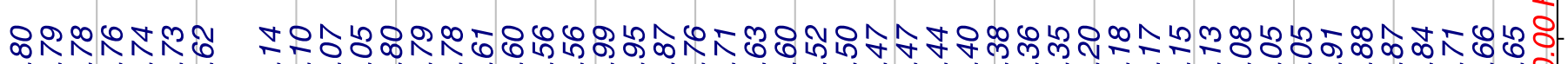

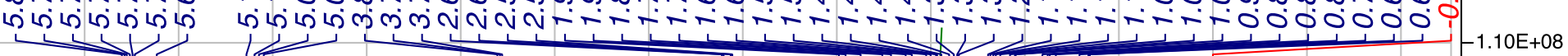

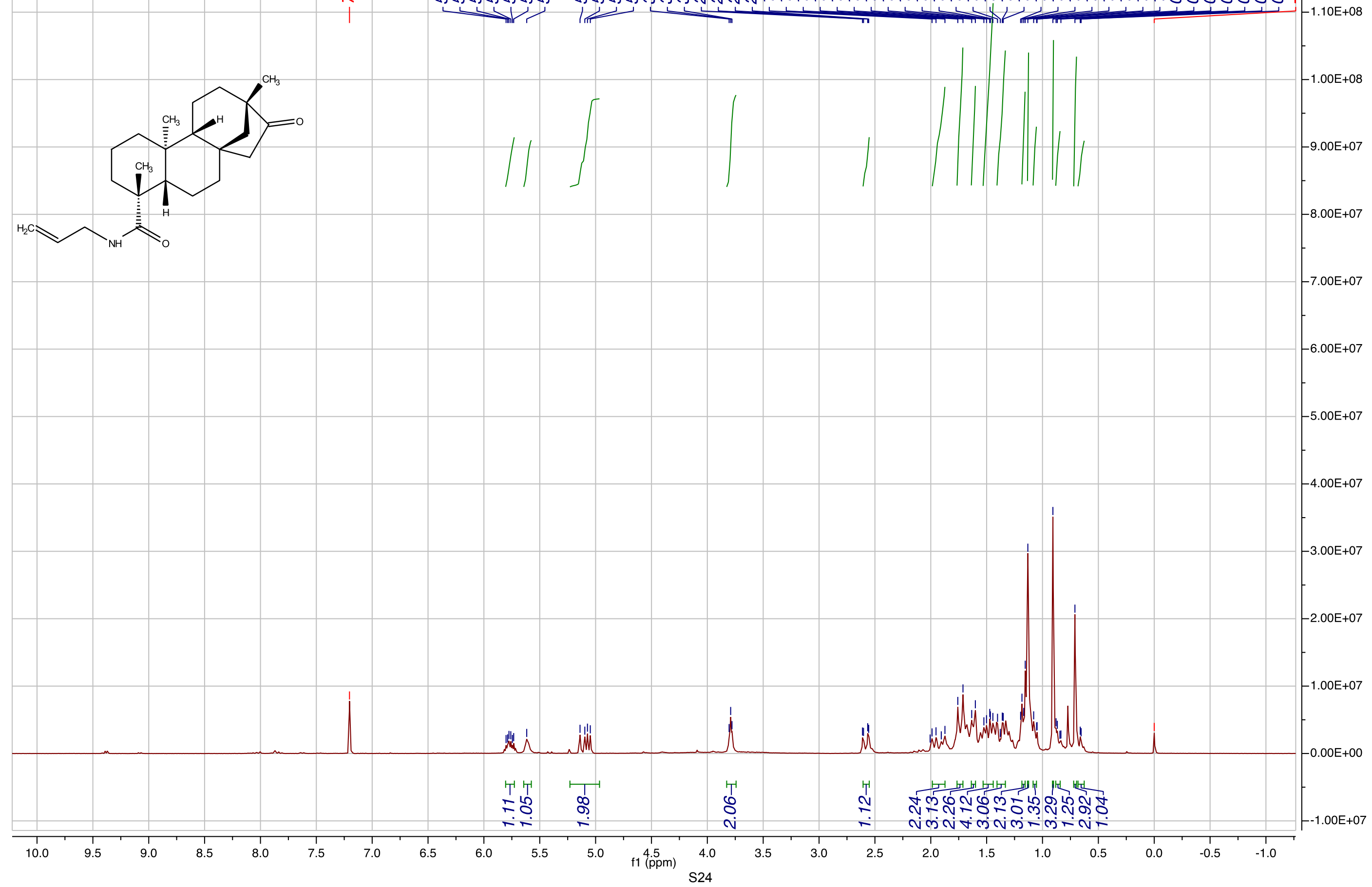




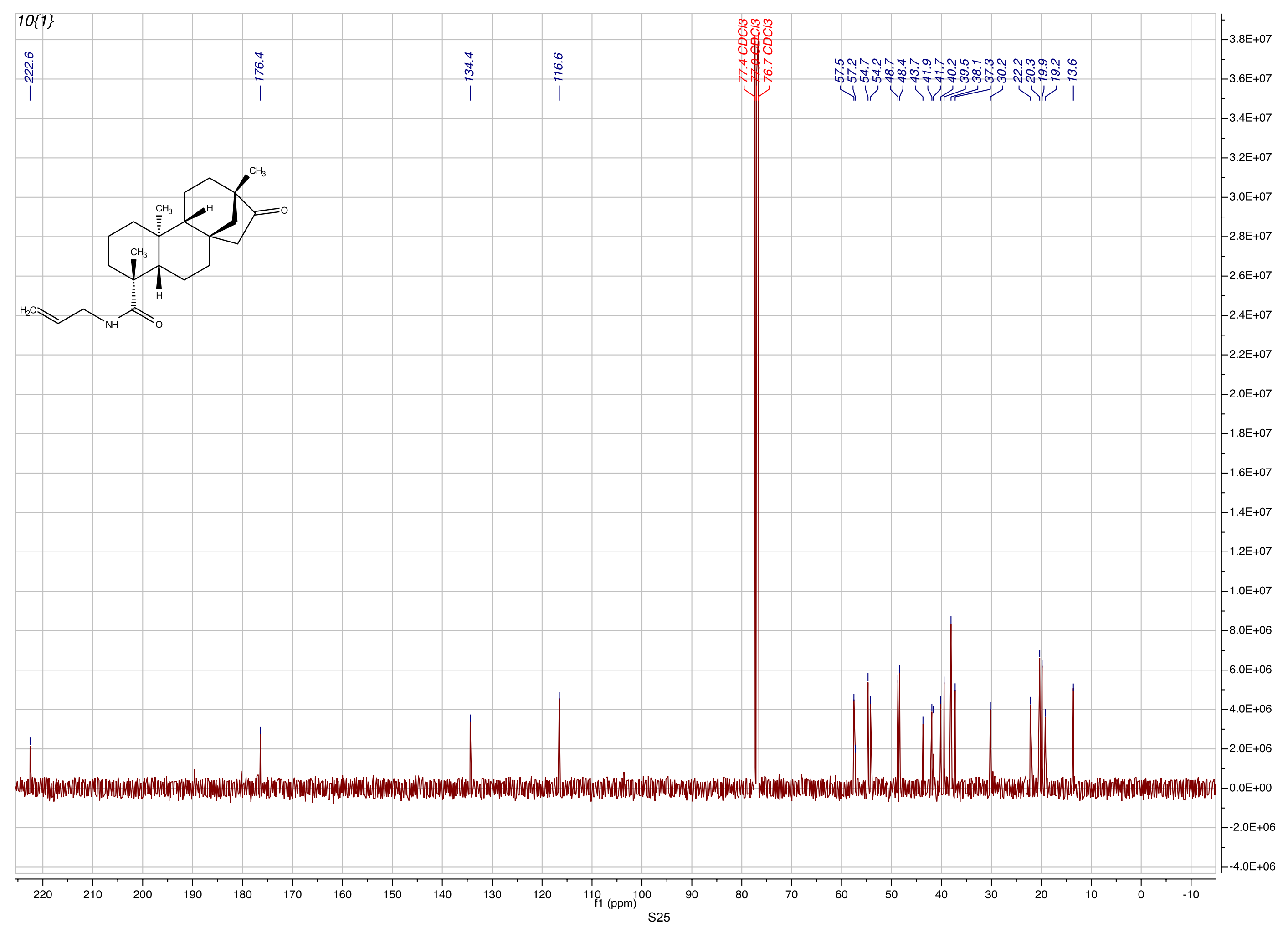




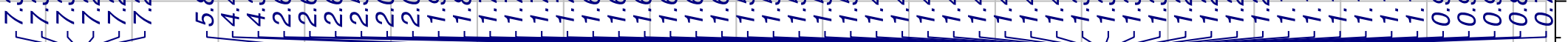

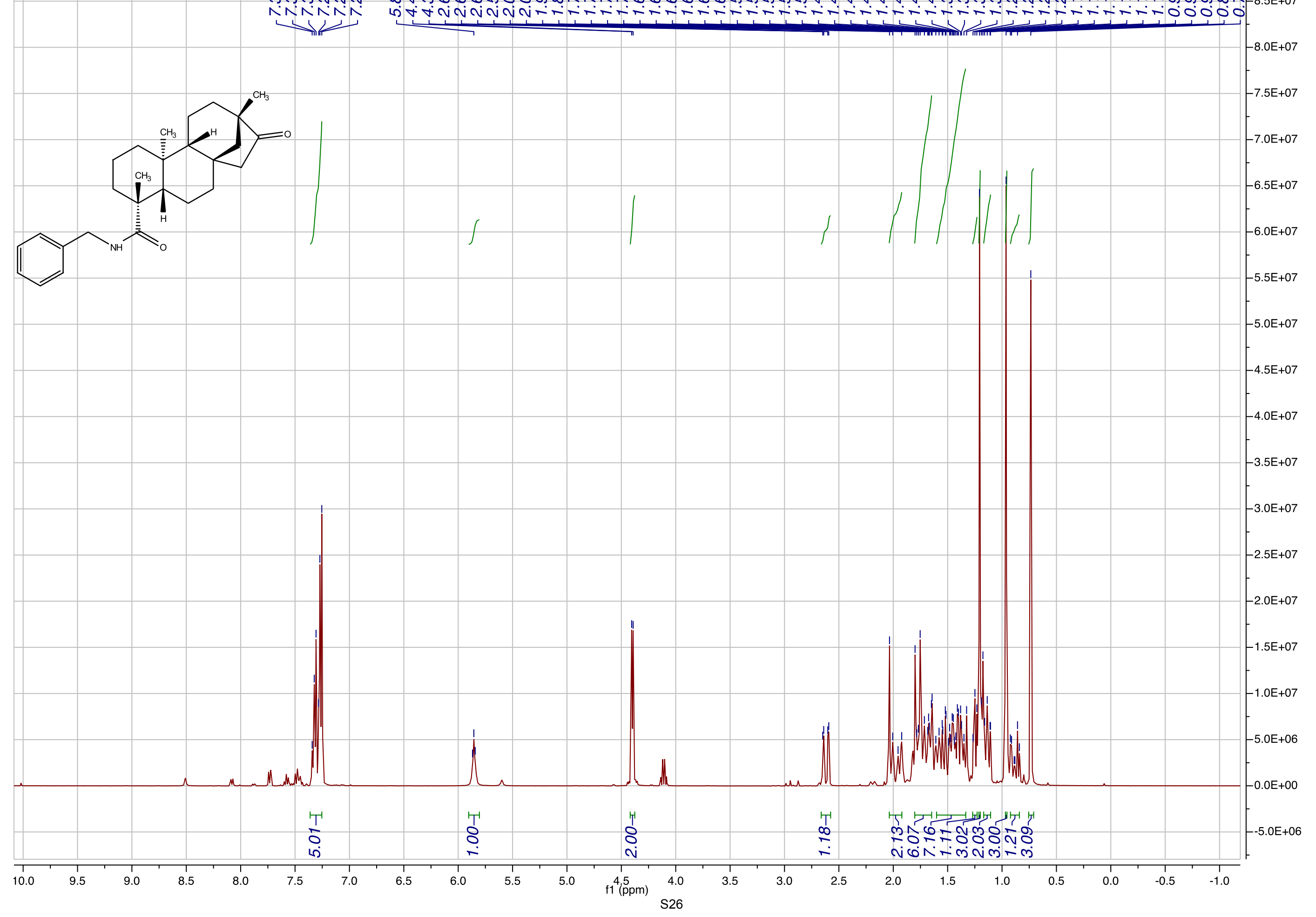




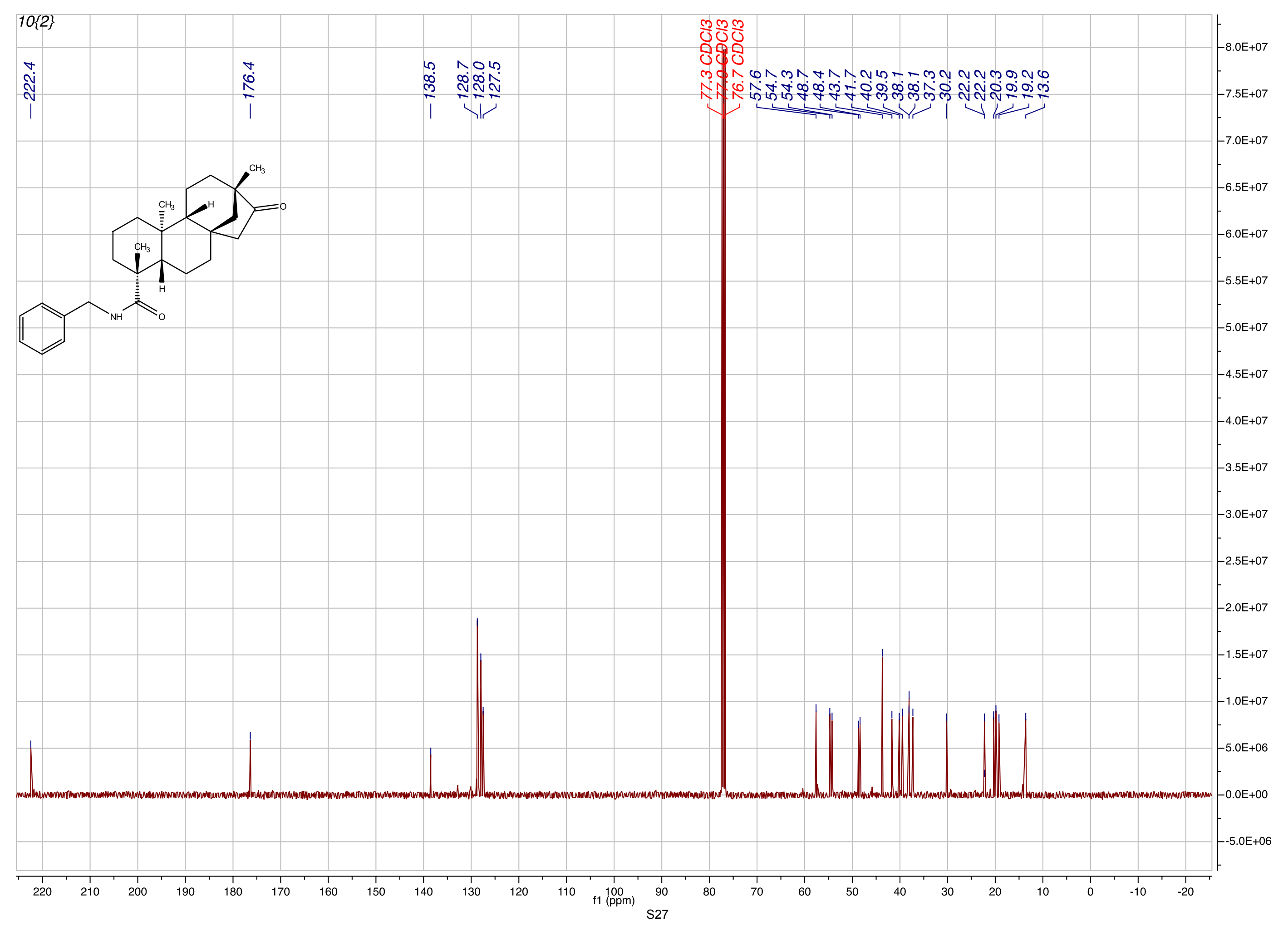




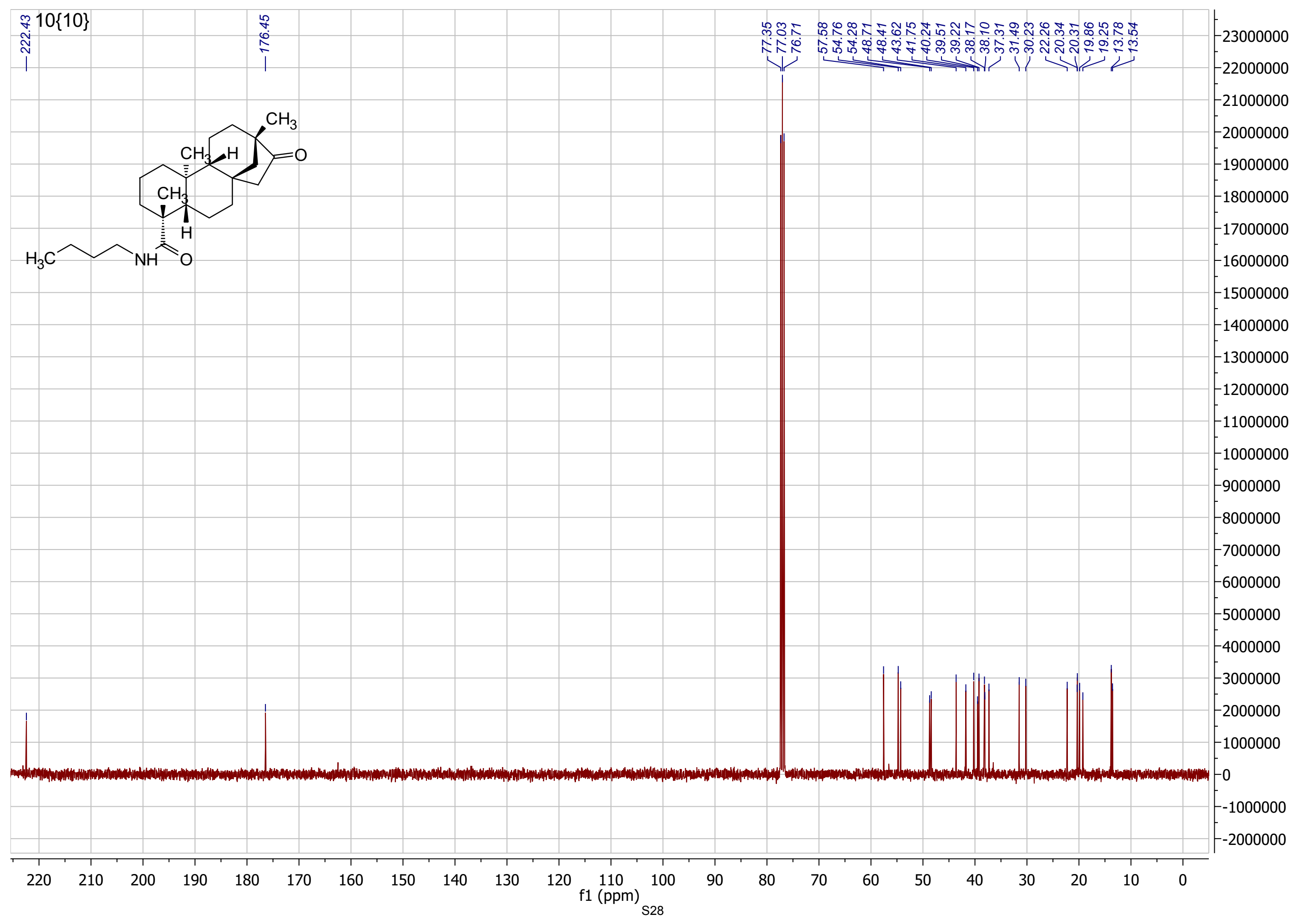




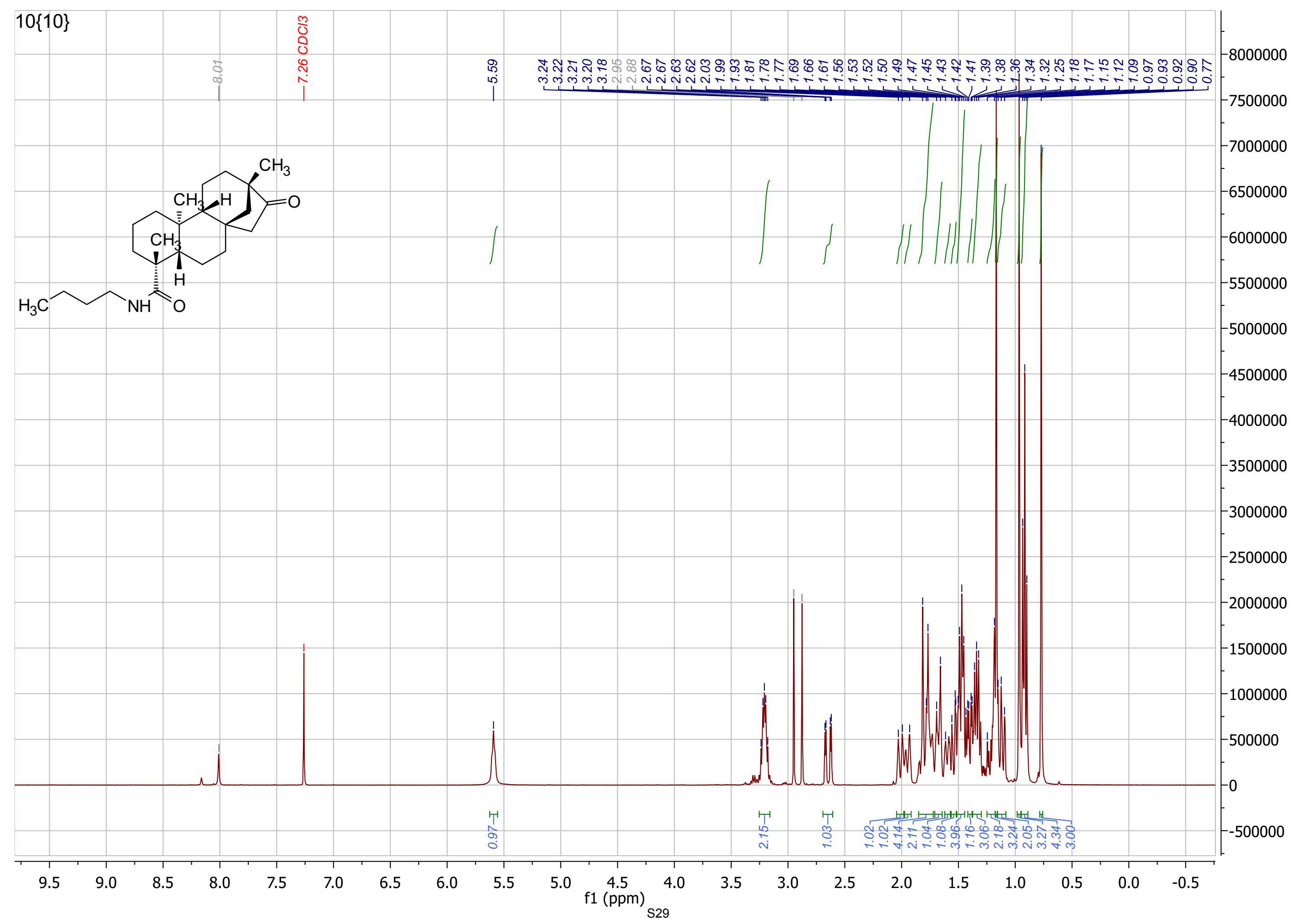




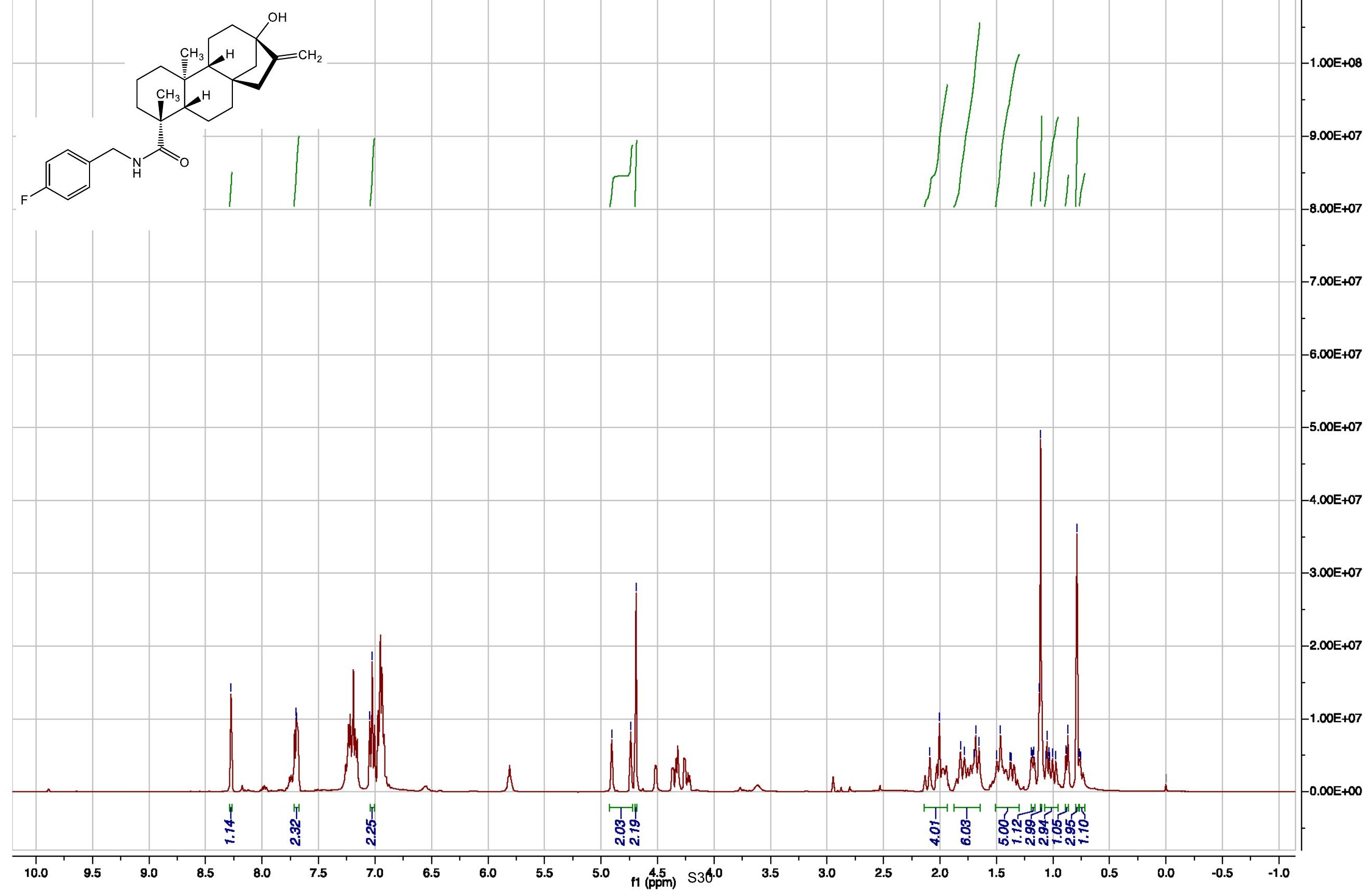




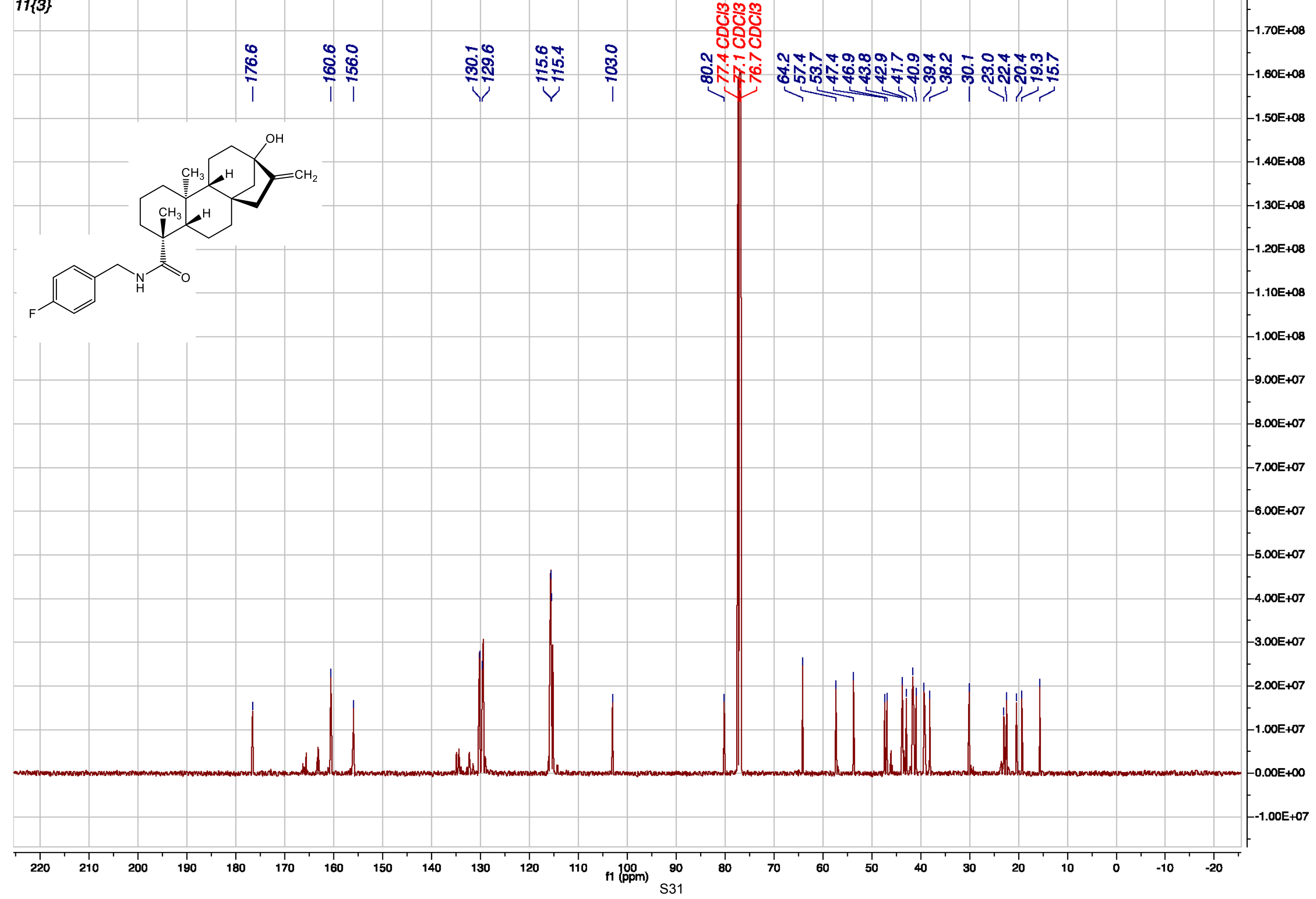




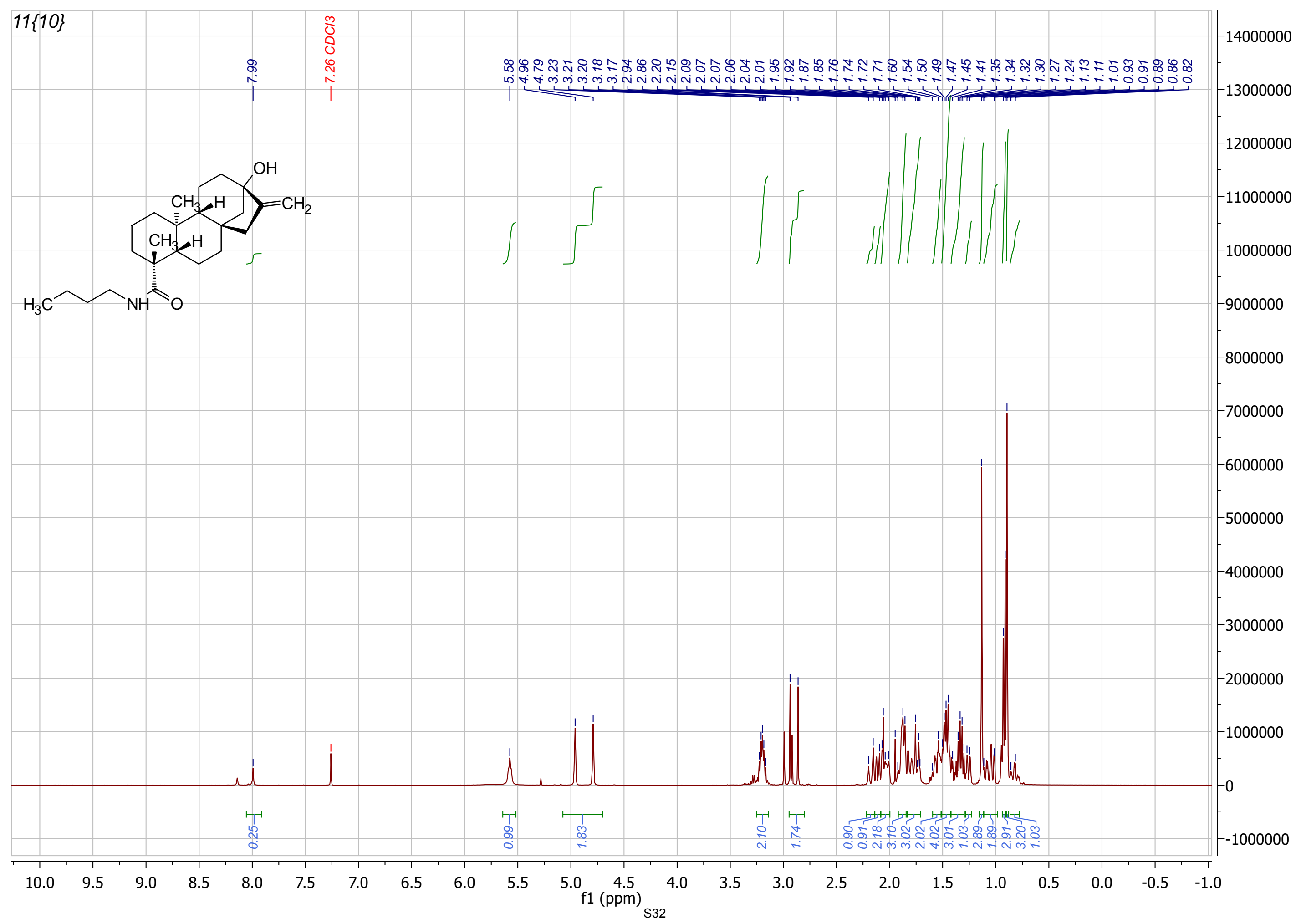




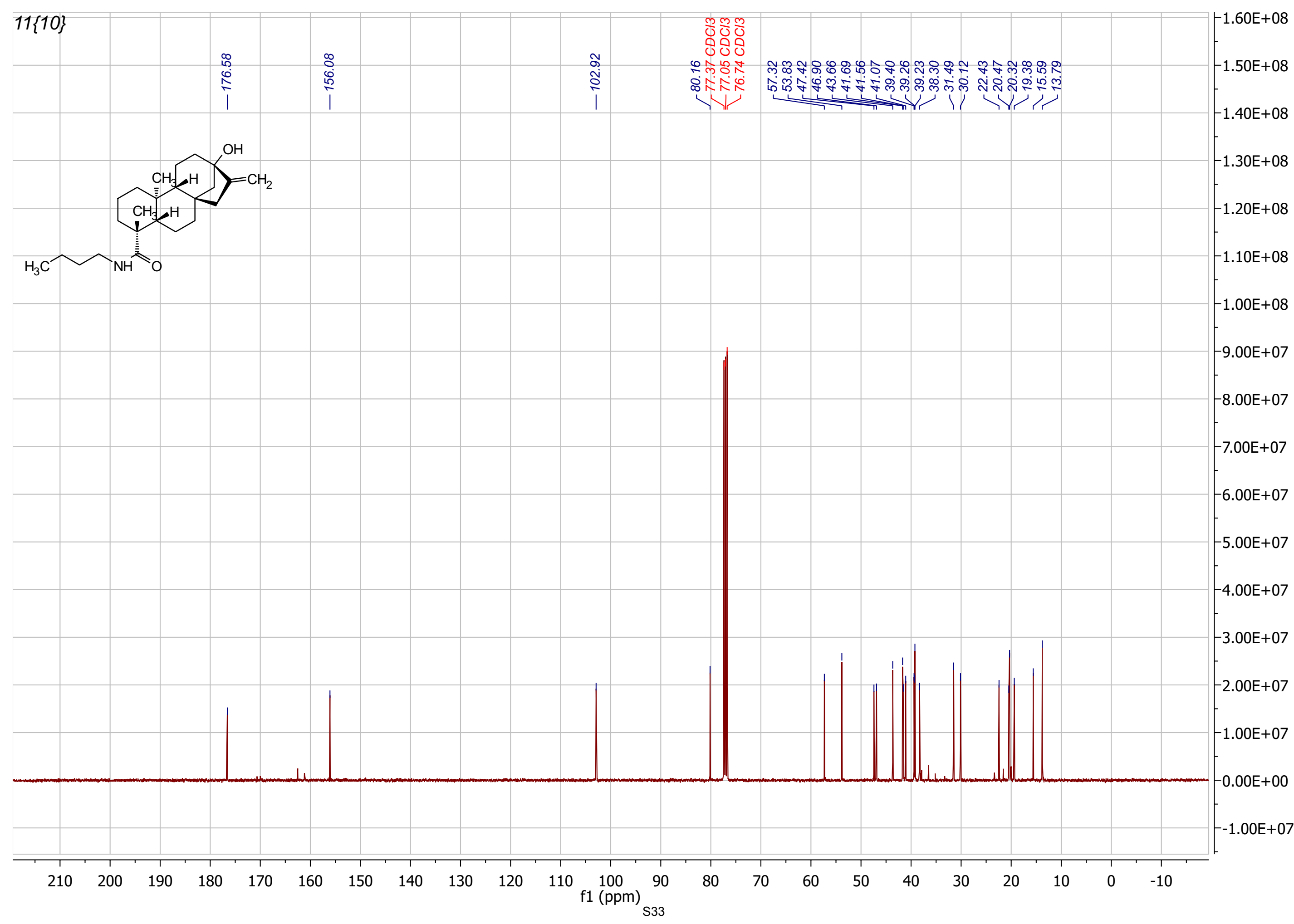




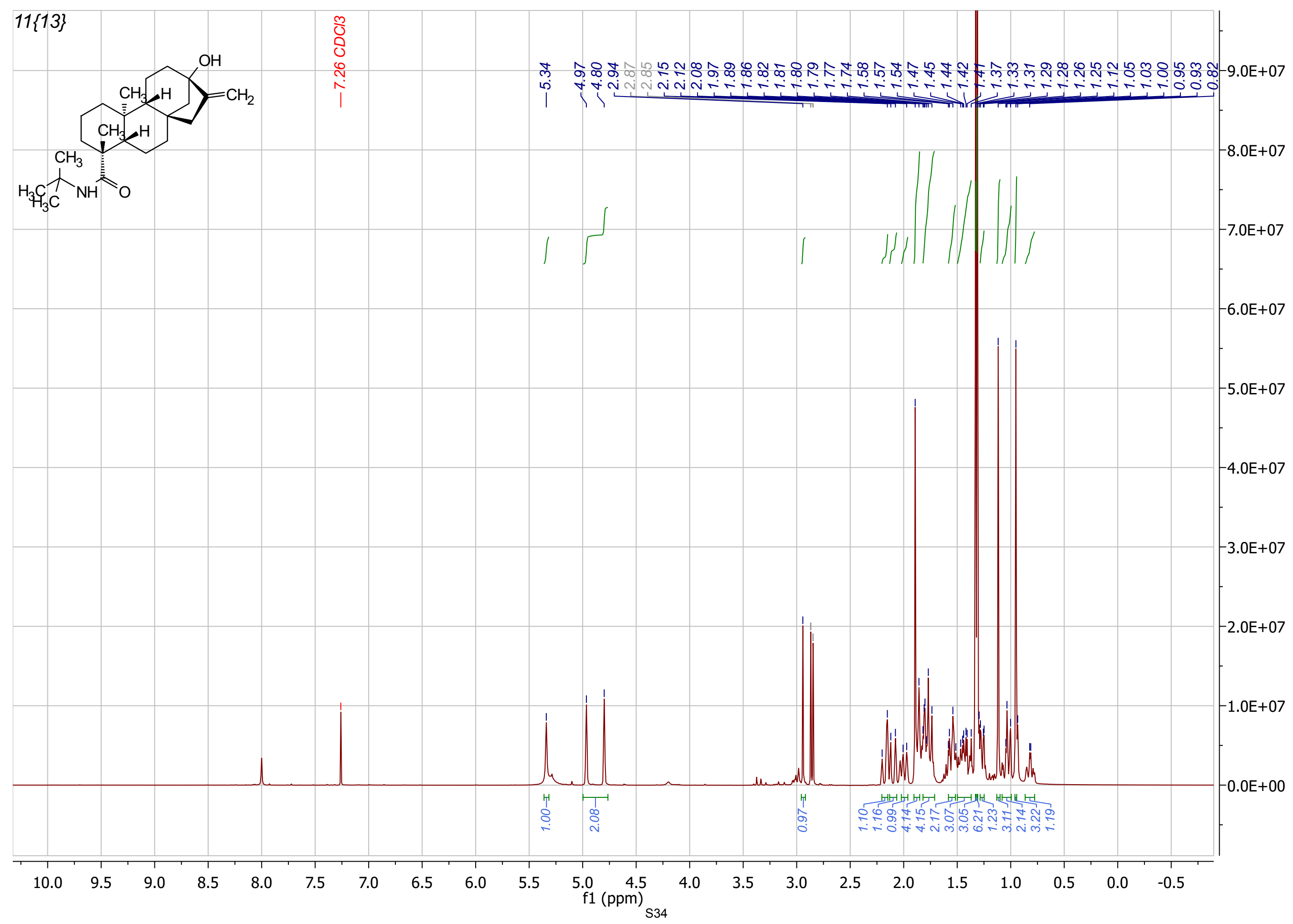




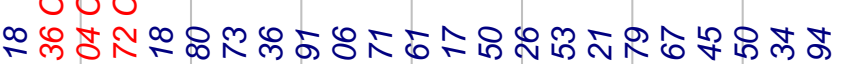

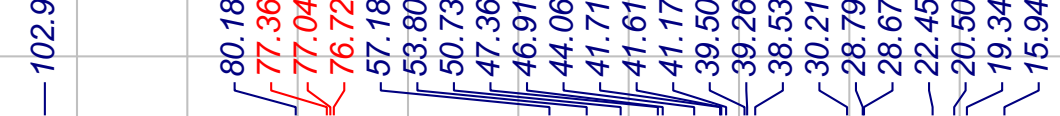

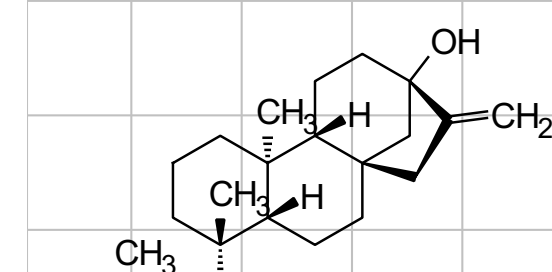

$\mathrm{CH}_{3}$

CH

$\mathrm{H}_{3} \mathrm{C}$ 到 $\mathrm{NH}$

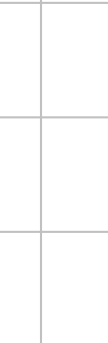

\begin{tabular}{|l|l|l|l|l|l|l|l|} 
& & & & \\
\hline
\end{tabular}




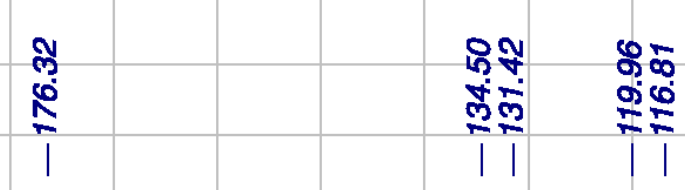

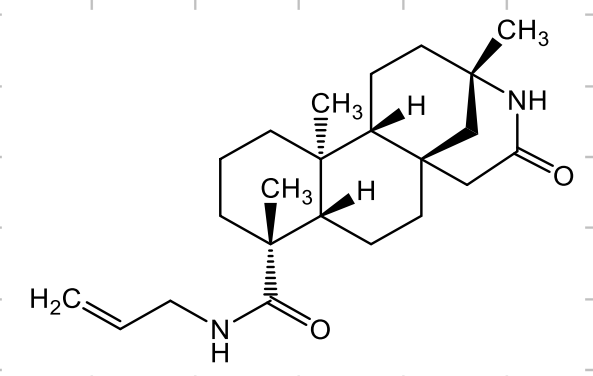

nL 


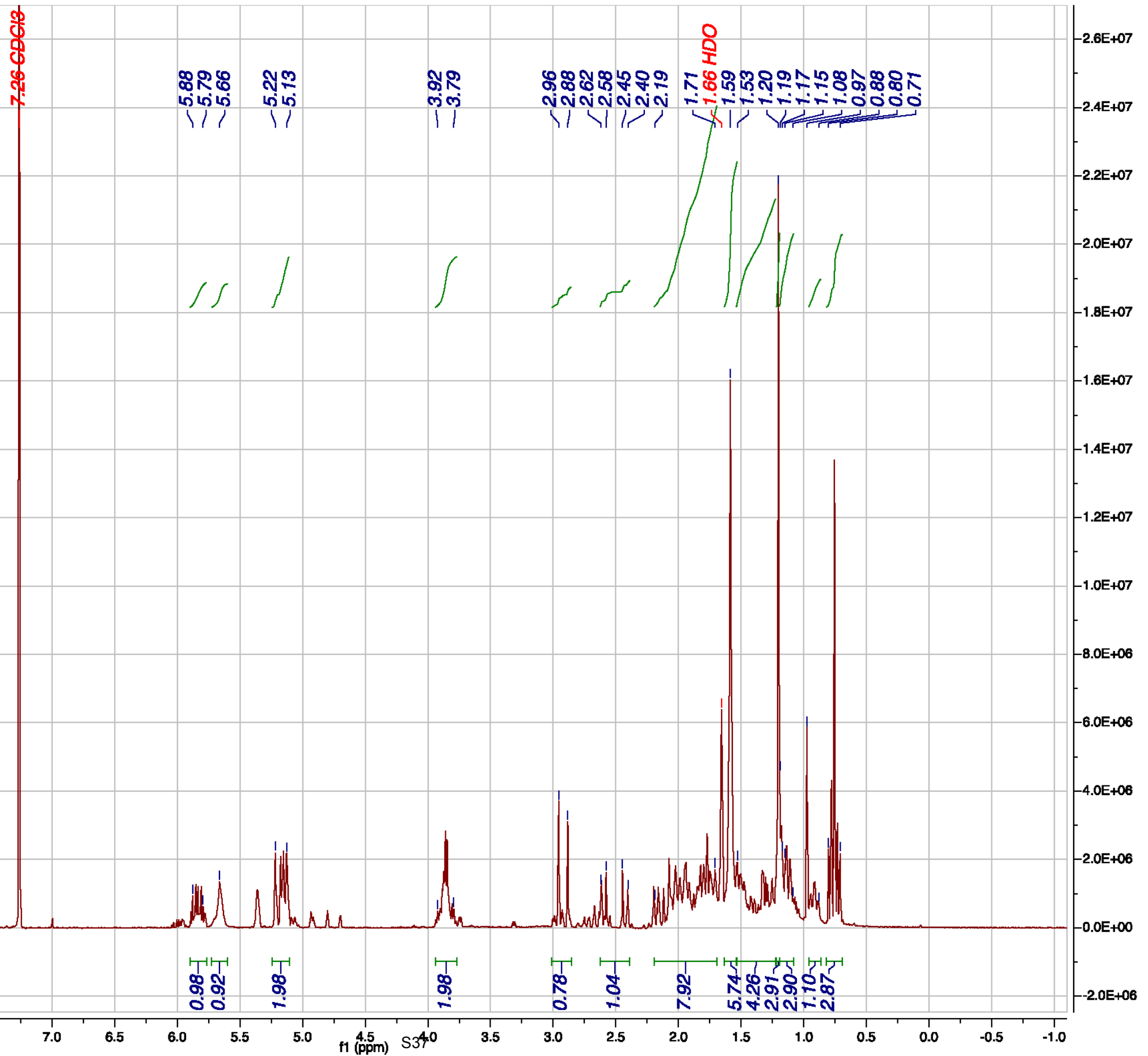




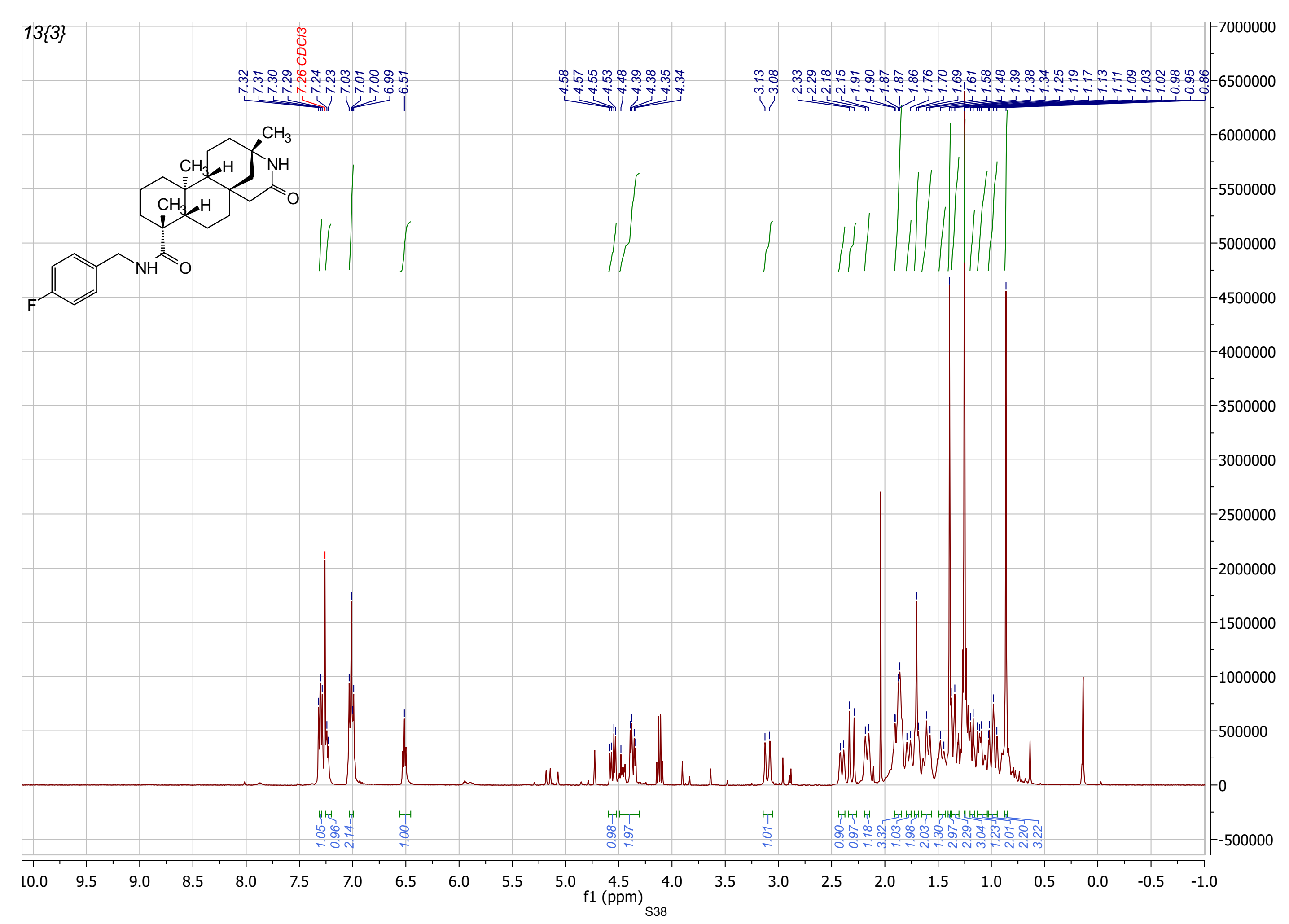




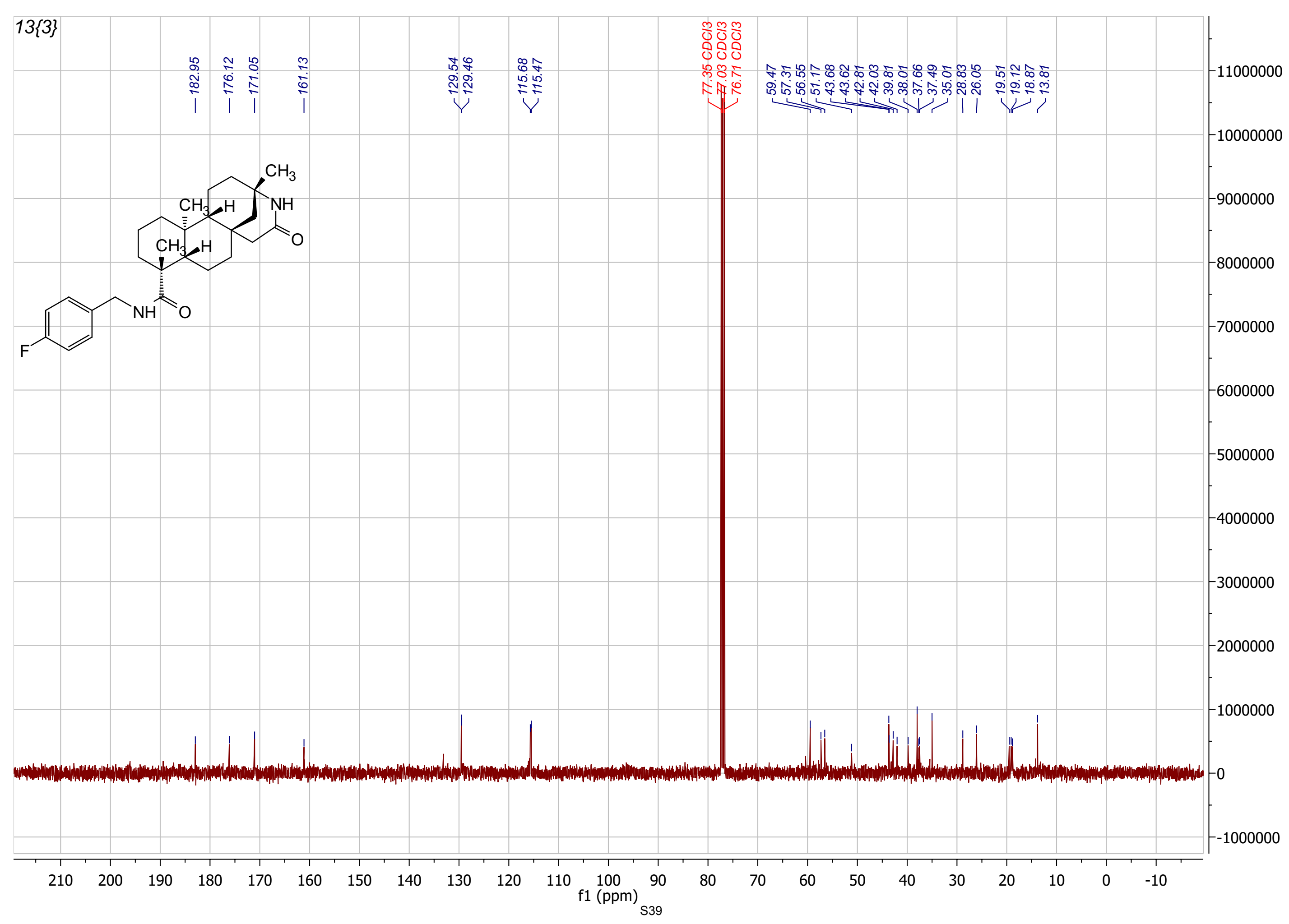




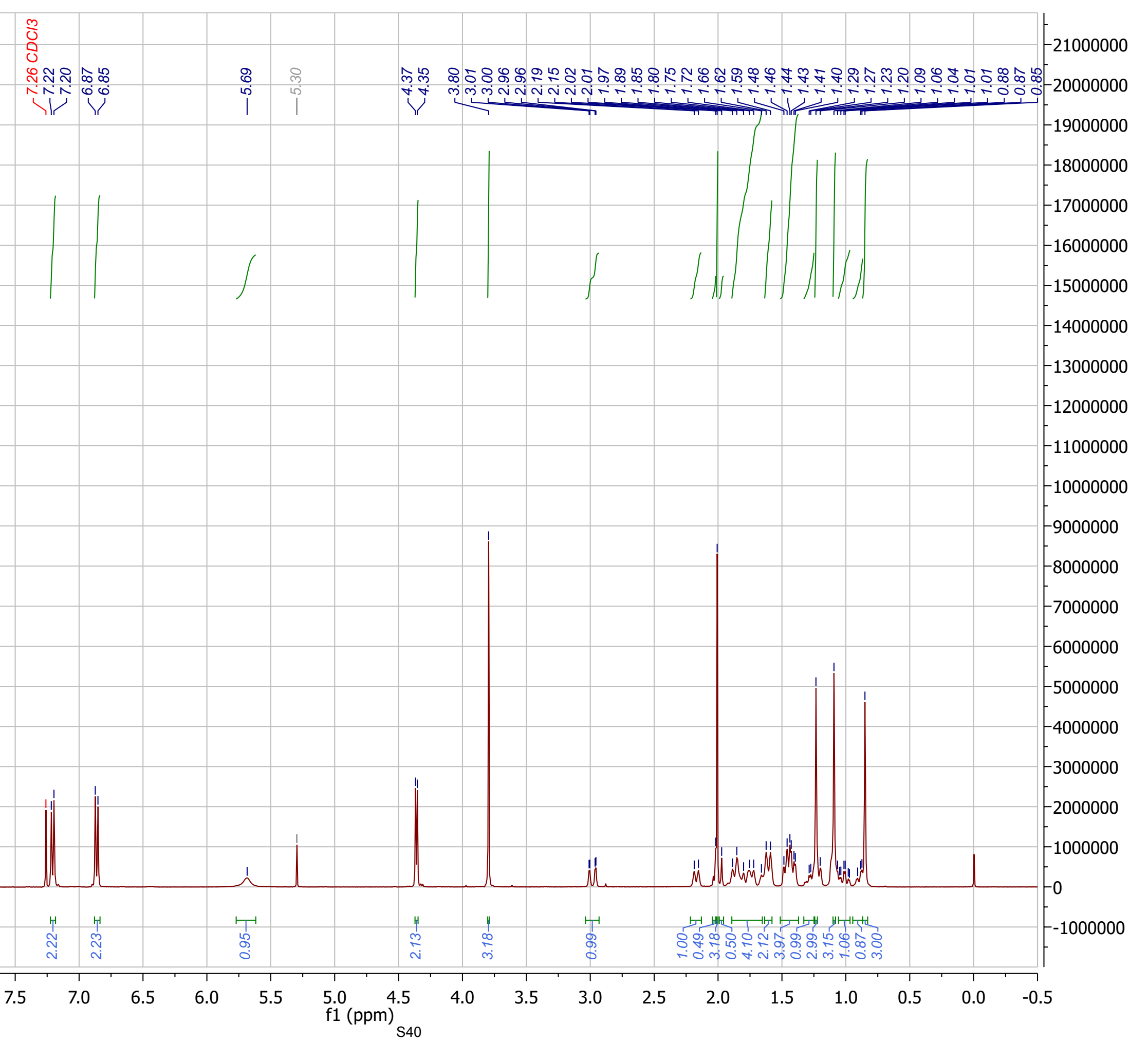




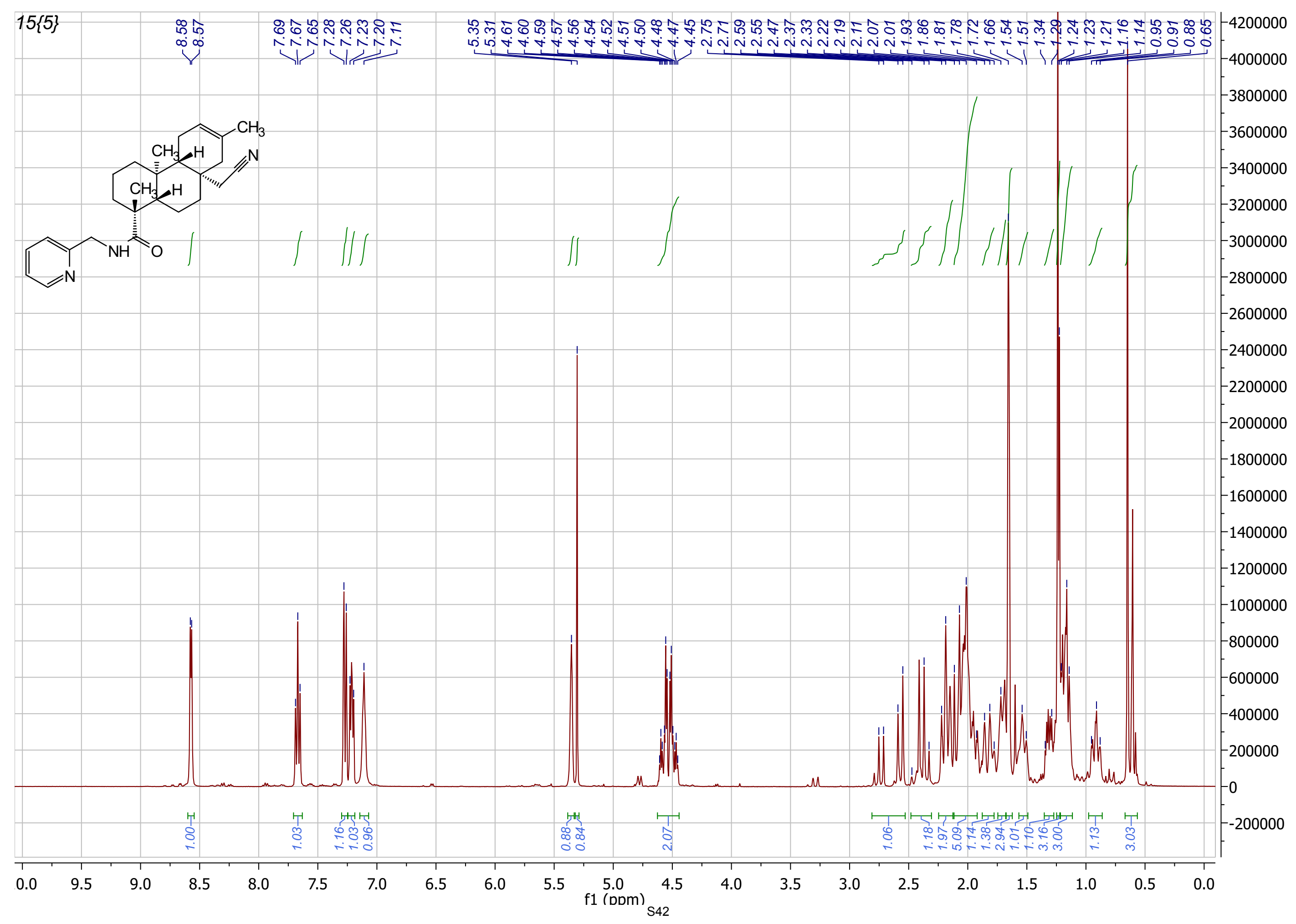




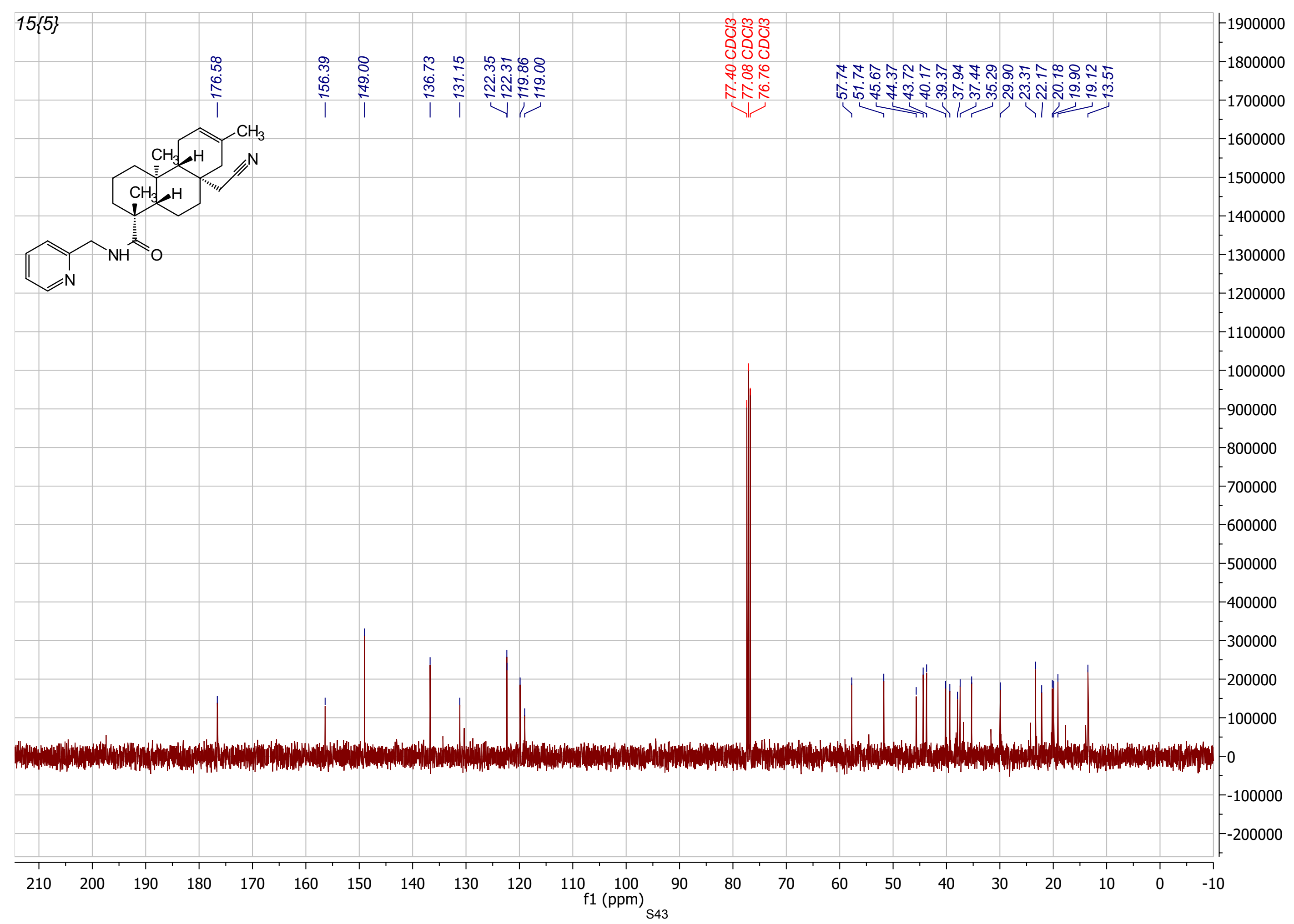




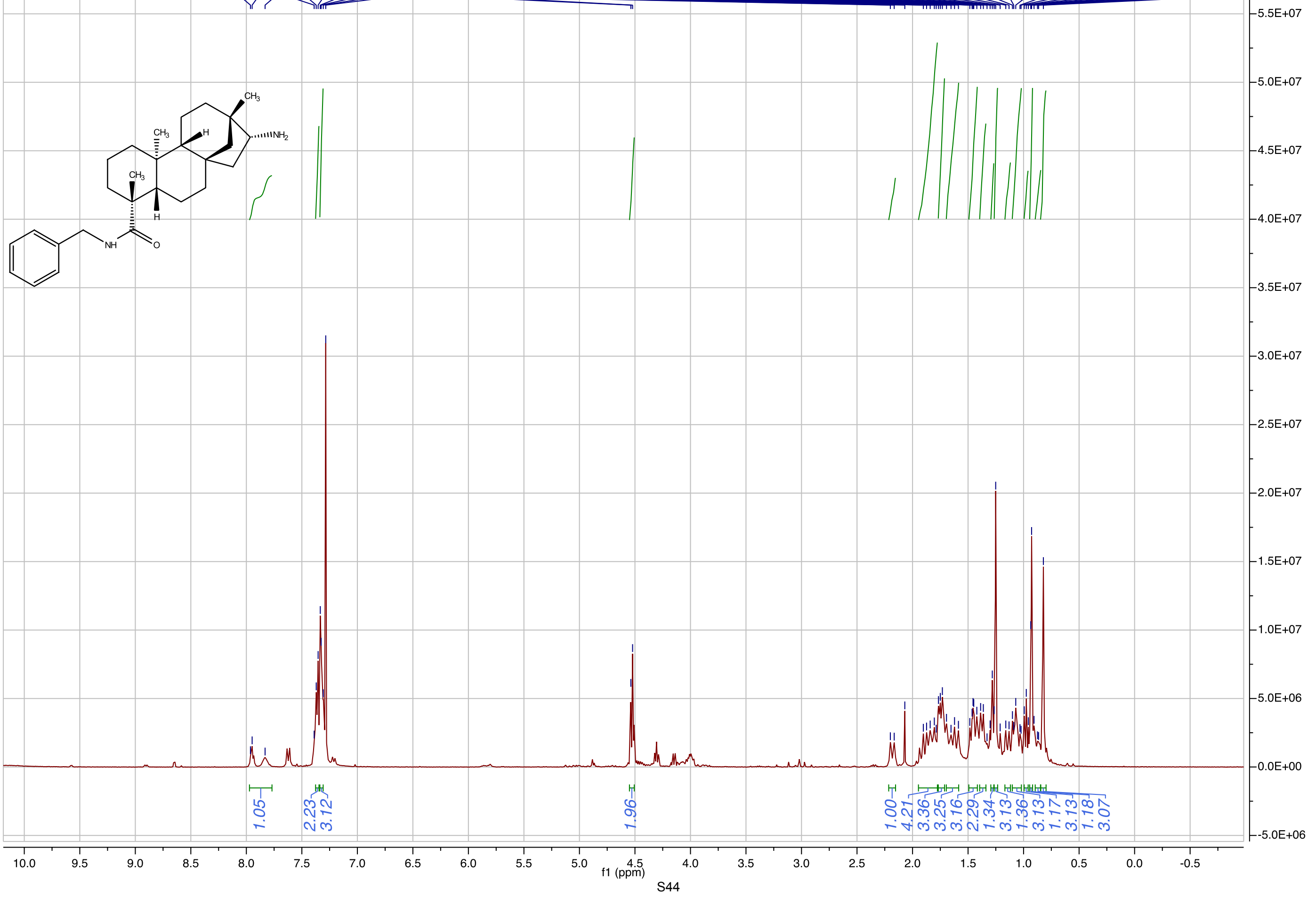




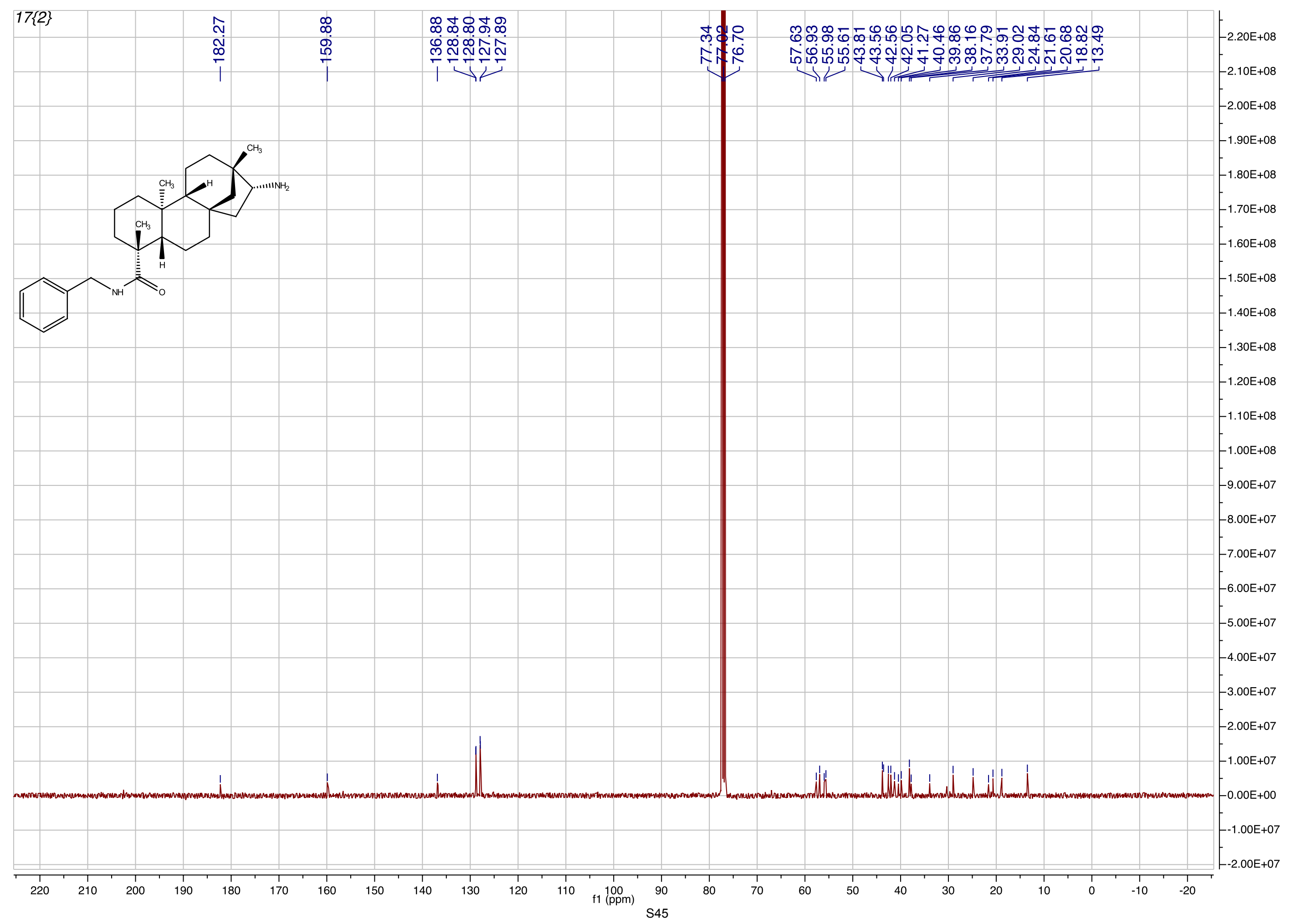




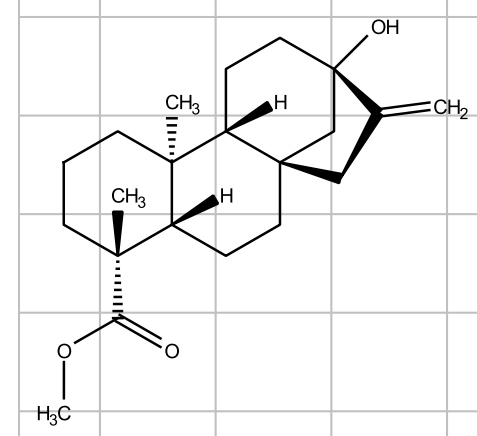

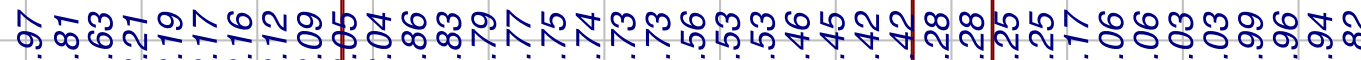

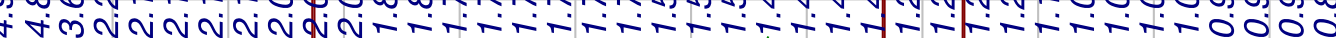
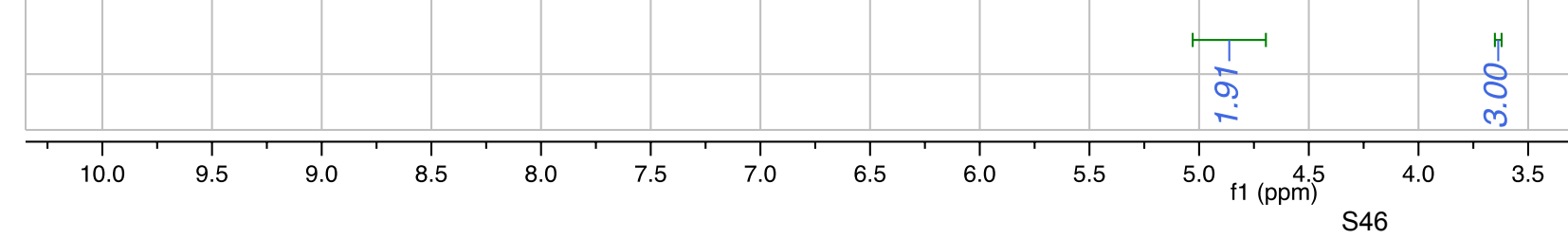

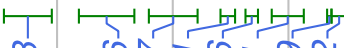

क जी ल Nं 


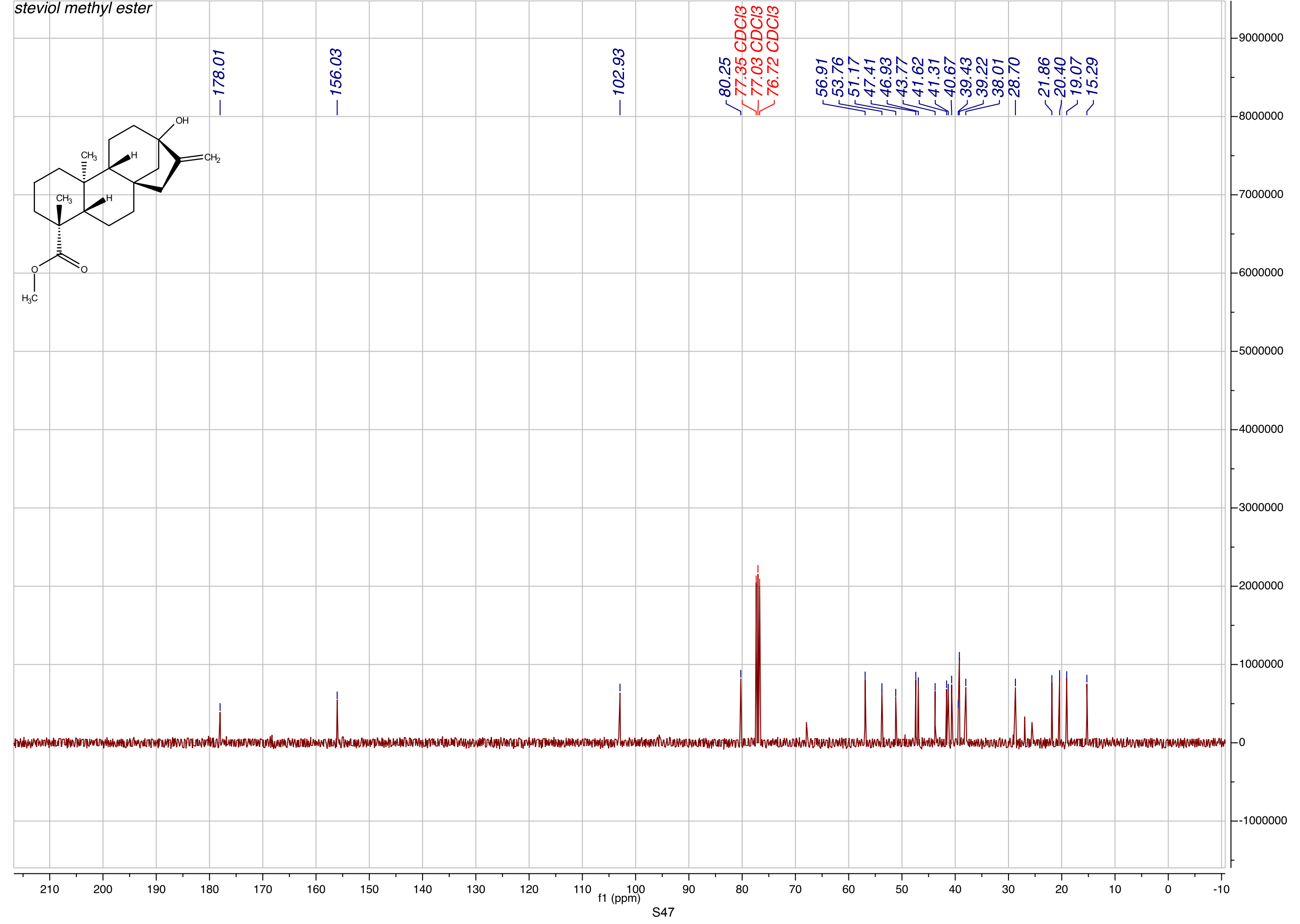




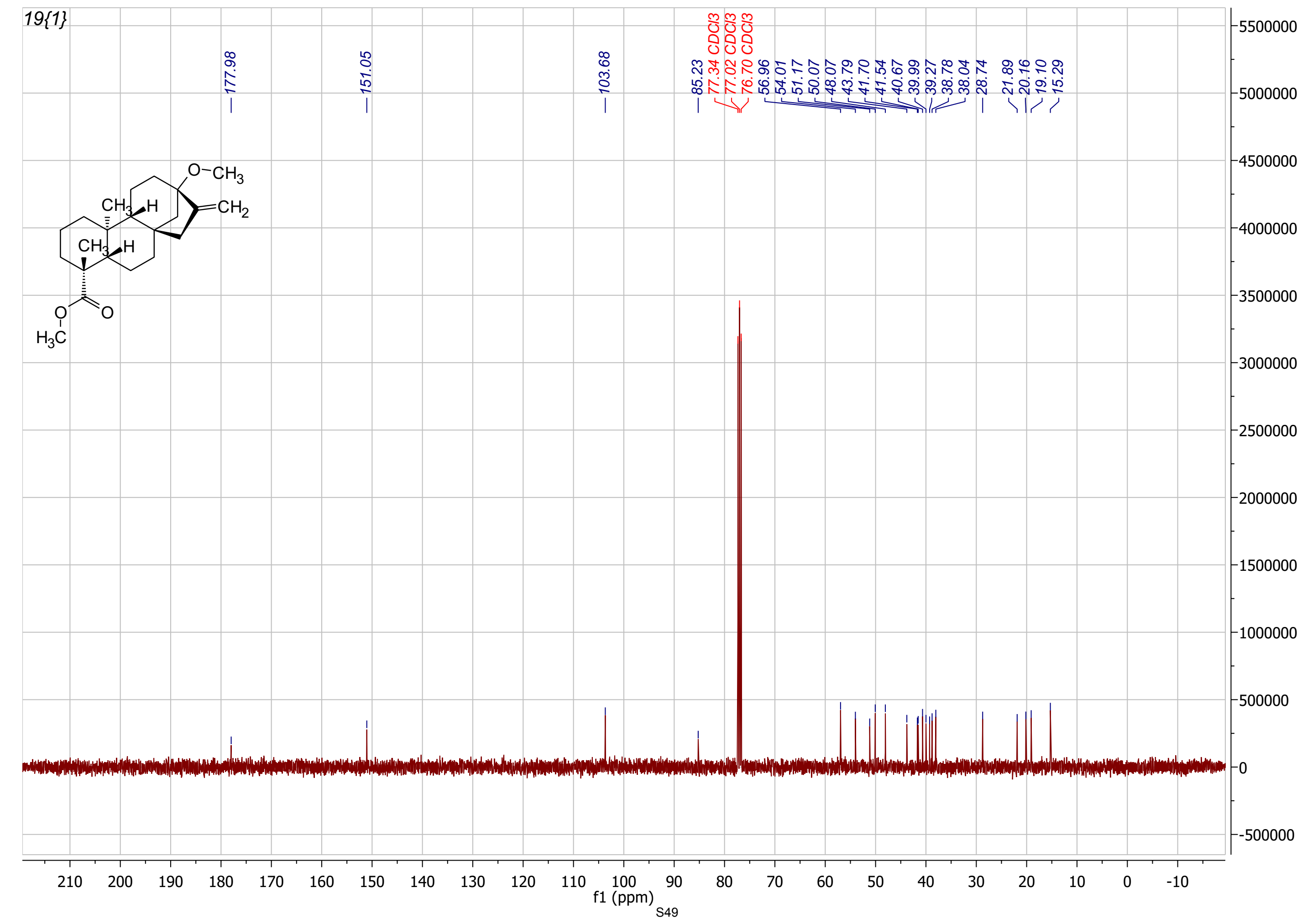




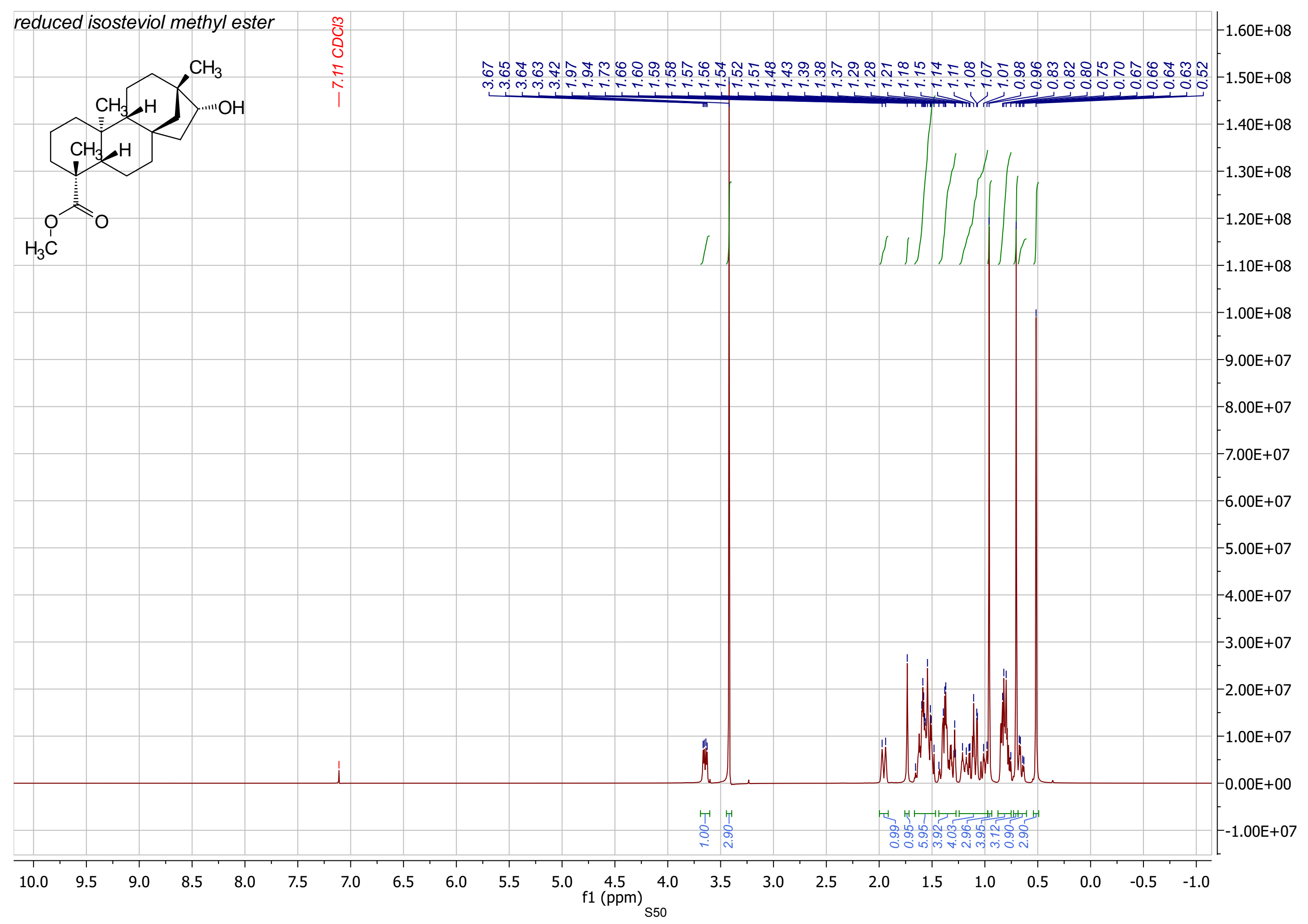




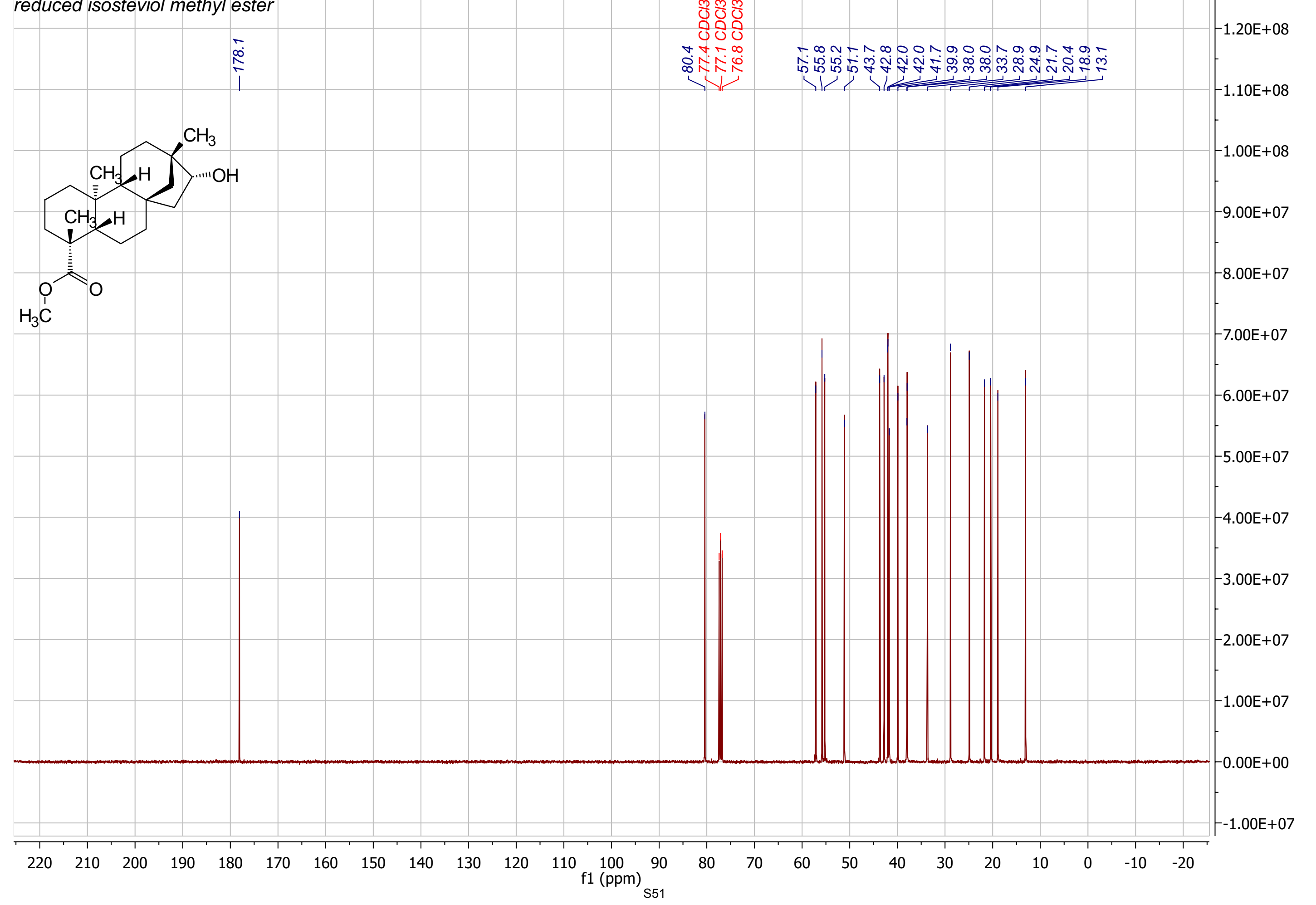




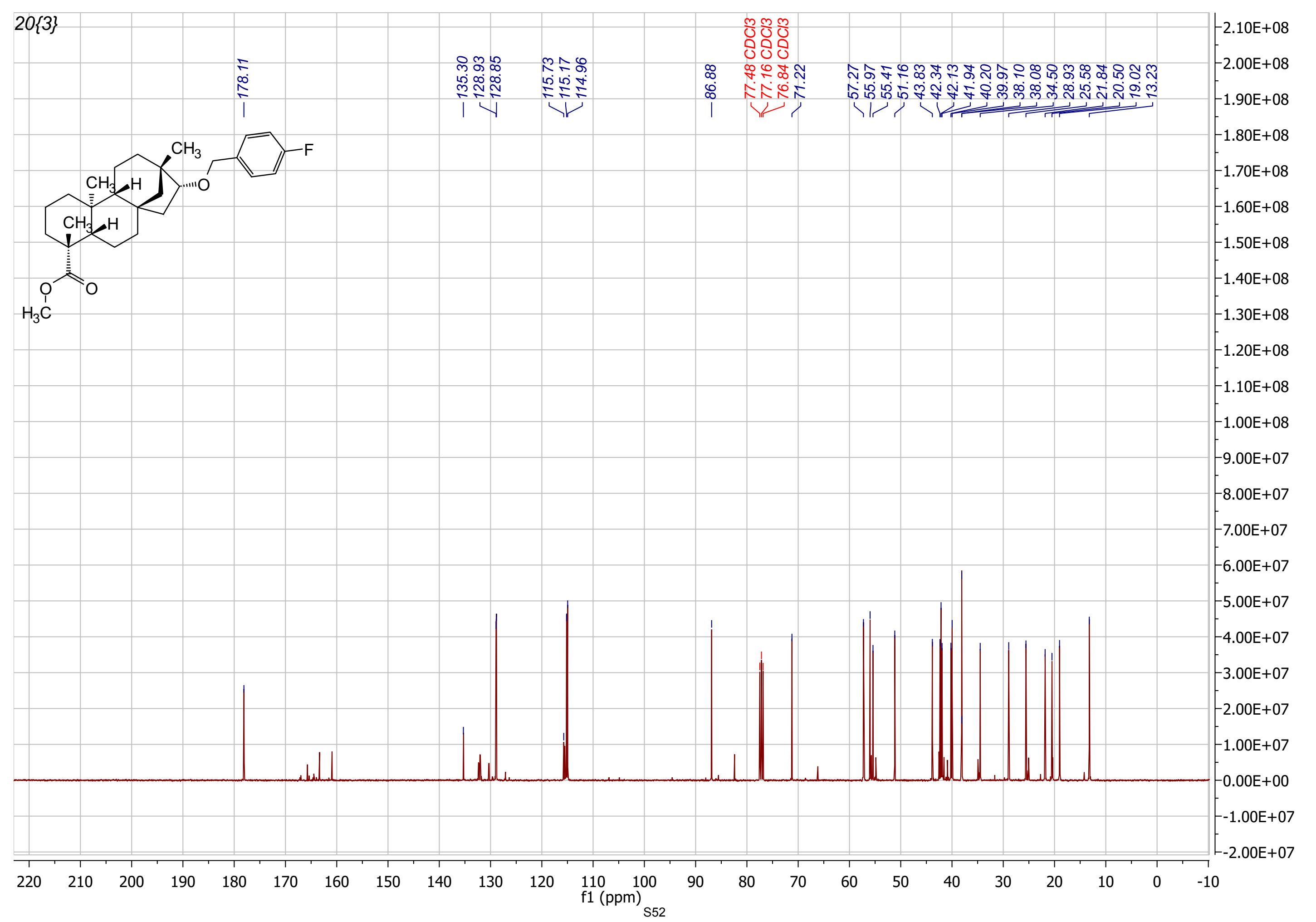




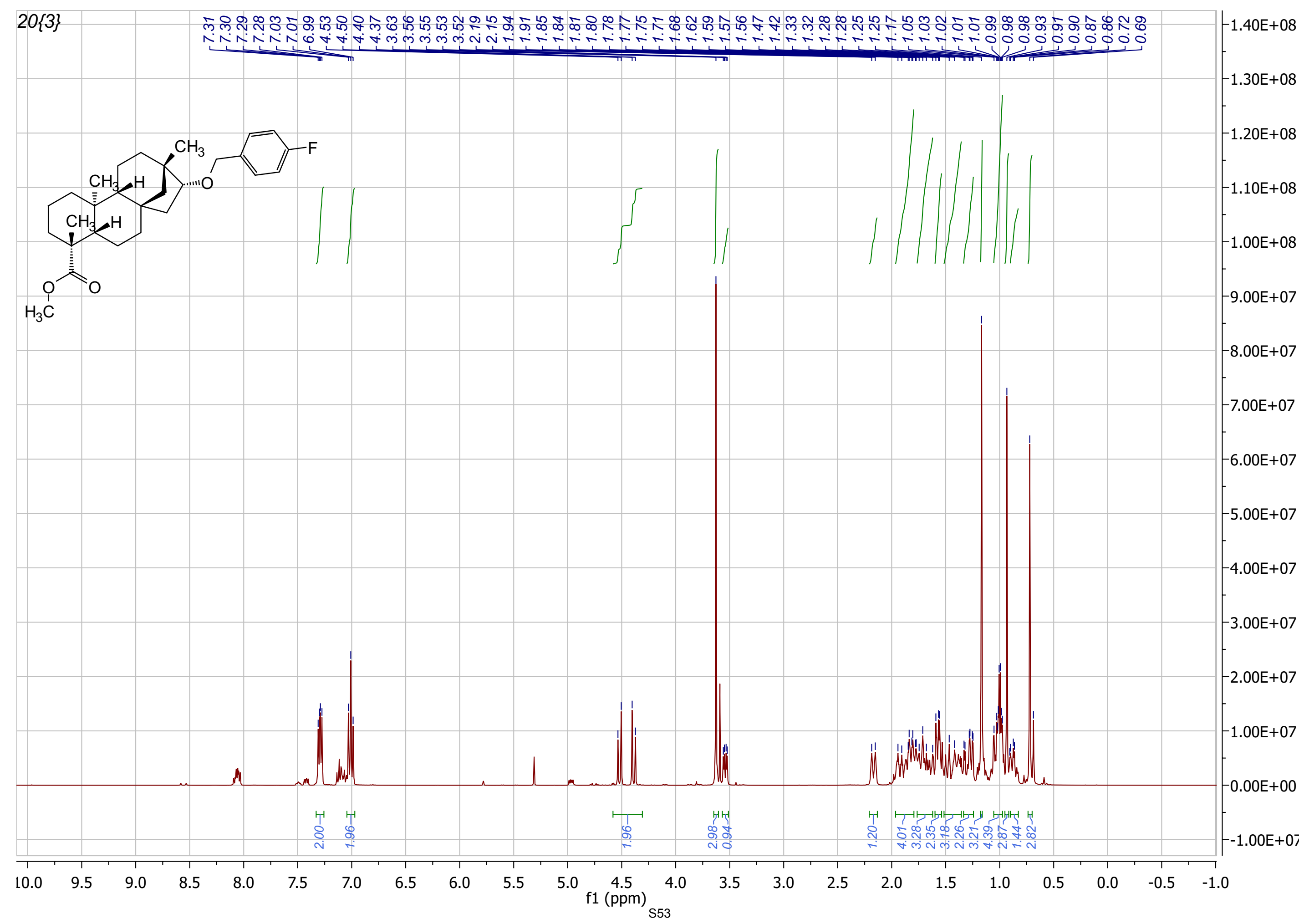




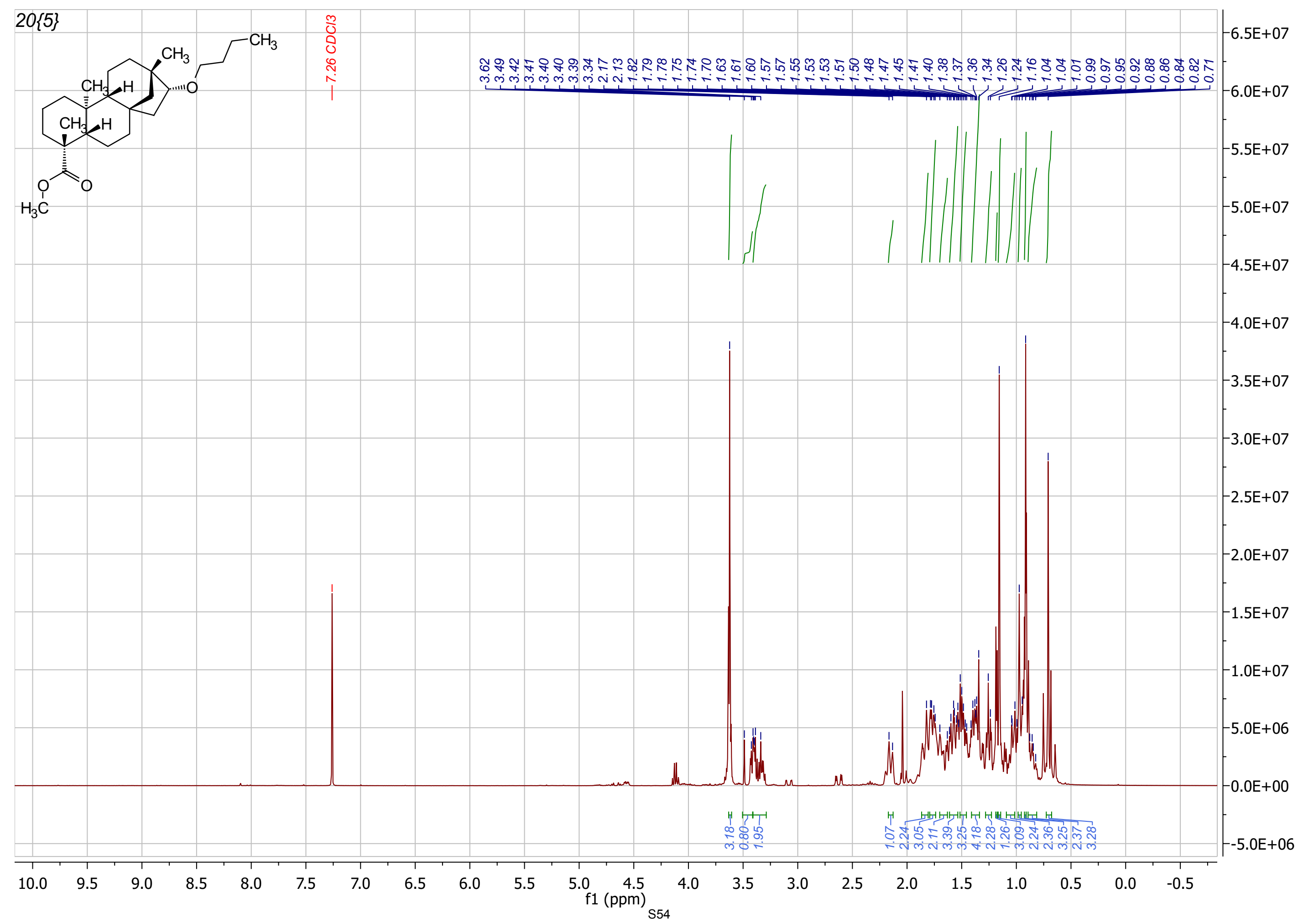



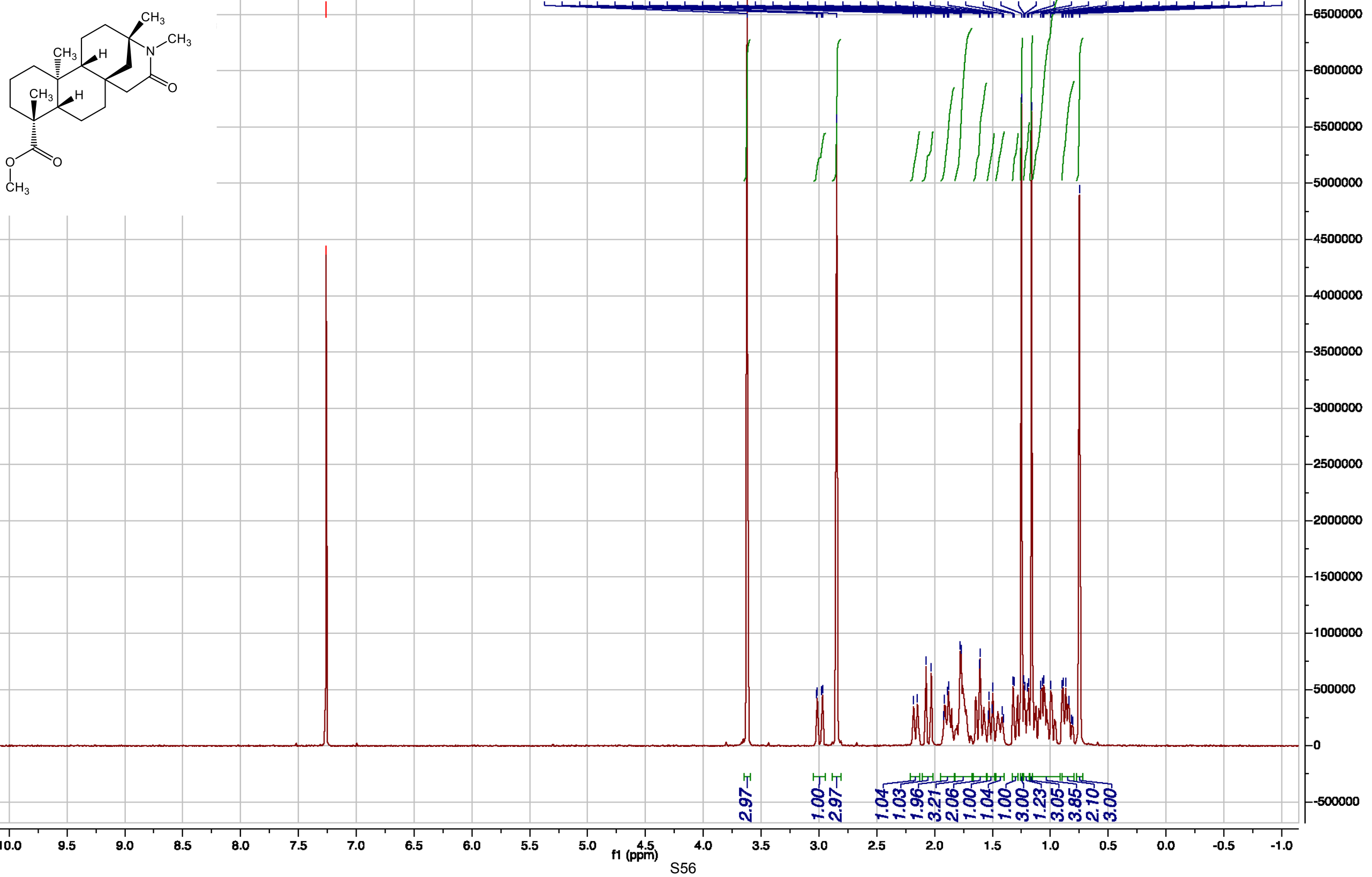
온 $\frac{2}{\pi}$

$\leqslant \frac{1}{5}$

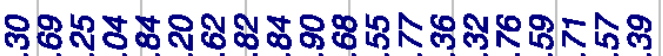

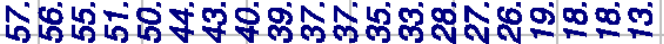

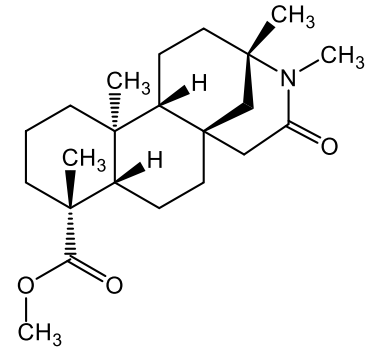



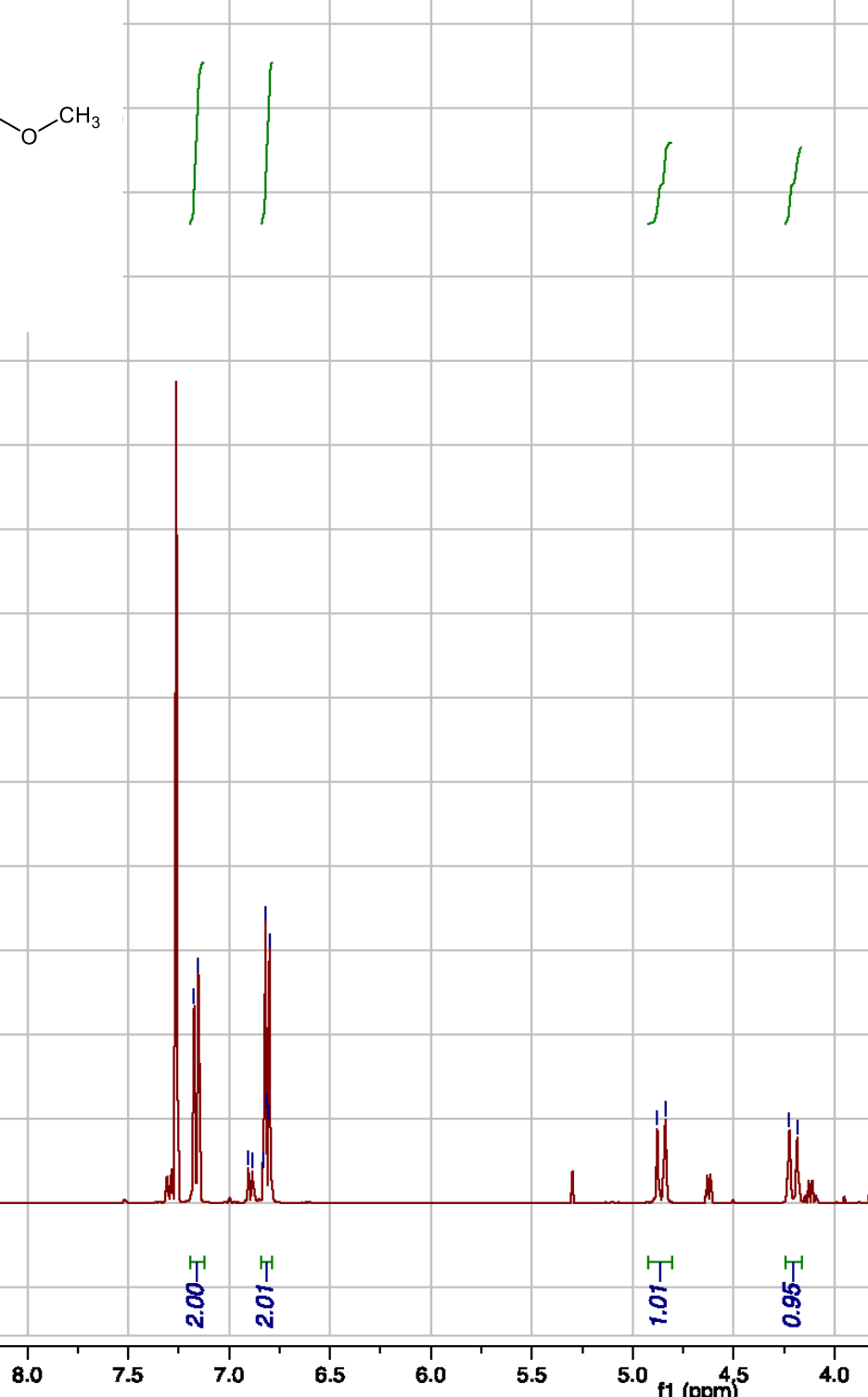

$+\ldots$

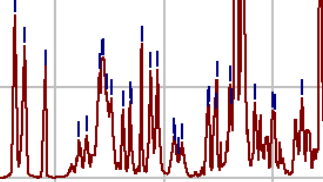

$7.5 E+07$

$7.0 \mathrm{E}+07$

$6.5 \mathrm{E}+07$

$-6.0 E+07$

$5.5 E+07$

$5.0 E+07$

4.5E+07

4.0E+07

3.5E+07

$-3.0 \mathrm{E}+07$

$2.5 E+07$

$-2.0 E+07$

$-1.5 E+07$

$1.0 \mathrm{E}+07$

$5.0 \mathrm{E}+06$

$0.0 E+\infty 0$ 


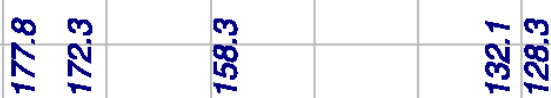

$\begin{array}{lll}1 & 1 \\ 2 & 1\end{array}$

not

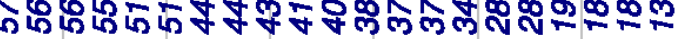
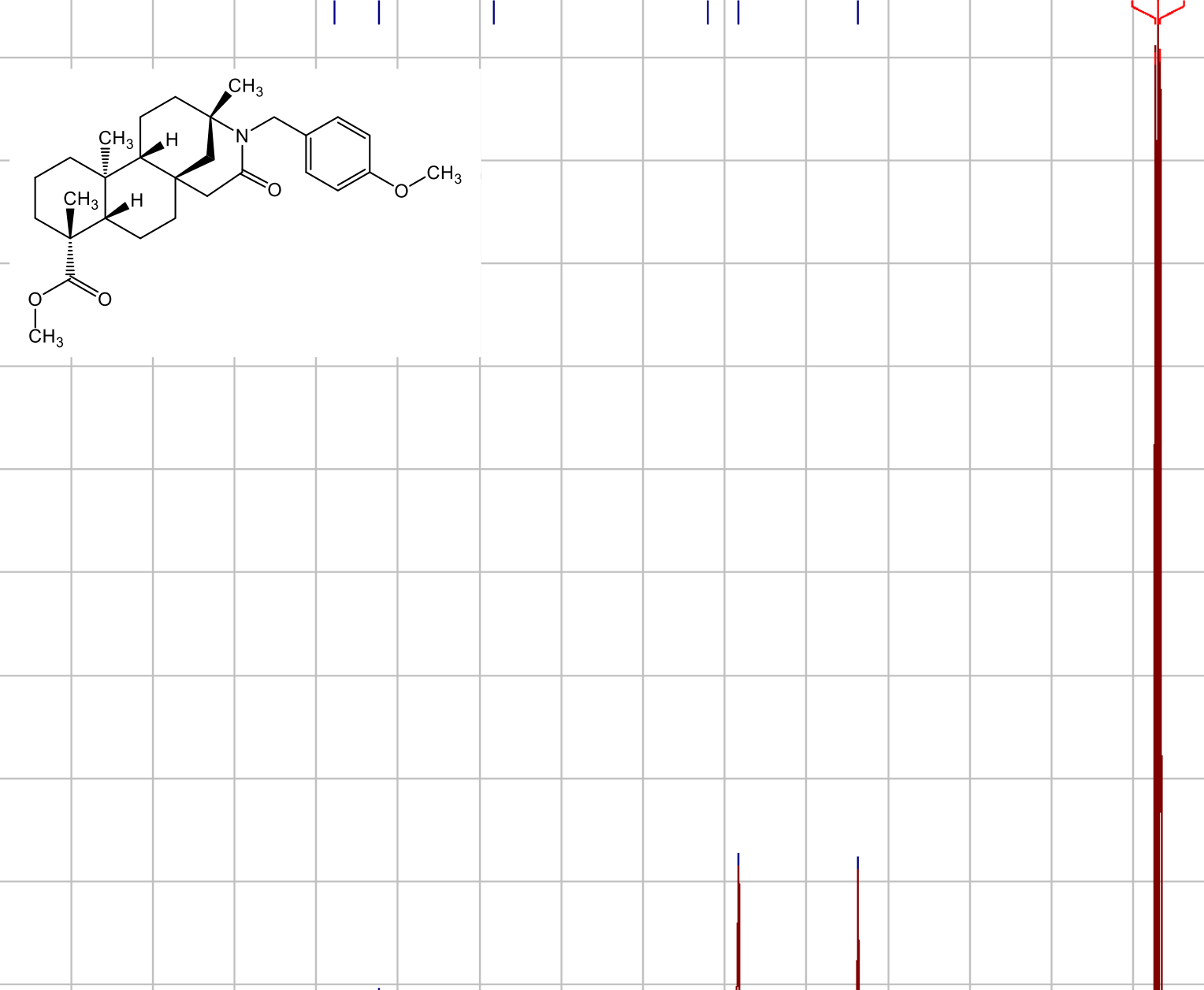

. 


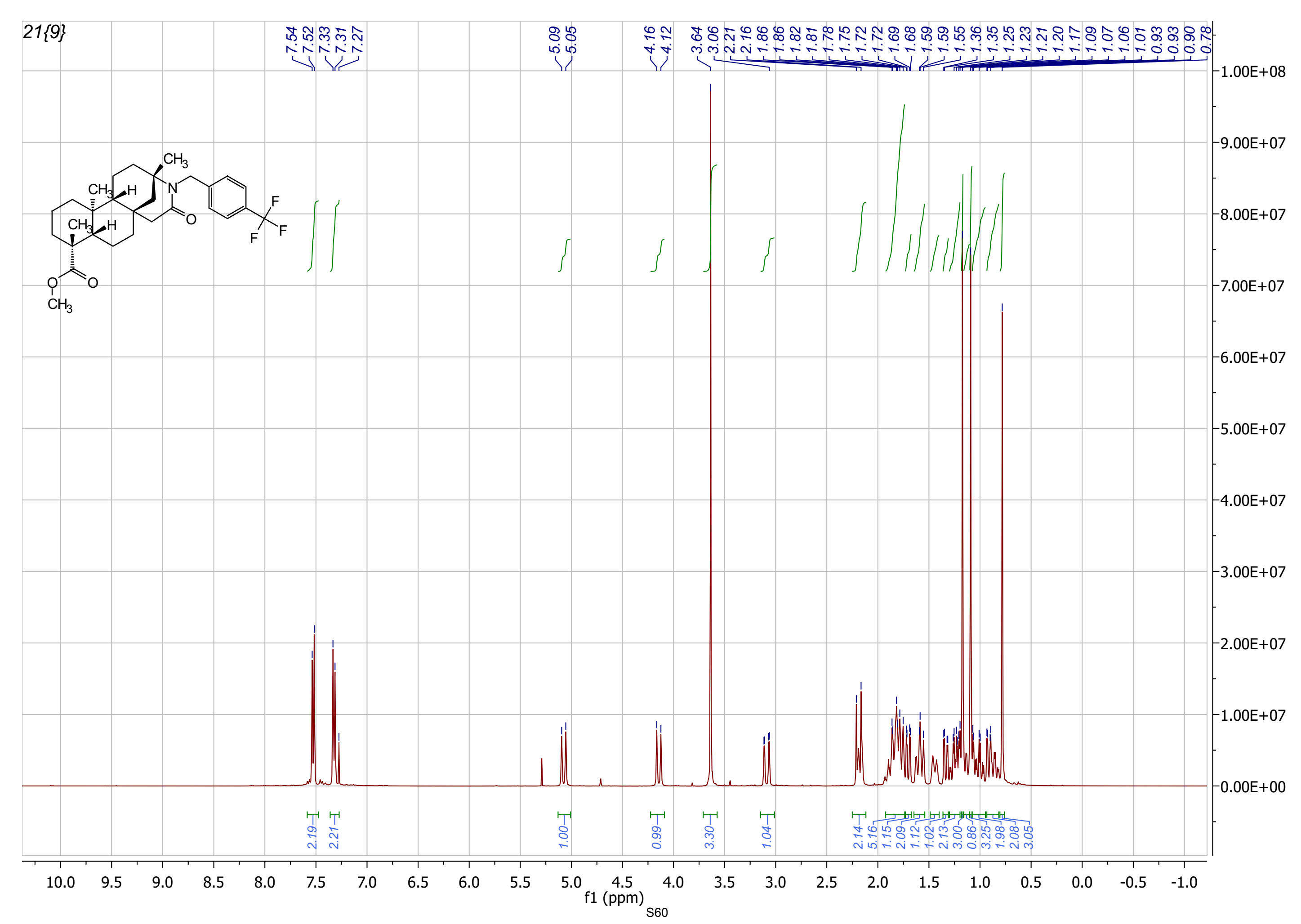




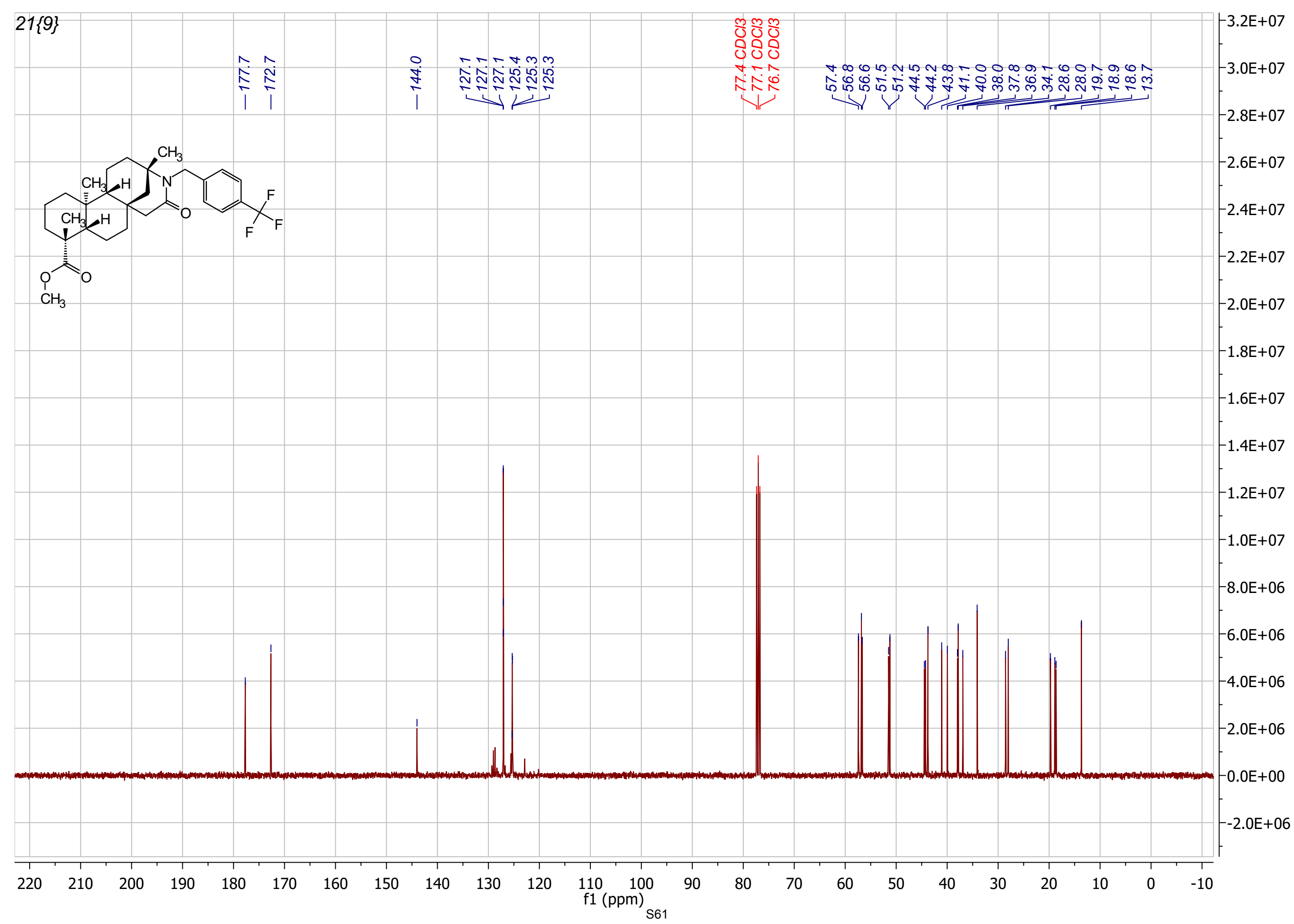




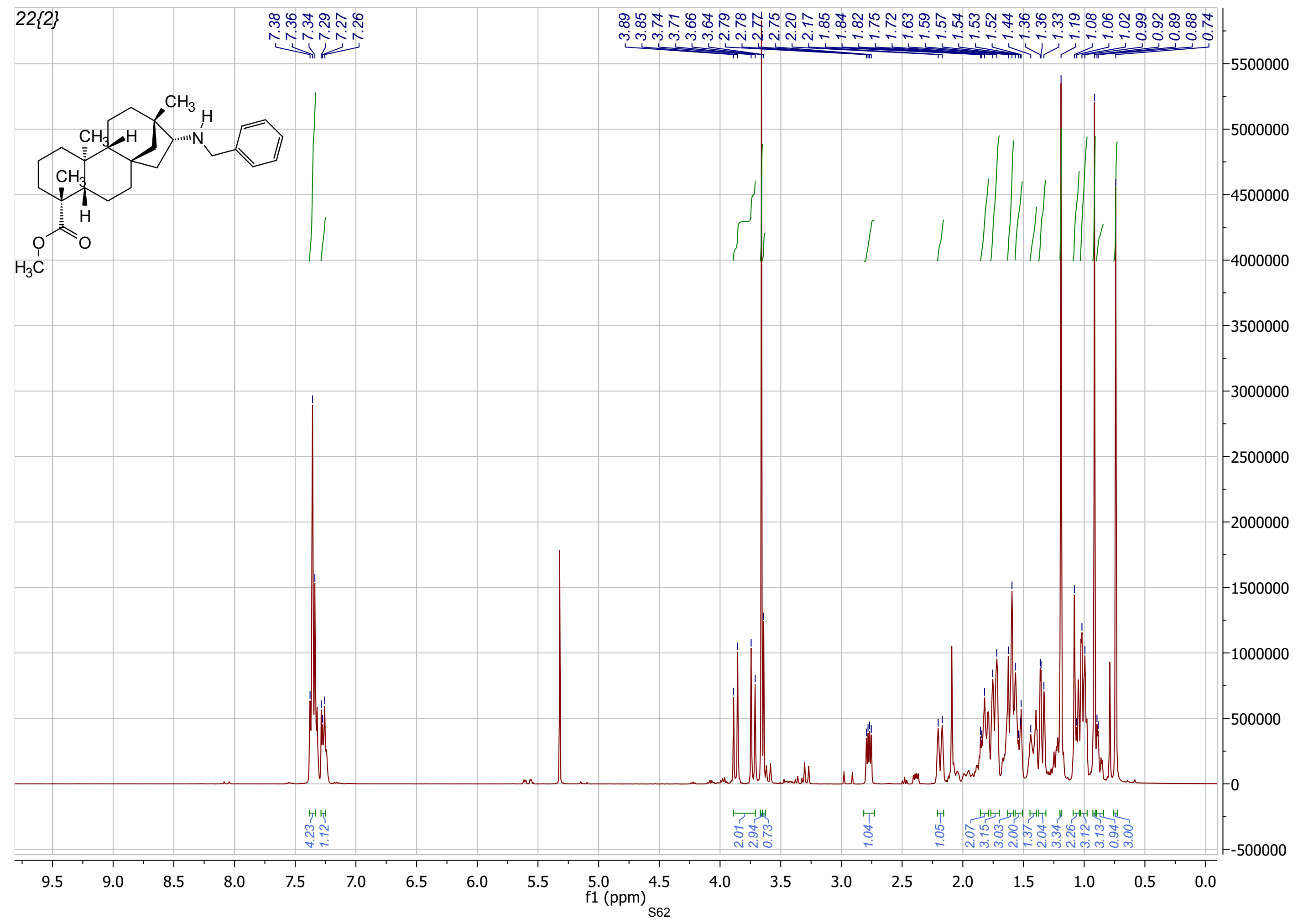




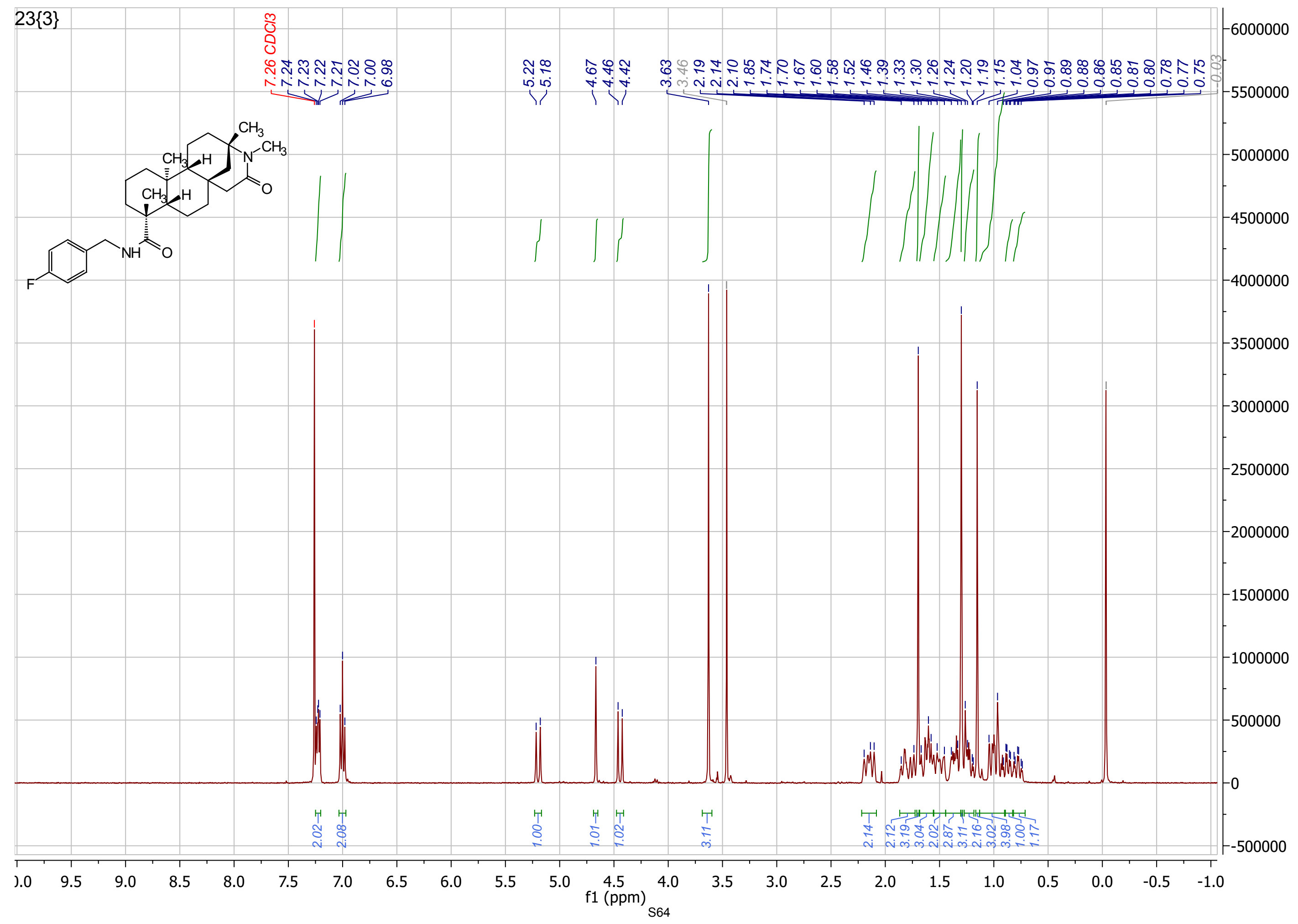




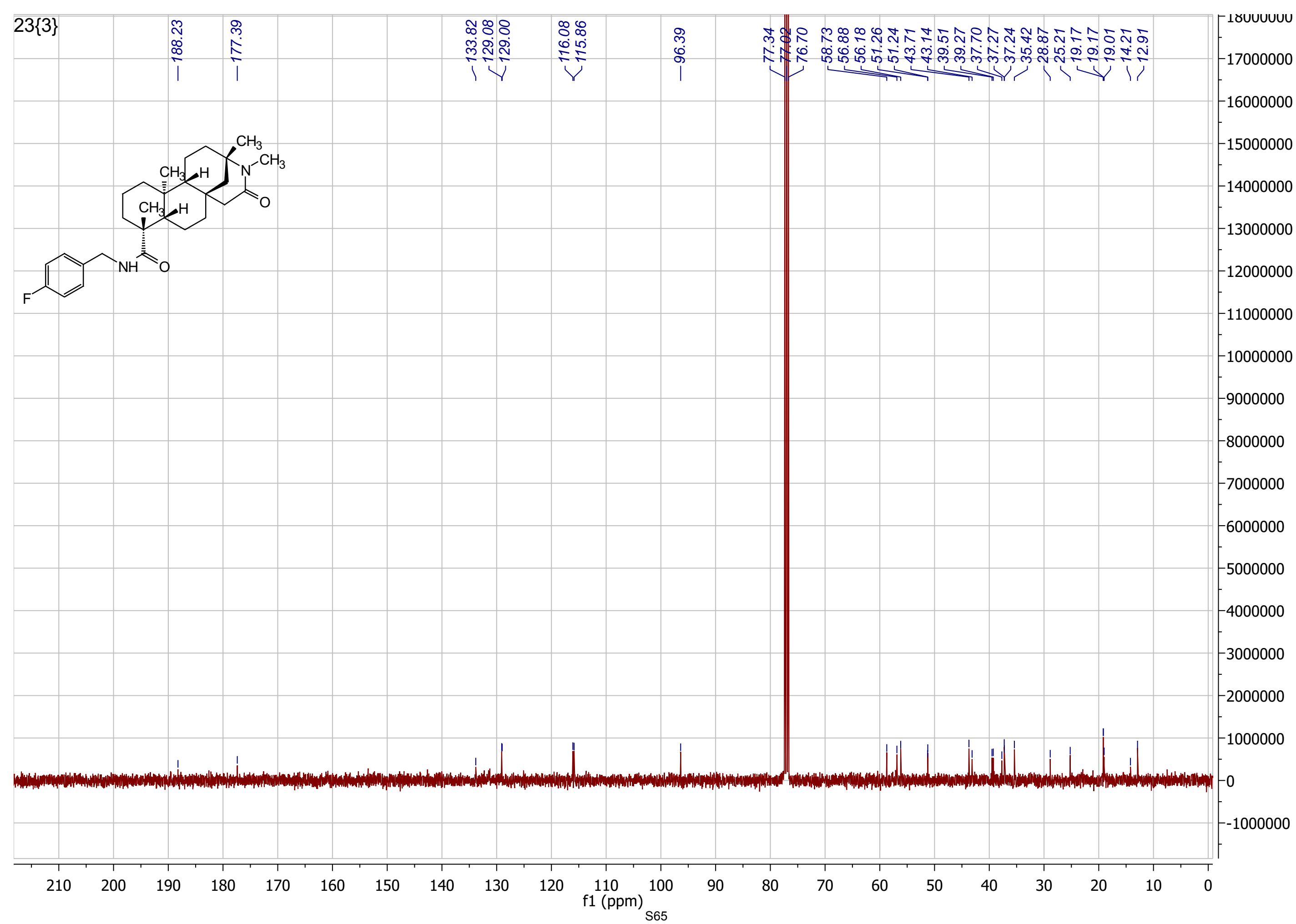




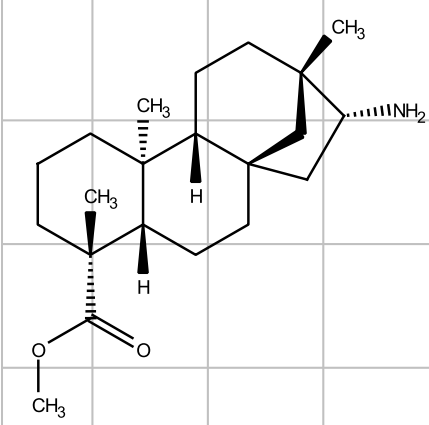

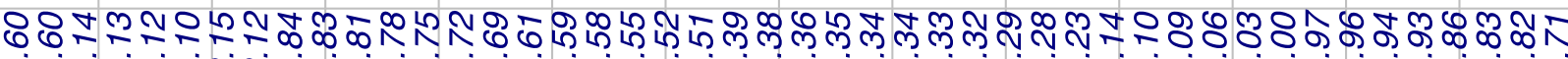

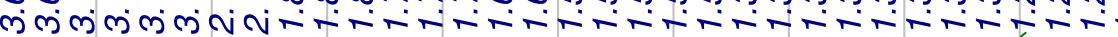
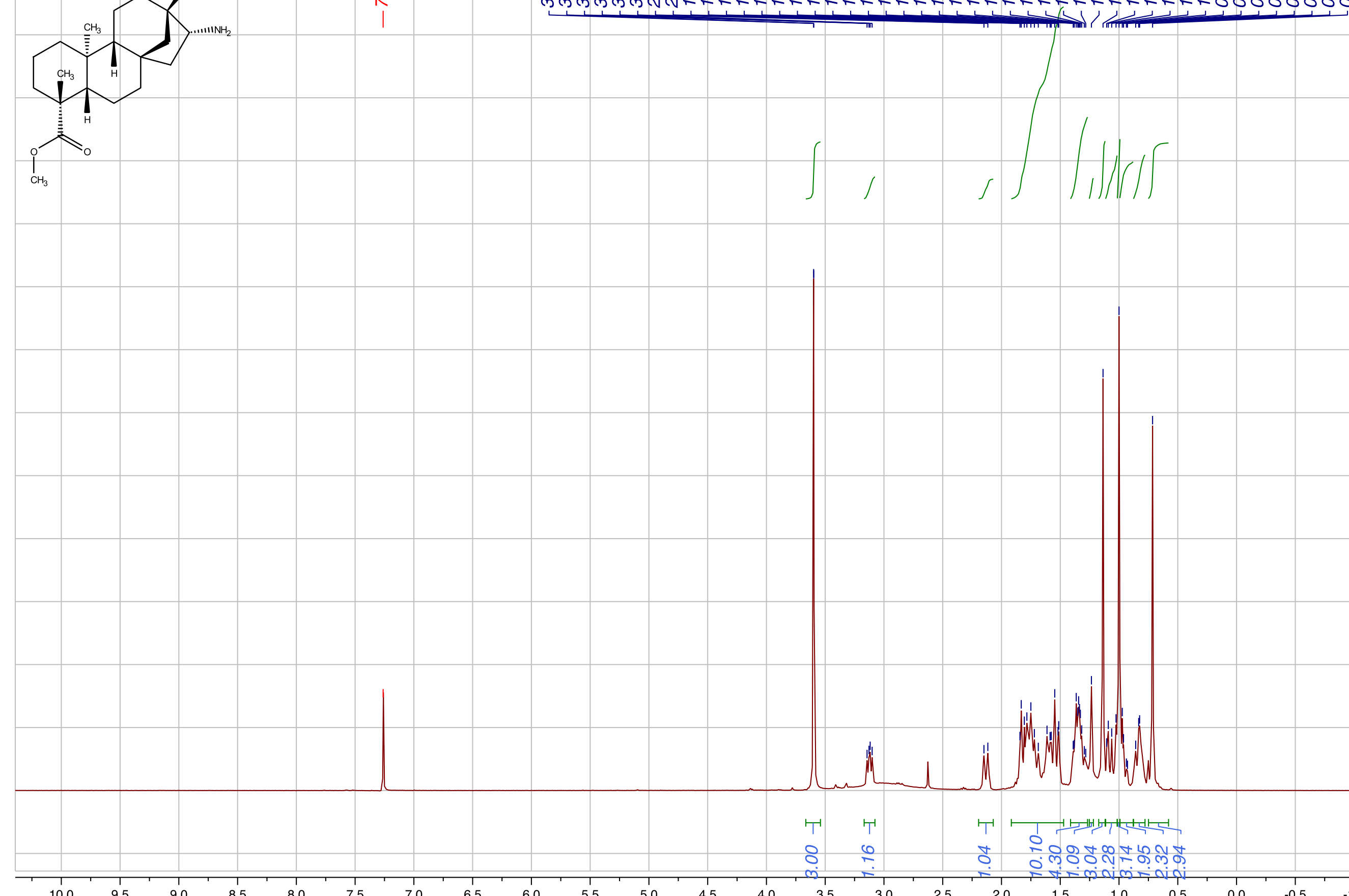

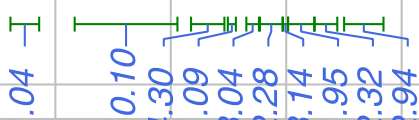


8

8

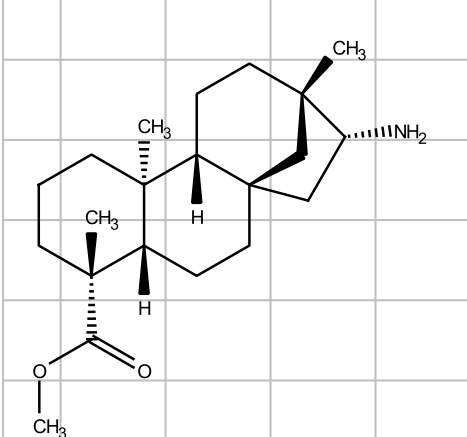

$\mathrm{CH}_{3}$
L人.

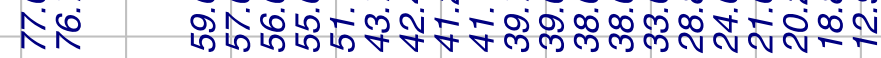

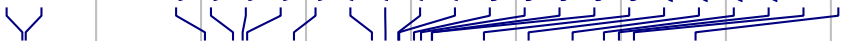

